NBER WORKING PAPER SERIES

\title{
THE PRICE OF POLITICAL UNCERTAINTY: THEORY AND EVIDENCE FROM THE OPTION MARKET
}

\author{
Bryan Kelly \\ Lubos Pastor \\ Pietro Veronesi \\ Working Paper 19812 \\ http://www.nber.org/papers/w19812
NATIONAL BUREAU OF ECONOMIC RESEARCH
1050 Massachusetts Avenue
Cambridge, MA 02138
January 2014

We are grateful for comments from participants at the 2015 AFA meetings, 2015 NBER Summer Institute, 2015 NYU/Penn Conference on Law and Finance, 2015 Queen Mary Conference on Recent Advances in Finance, 2014 Asset Pricing Retreat at Tilburg, 2014 Duke/UNC Asset Pricing Conference, 2014 EFA meetings, 2014 ESSFM Gerzensee, 2014 Princeton conference on The Causes and Consequences of Policy Uncertainty, 2014 Rising Stars Conference, 2014 SoFiE Conference, and seminars at Bocconi, Chicago, EDHEC, Pennsylvania, Rochester, UCLA, Wisconsin, and the National Bank of Slovakia. We also thank Jonathan Brogaard, Andrea Buraschi, Hui Chen, John Cochrane, George Con- stantinides, Ian Dew-Becker, Michael Gofman, Brandon Julio, Juhani Linnainmaa, Rajnish Mehra, Toby Moskowitz, Stavros Panageas, Jay Shanken, Ken Singleton, Raghu Sundaram, Eric Talley, Moto Yogo, and two anonymous referees. Gerardo Manzo and Sarah Kervin provided excellent research assistance. This research was funded in part by the Fama-Miller Center for Research in Finance and by the Center for Research in Security Prices at the University of Chicago Booth School of Business. The views expressed herein are those of the authors and do not necessarily reflect the views of the National Bureau of Economic Research.

NBER working papers are circulated for discussion and comment purposes. They have not been peerreviewed or been subject to the review by the NBER Board of Directors that accompanies official NBER publications.

(C) 2014 by Bryan Kelly, Lubos Pastor, and Pietro Veronesi. All rights reserved. Short sections of text, not to exceed two paragraphs, may be quoted without explicit permission provided that full credit, including $(\odot$ notice, is given to the source. 
The Price of Political Uncertainty: Theory and Evidence from the Option Market Bryan Kelly, Lubos Pastor, and Pietro Veronesi

NBER Working Paper No. 19812

January 2014, Revised July 2015

JEL No. G12,G15,G18

\section{ABSTRACT}

We empirically analyze the pricing of political uncertainty, guided by a theoretical model of government policy choice. To isolate political uncertainty, we exploit its variation around national elections and global summits. We find that political uncertainty is priced in the equity option market as predicted by theory. Options whose lives span political events tend to be more expensive. Such options provide valuable protection against the price, variance, and tail risks associated with political events. This protection is more valuable in a weaker economy and amid higher political uncertainty. The effects of political uncertainty spill over across countries.

Bryan Kelly

University of Chicago

Booth School of Business

5807 S. Woodlawn Avenue

Chicago, IL 60637

and NBER

bryan.kelly@chicagobooth.edu

Lubos Pastor

University of Chicago

Booth School of Business

5807 South Woodlawn Ave

Chicago, IL 60637

and NBER

lubos.pastor@chicagobooth.edu
Pietro Veronesi

University of Chicago

Booth School of Business

5807 South Woodlawn Avenue

Chicago, IL 60637

and NBER

pietro.veronesi@chicagobooth.edu 


\section{Introduction}

Political uncertainty has featured prominently in the economic landscape of recent years. In the United States, much uncertainty surrounded the government bailouts during the financial crisis of 2008, the reforms of finance and health care, the Federal Reserve's innovative monetary policy, tax policy, as well as the political brinkmanship over the debt ceiling in 2011 and 2013. Standard \& Poor's named political uncertainty as a key reason for its first-ever downgrade of the U.S. Treasury debt in 2011. In Europe, the sovereign debt crisis has witnessed tremendous uncertainty about the actions of European politicians, central bankers, and Greek voters. Alas, despite the salience of political uncertainty, our understanding of its effects on the economy and financial markets is only beginning to emerge.

Recent research suggests that uncertainty about government actions has negative real and financial effects. For example, Baker, Bloom, and Davis (2013) find that this uncertainty, measured by their index, increases unemployment and reduces investment. By using the same index, Pástor and Veronesi (2013) find that this uncertainty commands a risk premium, and that stocks are more volatile and more correlated in times of high uncertainty. FernándezVillaverde et al. (2012) find that uncertainty about fiscal policy, measured by time-varying volatility of tax and spending processes, has negative effects on economic activity.

A key obstacle in assessing the impact of political uncertainty is the difficulty in isolating exogenous variation in this uncertainty. Political uncertainty likely depends on a host of factors, such as macroeconomic uncertainty. The time-series measures of Baker et al. and Fernández-Villaverde et al. might potentially reflect not only government-related uncertainty but also broader uncertainty about economic fundamentals.

In this paper, we isolate political uncertainty by exploiting its variation around major

political events, namely, national elections and global summits. We investigate whether and how the uncertainty associated with these events is priced in the option market. Options are uniquely well suited for this analysis, for two reasons. First, they have relatively short maturities, which we can choose to cover the dates of political events. An option whose life spans a political event provides protection against the risk associated with that event. Since the political event is often the main event that occurs during the option's short life, the option's price is informative about the value of protection against political risk. Second, options come with different strike prices, which allow us to examine various types of risk associated with political events, such as tail risk. Elections and summits are also well suited for our analysis because they can result in major policy shifts. Moreover, the dates of elections and summits are determined sufficiently far in advance so that they are publicly 
known on the dates at which we calculate the prices of the options spanning the events. These events thus provide a source of exogenous variation in political uncertainty.

Our analysis is guided by the theoretical model of Pástor and Veronesi (2013; hereafter PV). In this model, the government decides which policy to adopt and investors are uncertain about the future policy choice. We use this model directly when analyzing global summits. When we analyze national elections, we reinterpret the PV model so that voters decide whom to elect and investors face uncertainty about the election outcome. Under the election interpretation, political uncertainty is uncertainty about who will be elected; in the original version of the model, it is uncertainty about which government policy will be chosen. ${ }^{1}$

We derive the option pricing implications of the PV model, obtaining a closed-form solution for the prices of put options whose lives span a political event. We calculate three option-market variables: the implied volatility of an at-the-money option, the slope of the function relating implied volatility to moneyness, and the variance risk premium. These variables capture the value of option protection against three aspects of risk associated with political events: price risk, tail risk, and variance risk, respectively. In response to a political event, stock prices might drop (price risk), the price drop might be large (tail risk), and return volatility might rise (variance risk). These risks are correlated inside the PV model; for example, the adoption of a risky policy can raise volatility while depressing stock prices. The model implies that all three option-market variables should be larger, on average, than the same variables calculated for options whose lives do not span a political event.

The model also predicts a negative relation between all three option-market variables and economic conditions. This prediction follows from a key result in the PV model: when the economy is weaker, the current government policy is less likely to be retained, creating uncertainty about which new policy will be adopted instead. Similarly, in the election version of the model, the incumbent government is less likely to be reelected in a weaker economy, creating uncertainty about the new government. Options provide protection against an unfavorable policy decision or an undesirable election outcome. Since the probability of such an outcome is higher in a weaker economy, so is the value of the option protection.

Finally, the model predicts that all three option-market variables should be larger amid higher political uncertainty. When there is no such uncertainty, option prices are governed by the Black-Scholes formula, so that implied volatility equals expected volatility and both

\footnotetext{
${ }^{1}$ Both interpretations of political uncertainty are mentioned in the following recent quote: "When economists talk of political risk, they usually mean... national elections... But there is another kind of political risk: the temptation for governments of all political colours to change the rules, whether they relate to tax, the way that companies operate or how markets behave. And that risk has increased significantly since the 2008 crisis." (The Economist, Buttonwood, November 9, 2013)
} 
the implied volatility slope and the variance risk premium are zero. When the uncertainty is present, the option protection against all three aspects of political risk is valuable.

In our empirical analysis, we test the model's predictions on option data from 20 countries. We analyze two types of political events: national elections and global summits. Each summit counts as a separate event for all countries participating in the summit, while elections count only for the country in which they are held. For each political event, we calculate the three option-market variables based on options whose lives span the event, adjusting each variable for its mean calculated for neighboring options whose lives do not span the event.

We find strong empirical support for the model's predictions. First, the unconditional means of all three variables are significantly positive, for both elections and summits. The average (mean-adjusted) implied volatility is $1.43 \%$ per year, which implies that one-month at-the-money put options whose lives span political events tend to be more expensive by about $5.1 \%$ compared to neighboring options. ${ }^{2}$ Implied volatilities are especially high before pivotal events such as the 2008 U.S. presidential election and the 2012 Greek election, both of which took place during financial crises. The positive average slope means that investors value the protection provided by deep-out-of-the-money puts against the tail risk inherent in political events. For example, among one-month puts that are 5\% out-of-the-money, options whose lives span political events are more expensive by $9.6 \%$ compared to neighboring options, on average. Among options that are $10 \%$ out-of-the-money, they are more expensive by $16.0 \%$. The average variance risk premium is also positive, 0.0107 per year, implying that insurance against variance risk costs significantly more before political events.

Second, we find that all three option-market variables tend to take larger values in weaker economic conditions. These findings hold across four different country-level measures of economic conditions, they apply to both elections and summits, and they emerge from both regressions and mean comparisons. Option protection against the three aspects of political risk is thus more valuable when the economy is weaker. For example, one-month at-themoney options providing protection against political events are about $8 \%$ more expensive when the economy is weak but only $1 \%$ more expensive when the economy is strong.

Finally, the option-market variables tend to be larger when the election outcome is more uncertain, as measured by a lower electoral poll spread. The relation to uncertainty is significant for both implied volatility and the variance risk premium but insignificant for the

\footnotetext{
${ }^{2}$ The $5.1 \%$ price premium is economically large. For example, if one were to purchase enough one-month at-the-money put options to insure the total market value of the S\&P 500 index in March 2014, the additional cost for options that span political events would be over $\$ 15$ billion. To obtain this number on the back of the envelope, we multiply 0.051 by the $\$ 17$ trillion market value of $\mathrm{S} \& \mathrm{P} 500$ and by the ratio of the price of a one-month at-the-money S\&P 500 put option to the level of the same index, which is about 0.018.
} 
slope. These results suggest that higher uncertainty increases the value of option protection against the price and variance risks associated with the election outcome.

We also extend the PV model to settings with two countries and asymmetric information. The two-country extension predicts spillovers of political uncertainty across countries. These spillovers should be stronger in weaker conditions and positively correlated with foreign exchange option effects. We find empirical support for these predictions. The asymmetric-information extension makes different predictions for elections and summits, but those predictions are not supported in the data. There does not seem to be much information asymmetry between governments and investors in our sample of political events.

To summarize our empirical results, we find that political uncertainty is priced in the option market. Option protection against three types of risk associated with political eventsprice risk, tail risk, and variance risk - is more valuable when the economy is weaker as well as when the uncertainty is higher, consistent with theory. Our results survive many robustness tests, including placebo tests designed to detect any relations between option prices and economic conditions that are unrelated to political uncertainty. We also find spillovers of political uncertainty across countries, especially in weaker economic conditions.

Our paper is related to empirical studies of the risk premium associated with political uncertainty, such as Erb, Harvey, and Viskanta (1996), Brogaard and Detzel (2013), and PV. The former study measures political risk based on the International Country Risk Guide, while the latter studies use the policy uncertainty index of Baker, Bloom, and Davis (2013). Bittlingmayer (1998) and Voth (2002) find a positive relation between political uncertainty and stock volatility by using data from the interwar period. Belo, Gala, and Li (2013) link the cross-section of stock returns to firms' exposures to the government sector. All of these studies focus on stocks; none of them analyze options. While these studies share our focus on the financial effects of political uncertainty, others have analyzed its real effects. ${ }^{3}$

This paper is also related to studies that analyze the financial effects of electoral uncertainty. Pantzalis, Stangeland, and Turtle (2000) examine 33 countries and find abnormally high stock returns in the two weeks preceding national elections. Li and Born (2006) find a similar result for U.S. presidential elections. Gao and Qi (2013) show that municipal bond

\footnotetext{
${ }^{3}$ Two prominent examples are Baker, Bloom, and Davis (2013) and Fernández-Villaverde et al. (2012), mentioned earlier. Gulen and Ion (2013) find that the negative effect of the Baker-Bloom-Davis policy uncertainty index on investment is stronger for firms with a higher degree of investment irreversibility and firms that are more financially constrained. The literature on the real effects of electoral uncertainty includes Julio and Yook (2012), who find that firms reduce their investment before national elections, Jens (2013), who finds that firms reduce their investment before U.S. gubernatorial elections, Julio and Yook (2013), who find that U.S. firms cut FDI flows to foreign affiliates before elections in recipient countries, and Durnev (2012), who finds that corporate investment is less sensitive to stock prices during election years.
} 
yields rise around U.S. gubernatorial elections. These results are suggestive of a risk premium for electoral uncertainty, though Bialkowski, Gottschalk, and Wisniewski (2008) find an insignificant premium in their sample of 27 countries. Bialkowski et al. also find that stock market returns tend to be more volatile around national elections. Boutchkova et al. (2012) find that industries sensitive to politics have more volatile returns around national elections. Two studies analyze option-implied volatilities around elections. Gemmill (1992) finds that the implied volatility of the FTSE 100 index rose in the last two weeks before the British parliamentary election of 1987. Goodell and Vahamaa (2013) find that the implied volatility of the S\&P 500 index is related to the outcome of a U.S. presidential election. While Gemmill has a sample of one, Goodell and Vahamaa's sample includes five elections. Our sample is much larger; in addition, we analyze not only implied volatility but also its slope and the variance risk premium. Snowberg, Wolfers, and Zitzewitz (2007) examine the ex-post effects of election outcomes on equity markets, whereas we analyze how markets respond to the ex-ante uncertainty about those outcomes. Most important, unlike all studies mentioned in this paragraph, our empirical analysis has clear theoretical guidance.

Our theoretical contribution builds on PV, who in turn extend the simpler model of Pástor and Veronesi (2012). The remaining theoretical literature on the effects of governmentinduced uncertainty on asset prices is fairly small, quite different, and mostly focused on fiscal uncertainty. Sialm (2006) analyzes the effect of stochastic changes in taxes on asset prices. Tax uncertainty also features in Croce, Kung, Nguyen, and Schmid (2012), who explore its asset pricing implications in a production economy with recursive preferences. Croce, Nguyen, and Schmid (2012) examine the effects of fiscal uncertainty on long-term growth when agents facing model uncertainty care about the worst-case scenario. Finally, Ulrich (2013) analyzes the bond market implications of Knightian uncertainty about the effectiveness of government policies. Our paper is the first, to our knowledge, to derive theoretical predictions for the effects of political uncertainty on option prices.

We derive those predictions in a rich model that features economic and political shocks, endogenous uncertainty about the government's policy choice, and a potential jump in the government's impact on profitability. The model generates state-dependent risk premia, stochastic volatility, and a jump in stock prices at the time of the policy decision. Others recently derived option prices in different settings with jumps in the fundamentals, such as models of rare disasters (Backus, Chernov, and Martin, 2011; Seo and Wachter, 2013), habit formation (Du, 2011), and long-run risk (Benzoni, Collin-Dufresne, and Goldstein, 2011; Drechsler and Yaron, 2011). ${ }^{4}$ Unlike those models, our model features jumps that

\footnotetext{
${ }^{4}$ Studies that analyze jump risk in equity index options include Bates (1991, 2000), Bakshi, Cao, and Chen (1997), Duffie, Pan, and Singleton (2000), Pan (2002), Eraker, Johannes, and Polson (2003), Eraker
} 
are caused by the resolution of political uncertainty at the time of the political event. The endogeneity of the jumps in our setting generates new testable predictions, such as those relating option prices to the state of the economy. Other related papers include empirical studies of option price behavior around non-political events, such as the announcements of macroeconomic news (e.g., Ederington and Lee, 1996, and Beber and Brandt, 2006) and corporate earnings (e.g., Patell and Wolfson, 1979, and Dubinsky and Johannes, 2006).

The paper is organized as follows. Section 2. describes our data and the design of our empirical analysis. Section 3. reports the empirical results. Section 4. derives theoretical implications for option prices before political events. Section 5. extends the theoretical model to allow for multiple countries and asymmetric information. Section 6. concludes.

\section{Empirical Design}

We construct an international dataset of political events, option prices, and macroeconomic variables. In this section, we describe our dataset and introduce the variables used in our empirical analysis. These variables include three option-market quantities - differences in implied volatility, variance risk premium, and implied volatility slope - designed to capture the price risk, variance risk, and tail risk associated with political events. All three quantities represent differences between variables computed from "treatment-group" options, whose lives span political events, and neighboring "control-group" options, whose lives do not span those events. In addition to the option-market variables, we construct four measures of economic conditions and a proxy for uncertainty about the election outcome.

\subsection{Options}

The main source of our option data is OptionMetrics. We use daily data on implied volatilities, deltas, and open interest for 20 countries. For 15 of these countries, OptionMetrics provides data on options on the country's premier stock market index. For five additional countries, for which such data are unavailable, we use data on U.S.-traded options on the iShares exchange-traded fund (ETF) for the country's MSCI index. ${ }^{5}$ Table 1 lists the 20 countries along with the indices underlying the country options and the corresponding sam-

(2004), Broadie, Chernov, and Johannes (2007, 2009), Todorov (2010), Bollerslev and Todorov (2011), etc.

${ }^{5}$ The only other countries for which we have found option data in OptionMetrics are Hong Kong, India, Peru, and Malaysia. We exclude Hong Kong because it is technically not an independent country but rather a special administrative region of the People's Republic of China. We exclude India and Peru as they do not appear in the database until 2011. We exclude Malaysia due to insufficient option data for the only Malaysian election that took place during the country's option sample period. 
ple periods. For most countries, the option data begin between 2002 and 2006; for all countries, the data end in 2012. The longest sample, beginning in 1990, is available for the U.S. S\&P 500 index. OptionMetrics provides S\&P 500 index option data back to 1996. Our pre-1996 S\&P 500 data are from Market Data Express (MDR).

\subsubsection{Implied Volatility}

Let $I V_{t, m}$ denote the implied volatility at time $t$ of an at-the-money option maturing at time $m>t$. For each option in our sample, this implied volatility is calculated by OptionMetrics. ${ }^{6}$ Our main interest is in options whose lives span the dates of political events. Denoting the date of any such event by $\tau$, our interest is in $I V_{t, m}$ for $t<\tau<m$.

For all countries in our sample, equity options expire on a regular monthly grid. ${ }^{7} \mathrm{We}$ find the location of each political event $\tau$ relative to this grid. We label the expiration dates that straddle $\tau$ as $a$ and $b$, so that $a<\tau<b$. Our choice of $a$ and $b$ depends on the distance from $\tau$ to the nearest expiration date. If this distance is more than five days, we choose $a$ and $b$ that are one month apart (i.e., $b=a+1$ month). But if $\tau$ is within five days of the nearest expiration date, we choose $a$ and $b$ that are two months apart so that neither of them is within five days of $\tau$. By imposing this minimum-distance requirement, we avoid two potential problems. First, some of the uncertainty about the outcome of a political event could be resolved a few days before or after the event. Second, we avoid using ultra-shortmaturity options. Given our five-day requirement, our procedure outlined below never uses options that have six or fewer days to maturity. ${ }^{8}$ After choosing $a$ and $b$, we define $c$ as the expiration date immediately following $b$, so that $b$ and $c$ are always one month apart. See Figure 1 for the timeline. Our interest is in $I V_{b-s, b}$, where $b-s<\tau<b$.

We modify $I V_{b-s, b}$ in two ways to create a more robust measure. First, we subtract the average $I V$ of the same country's options with neighboring expiration dates, by computing

\footnotetext{
${ }^{6}$ For European options, OptionMetrics first calculates the theoretical option price as the midpoint of the best closing bid and offer prices, and then computes the implied volatility by inverting the Black-Scholes formula. This calculation applies to the 15 countries in our sample for which we have options on the country's premier stock index. For American options, OptionMetrics obtains implied volatilies by applying a proprietary pricing algorithm based on the Cox-Ross-Rubinstein binomial tree model. This calculation applies to the five countries for which we use ETF options on the MSCI country indices. We discard options with implied volatilities exceeding $100 \%$ per year. This filter affects only one political event in our sample, which appears to be a data error for Australia, judging by other Australian options at the time.

${ }^{7}$ In the U.S., the expiration date is the Saturday that follows the third Friday of each month. All countries in our sample have the same option expiration schedule as the U.S., except for Australia, where the expiration date is the third Thursday, and Japan and Korea, where it is the second Friday.

${ }^{8}$ Ultra-short-maturity options have very small time premiums. Their implied volatilities tend to be inaccurate due to high sensitivity to price nonsynchronicity and other measurement errors. Beber and Brandt (2006), among many others, exclude options with less than a week to maturity.
} 
$I V_{b-s, b}-\frac{1}{2}\left(I V_{a-s, a}+I V_{c-s, c}\right)$. By subtracting the average of $I V$ values for the same country, this modification adjusts for cross-country differences in volatility, similar in spirit to using country fixed effects. By subtracting $I V$ values from nearby dates, the modification accounts for slow-moving time variation in volatility, which would be unaccounted for in a countryfixed-effect approach. Second, we replace $I V_{b-s, b}, I V_{a-s, a}$, and $I V_{c-s, c}$ for any given $s$ by averages of $I V$ 's across multiple values of $s$, to reduce noise in the estimation.

For each political event $\tau$, we define the implied volatility difference, $I V D_{\tau}$, as

$$
I V D_{\tau}=\overline{I V}_{b}-\frac{1}{2}\left(\overline{I V}_{a}+\overline{I V}_{c}\right)
$$

where $\overline{I V}_{a}, \overline{I V}_{b}$, and $\overline{I V}_{c}$ are square roots of averages of implied variances computed across all acceptable put and call options expiring at times $a, b$, and $c$, respectively. Acceptable options satisfy three criteria. First, they are at-the-money (ATM) options, which we define as options whose deltas satisfy $0.4<|\Delta|<0.5$. We choose this definition to obtain a liquid set of ATM options since it is well known that options that are slightly out-of-the-money (OTM) tend to be more liquid than options that are in-the-money (ITM). If multiple options satisfy this ATM definition, they are all used in the average. Second, acceptable options have positive open interest. The only exception is U.S. data prior to 1996, for which we require positive volume instead because the pre-1996 data come from a different source (MDR) that does not report open interest. Third, acceptable options have $s$ days until expiration, where $s$ belongs to a given time window. Specifically, we define $\overline{I V}_{b}$ as follows:

$$
\overline{I V}_{b}=\operatorname{Mean}\left\{I V_{b-s, b}: b-s \in[\tau-20, \tau-1]\right\},
$$

which is the equal-weighted average of $I V_{b-s, b}$ across the values of $s$ for which $b-s$ is in the 20-trading-day window preceding time $\tau$. We choose this window of 20 trading days, or about one month, to smooth out the noisy day-to-day fluctuations in international option prices. In short, $\overline{I V}_{b}$ is the average implied volatility across all ATM options with open interest that expire at time $b$ and whose values are computed in the month before $\tau$. $\overline{I V}_{a}$ and $\overline{I V}_{c}$ are defined analogously. For those variables, we choose 20-day windows that end $b-\tau+1$ trading days before $a$ and $c$, respectively, to ensure that the times to maturity for options entering into $\overline{I V}_{a}, \overline{I V}_{b}$, and $\overline{I V}_{c}$ are fully comparable. A positive value of $I V D_{\tau}$ in equation (1) indicates that options whose lives span time $\tau$ are more expensive, on average, than the neighboring options whose lives do not $\operatorname{span} \tau$.

\subsubsection{Variance Risk Premium}

Empirical studies typically calculate the variance risk premium as the difference between the implied and realized variances (e.g., Bollerslev, Tauchen, and Zhou, 2009). Following that 
approach, we construct a daily panel of variance risk premia for each country as

$$
V R P_{t, m}=I V_{t, m}^{2}-R V_{t, m}^{2}
$$

where $I V_{t, m}^{2}$ is the implied variance at time $t$ of an ATM option that matures at time $m>t$ and $R V_{t, m}^{2}$ is the average realized variance of the same underlying country stock index over the life of the option (i.e., between times $t$ and $m$ ). The average realized variance provides an unbiased estimate of the expected variance over the option's life. ${ }^{9}$

Our realized variance data come from two sources. Our first choice is the Oxford-Man Institute's Realized Library (http://realized.oxford-man.ox.ac.uk/), which estimates daily realized variance from intraday returns. From this source, we obtain data for Brazil, Canada, France, Germany, Italy, Japan, Korea, Mexico, Netherlands, Singapore, Spain, Switzerland, UK, and U.S. For the remaining six countries, the Oxford-Man data are unavailable, so we estimate their variance by exponential smoothing. ${ }^{10}$

For each political event $\tau$, we determine the option expiration dates $a, b$, and $c$ as in the previous subsection. We define the variance risk premium difference, $V R P D_{\tau}$, as

$$
V R P D_{\tau}=\overline{V R P}_{b}-\frac{1}{2}\left(\overline{V R P}_{a}+\overline{V R P}_{c}\right)
$$

where $\overline{V R P}_{a}, \overline{V R P}_{b}$, and $\overline{V R P}_{c}$ are averages of variance risk premia calculated in the same way as their implied volatility counterparts. That is, analogous to equation (2), we define

$$
\overline{V R P}_{b}=\text { Mean }\left\{V R P_{b-s, b}: b-s \in[\tau-20, \tau-1]\right\}
$$

where the mean is calculated across all acceptable options expiring at time $b$, and the set of acceptable options is identical to the set used previously for $\overline{I V}_{b}$. The averages $\overline{V R P}_{a}$ and $\overline{V R P}_{c}$ are also calculated analogously. A positive value of $V R P D_{\tau}$ indicates that optionmarket investors pay more for insurance against variance risk over intervals that include time $\tau$, on average, than over neighboring intervals that do not include $\tau$.

In the data, $V R P$ in equation (3) is positively correlated with $I V$ over time (e.g., Bollerslev, Tauchen, and Zhou, 2009), suggesting that our empirical analyses based on $I V$ and

\footnotetext{
${ }^{9}$ We obtain similar empirical results if we construct $V R P_{t, m}$ in equation (3) in three alternative ways: (i) by replacing $R V_{t, m}^{2}$ with the variance realized on day $t$, (ii) by replacing $R V_{t, m}^{2}$ with a variance forecast from an AR(1) model, and (iii) by replacing $I V_{t, m}^{2}$, which is model-based (see footnote 6 ), with a model-free implied variance. In all three cases, the results are slightly noisier, which makes sense: approach (i) uses a single-day variance, approach (ii) relies heavily on the AR model, and approach (iii) requires a wide range of strike prices, which shrinks the sample size. Yet all three sets of results lead to the same conclusions.

${ }^{10}$ See, for example, Andersen et al. (2006). The exponential smoothing method estimates the current variance by an exponentially-weighted moving average of past squared returns. We use the smoothing parameter of 0.2 , which maximizes the correlation between the smoothed series and the realized variance series for the countries that have realized variance data in the Oxford-Man database.
} 
$V R P$ are not entirely independent. However, the two analyses are different conceptually. While the $I V$ analysis is informative about the extent to which political uncertainty affects the level of option prices, the $V R P$ analysis aims to determine whether this uncertainty is priced in the sense of affecting the state price density (since $V R P$ is an estimate of the difference between the objective and risk-neutral expectations of future variance).

\subsubsection{Implied Volatility Slope}

The implied volatility slope measures the steepness of the function that relates implied volatility to moneyness, as measured by the option's Black-Scholes delta. Delta is a natural measure of moneyness because it takes into account option contract features such as time to maturity, volatility, and the risk-free rate, all of which affect the probability that an option with a given strike price expires in the money. For each country, we construct a daily panel of slopes, $S$ lope $_{t, m}$, similar to the panels of $I V_{t, m}$ and $V R P_{t, m}$ described earlier. We define OTM put options as those whose deltas satisfy $-0.5<\Delta<-0.1 .^{11}$ At any time $t$, we consider all OTM put options that mature at time $m$ and have positive open interest. If there exist at least three such options, we calculate $S_{l o p e}, m$ as the slope coefficient from the regression of these options' implied volatilities on the same options' deltas. (If there are at most two such options, we treat Slope $t, m$ as missing.) A positive slope indicates that options that are deeper OTM are relatively more expensive (since $\Delta<0$ for puts).

For each political event $\tau$, we define the implied volatility slope difference as

$$
\text { Slope } D_{\tau}=\overline{\text { Slope }}_{b}-\frac{1}{2}\left(\overline{\text { Slope }}_{a}+\overline{\text { Slope }}_{c}\right) \text {, }
$$

where $\overline{S l o p e}_{a}, \overline{S l o p e}_{b}$, and $\overline{S l o p e}_{c}$ are averages of Slope $_{t, m}$ values calculated in the same manner as the averages of implied volatilities and variance risk premia in the previous two subsections. A positive value of $S l o p e D_{\tau}$ indicates that deep-OTM put options are particularly expensive shortly before time $\tau$, suggesting that investors are willing to pay for protection against the downside tail risk associated with political events.

\subsubsection{Alternative Designs}

One alternative to our empirical design would compare, at a given time $t<\tau$, the prices of two options with different expiration dates, one before $\tau$ and one after $\tau$. A similar approach is followed by Dubinsky and Johannes (2006) in their firm-level analysis of implied volatilities around earnings announcements. One complication is that the maturities of the two options

\footnotetext{
${ }^{11}$ We avoid the deepest OTM put options, those with $\Delta \approx 0$, because their implied volatilities are extremely sensitive to small measurement errors in option prices (e.g., Hentschel, 2003, Beber and Brandt, 2006, etc.).
} 
are different (by at least a month, since options expire on a monthly grid); as a result, it is essential to control for the term structure of implied volatility. This is easier said than done because the term structure varies stochastically over time. Moreover, its variation is related to economic conditions: when the conditions are poor, the term structure is more likely to be downward-sloping. These facts would dramatically complicate our analysis since economic conditions play a key role in our tests. For example, if this approach led us to find a significant effect of economic conditions on the price of political uncertainty, it would be difficult to dismiss the concern that our results could be driven by changes in the term structure of volatility. For this reason, we find our empirical design more suitable for our needs. In our design, the term structure of volatility plays no role because our treatmentgroup options have exactly the same maturities as the control-group options.

Another alternative would analyze the time series of option prices around time $\tau$. Similar event studies have been used since Patell and Wolfson (1979) to analyze changes in implied volatility around earnings announcements. One complication of this approach is that a given option's maturity shrinks as time passes around the event date. Another complication is that the change in implied volatility at time $\tau$ reflects not only the resolution of uncertainty but also the option price response to the outcome of the event. Instead of measuring the ex-post price reaction to such outcomes, we measure the ex-ante uncertainty about them. Yet we supplement our analysis by reporting event-study-based correlations in Section 4.4.

\subsection{Economic Conditions}

Our data on economic conditions come from the Organization for Economic Cooperation and Development (OECD), International Monetary Fund (IMF), and Datastream. We construct four country-level variables. The first variable, GDP, is seasonally adjusted real GDP growth in the current quarter, obtained from OECD. These data are available throughout our sample. The second variable, FST, is the most recent real GDP growth forecast for the following year, obtained from the IMF World Economic Outlook. The data begin in 1999. The third variable, $C L I$, is the Composite Leading Indicator in the current month. OECD constructs this series by aggregating various component indicators that comove with the business cycle and tend to turn before it. OECD does not calculate CLI for Taiwan and Singapore, but it does for the remaining 18 countries in our sample. Finally, $M K T$ is the stock market index return over the previous three months, obtained from Datastream.

A high value of any of the four variables indicates strong economic conditions.

In subsequent analysis, we sometimes separate strong from weak economic conditions by comparing a given measure of these conditions to zero. Since the three real variables $(G D P$, 
$F S T$, and $C L I$ ) tend to take positive values, we standardize each of them to have zero mean and unit variance within each country. We perform this standardization by using data from 1990 through 2012, which is the longest available sample period in Table 1 (only for FST, we go back to 1999 when its data begin). We do not standardize $M K T$ because positive and negative stock returns occur with nearly equal frequency in our sample.

\subsection{Political Events}

We hand-collect data on two types of political events: national elections and global summits. For election data, our starting point is the advanced search feature of the Election Guide website provided by the International Foundation for Electoral Systems. ${ }^{12}$ Our data include the date and type of the election, the election outcome, the percentage shares of votes cast for both the winner and the runner-up, and the opinion poll data for the top contenders. In addition, we investigate each parliamentary election for potential ex-ante coalitions of multiple parties. If we find such coalitions, we view them as stand-alone entities for the purpose of calculating votes cast as well as opinion poll spreads. In other words, both the winner and the runner-up could be a single party or a coalition of multiple parties, depending on the election. Whenever possible, we cross-check data across multiple databases.

For each country listed in Table 1, we collect data on all national elections that took place between the starting and ending dates of our option dataset. For all countries, we collect data on national parliamentary elections. In addition, we collect data on presidential elections for countries in which the president has executive power, such as the United States, Brazil, and France, but not for countries whose presidents' roles are largely ceremonial, such as Germany and Greece. If an election has two rounds, we consider both rounds as separate elections. We provide the full list of elections in Table A.1 of the Appendix.

In addition to elections for countries listed in Table 1, we add two extraordinary elections to our sample - the May and June 2012 Greek parliamentary elections. ${ }^{13}$ While Greece is not in Table 1 due to the lack of option data, its 2012 elections seem particularly relevant given their critical importance in the development of the eurozone debt crisis. At the time, the elections were widely viewed as a de facto referendum on Greece's membership in the eurozone. ${ }^{14}$ With one of the leading political parties proposing renegotiating Greece's treaty

\footnotetext{
${ }^{12}$ See http://www.electionguide.org. We also use other online sources, such as Psephos, Parline Database on National Parliaments, Election Resources on the Internet, European Election Database, Wikipedia, World Bank Database of Political Institutions, Gallup, and Angus Reid Public Opinion.

${ }^{13}$ The May 6, 2012 election ended inconclusively since none of the three largest parties (ND, SYRIZA, and PASOK) managed to form a new government, necessitating a follow-up election on June 17, 2012.

${ }^{14}$ For example, German Foreign Minister Guido Westerwelle said: "What's at stake isn't just the next
} 
with Europe, a plausible election outcome would have involved a Greek exit from the eurozone, with uncertain consequences for other vulnerable members such as Italy and Spain. While the inclusion of the Greek elections strengthens our conclusions in Section 3., those conclusions remain unchanged if we exclude these elections from our sample.

In subsequent analysis, we examine how the prices of options on a country's stock market index behave around that country's elections. For example, we study how German options behave around German elections, but not around French elections. ${ }^{15}$ Only for Greece, we are unable to examine the effect of elections on Greek option data because we do not have such data. Given the importance of the 2012 Greek elections for the future of the eurozone as a whole, we treat those elections as relevant for all European countries.

Our measure of uncertainty about the election outcome, $U N C$, is the negative of the poll spread. The poll spread is the most recent opinion poll spread before the election; if it is unavailable, we use the ex-post election margin instead. We calculate the opinion poll spread as the difference between the percentage shares of the poll leader and the runner-up. For example, if the leader is favored by $44 \%$ of the voters while the runner-up is favored by $38 \%$, the spread is $6 \%$. Similarly, we calculate the election margin as the difference between the percentage shares of votes cast for the winner and the runner-up.

In addition to national elections, we analyze global summits that took place between January 2007 and December 2011. We consider three types of summits: G8 summits, G20 summits, and European summits. The European summits include both EU summits held by the European Council, which comprise leaders of all EU member states, and eurozone summits, which include only those EU states that have adopted the euro. While the G8 summits are annual, the G20 summits take place once or twice per year, and the European summits occur roughly every couple of months.

Given our focus on financial effects of political uncertainty, we are interested in those summits that could plausibly result in major changes in economic policy. To pick such a set, we adopt two screens. First, we consider only summits from 2007 through 2011. This period is dominated by two economic crises, the financial crisis of 2007-2008 and the eurozone debt crisis, which have been accompanied by extensive government interventions. Prior to 2007, few summits dealt with such pressing economic issues, and government interventions were less pervasive. Second, after reading through the summit agendas, we identify the subset of

Greek government. What's at stake is the Greek people's commitment to Europe and the euro." (Bloomberg, "Greek Vote Escalates Crisis as Schaeuble Raises Euro-Exit", May 15, 2012) The media were awash with headlines such as "The Greek election will determine the future of the eurozone."

${ }^{15}$ In Section 5.1., we examine spillover effects of elections in one country on options in other countries. 
summits whose primary focus is on economic issues. All G20 summits fit that description. This makes sense since the Group of Twenty was formed in 1999 as a forum for cooperation on matters pertaining to the international financial system. In contrast, most G8 summits focus on non-economic issues: for example, the 2007 summit focused on global warming, struggle against poverty, and missile defense, while the 2008 summit focused on African development, climate change, and intellectual property rights. Such summits are unlikely to keep option market participants in suspense. We include only one G8 summit in our sample, the 2010 summit, which focused on economic recovery from global recession, financial reform, and the European debt crisis. Following the same description-based procedure, we include about two thirds of all European summits (including all summits since the breakout of the eurozone debt crisis in late 2009 but none before the Lehman Brothers collapse in 2008). In Table A.2, we provide the list of all summits in 2007 through 2011, along with their brief descriptions and indicators of economic relevance. All summits whose primary focus is on economic issues are included in our sample. While identifying the subset of economically relevant summits requires some judgmental choices, those choices do not affect our conclusions because our results are very similar if we include all summits in the analysis. ${ }^{16}$

Table 2 reports the number of political events in our sample by event type and country. These are events for which option data are available so we can calculate $I V D$ in equation (1). ${ }^{17}$ The table shows 64 election observations and 216 summit observations. The number of summit observations is larger because we view each summit as pertaining to all countries participating in the summit: we include G20 summits as observations relevant for all G20 countries, G8 summits for all G8 countries, and European summits for all European countries. In contrast, national elections pertain only to the country in which they are held. As noted earlier, only the 2012 Greek elections are included as observations relevant for all European countries, effectively treating those critical elections as European summits.

The numbers of events in Table 2 do not "add up": for example, we count 57 parliamentary elections and 14 presidential elections but only 64 elections total. The reason is that if parliamentary and presidential elections take place on the same date (as they do every four years in the U.S.), we count them as one election in the total. In addition, we combine into a single observation all country events that are so close in calendar time that they are followed by the same option expiration date (i.e., they share the same date $b$ in

\footnotetext{
${ }^{16}$ In our robustness analysis in Section 3.4., we extend our sample to include all summits, regardless of their economic relevance. While the results get a bit weaker, as one would expect as a result of adding noise to the estimation, all of our main conclusions remain unchanged (see Table B1 in the Internet Appendix, which is available on the authors' websites).

${ }^{17}$ Whenever $I V D$ is available, so is $V R P D$ in equation (4) because both variables have the same data requirements. SlopeD in equation (6) requires more data as it needs at least three OTM options.
} 
Figure 1). For example, for Germany, we combine its parliamentary election on September 27, 2009 with the G20 summit on September 24-25, 2009. As a result, our count for Germany includes five elections and 21 summits, but only 25 events total. We combine summits in the same way, such as the G8 summit on June 25-26, 2010 and the G20 summit on June 26-27, 2010. By combining events, we avoid double counting since many of the same options would otherwise enter the calculations of our option-market variables for both events. The combinations reduce the number of events by 44, bringing their total to 271 .

Whenever we combine events, we calculate the option-market variables $(I V D, V R P D$ and Slope D) for the combined event by averaging the corresponding values for the individual events. If the combined events occur in the same calendar month, the values of their macroeconomic variables $(G D P, F S T$, and $C L I)$ are the same; if they occur in adjacent months, we choose the value corresponding to the earlier month. If we combine two elections, we calculate $U N C$ for the combined event by taking the larger of the two uncertainty values. Finally, if we combine an election and a summit, we use the combined observation in both the "elections only" and "summits only" subsample tests.

\subsection{Hypotheses}

To guide our empirical analysis, we formulate three hypotheses in terms of the variables defined earlier. These hypotheses relate to the value of option protection against the price risk $(I V D)$, tail risk (SlopeD), and variance risk (VRPD) associated with political events.

Hypothesis 1: Political uncertainty is priced in the option market.

That is, IVD, $V R P D$, and SlopeD are all positive, on average.

Hypothesis 2: The effects of political uncertainty are larger when the economy is weaker.

That is, IVD, VRPD, and SlopeD are larger when the economy is weaker.

Hypothesis 3: The effects of political uncertainty are larger when the uncertainty is higher. That is, $I V D, V R P D$, and SlopeD are larger when $U N C$ is higher.

All of these hypotheses are directly motivated by the PV model, as discussed in the introduction as well as in more detail in Section 4. Since each of the three hypotheses consists of three different predictions, we have a total of nine testable predictions. 


\section{Empirical Results}

In this section, we test the hypotheses outlined above. To preview our results, we find empirical support for all three hypotheses, with significant results for eight of the nine predictions. Only the evidence for Slope D in Hypothesis 3 is not statistically significant.

\subsection{The Average Price of Political Uncertainty}

We begin with Hypothesis 1. Table 3 shows that the average IVD across all 271 political events is $1.43 \%$ per year $(t=4.43)$. The averages for the election and summit subsamples are similar in magnitude and also significant. The positivity of $I V D$ means that options whose lives span political events - the treatment-group options - are more expensive, on average, than their chronological neighbors whose lives do not span the same events - the controlgroup options. This effect is not only statistically but also economically significant. The mean of $I V D, 1.43 \%$, implies that investors are willing to pay $5.1 \%$ extra for put options that provide protection against the price risk embedded in political events. To obtain the $5.1 \%$ price premium, note that the average implied volatility across all control-group options is $27.8 \%$ per year. Therefore, the implied volatilities of treatment-group options are $5.1 \%$ $(=1.43 / 27.8)$ higher, on average, than the control group's implied volatilities. For ATM put options, a given percentage increase in implied volatility is approximately equal to the same percentage increase in the option's price. ${ }^{18}$ Therefore, the $I V D$ mean of $1.43 \%$ implies that spanning a political event makes ATM put options 5.1\% more expensive, on average.

The full-sample mean of $I V D, 1.43 \%$, is smaller than the weighted average of the two subsample means, $1.63 \%$ and $1.42 \%$. The reason is that the election/summit combination observations, which appear in both subsamples, have higher values of $I V D$ on average: 2.61\%. One prominent example is the U.S. presidential election on November 4, 2008 (Obama vs. McCain), which is combined with the G20 summit on November 14-15, 2008 since both events share the same first post-event option expiration date (November 22). The value of $I V D$ for this observation is $12.2 \%$ ! It makes sense for such "combo" observations to have higher $I V D$ : options expiring after multiple political events should be more valuable as they provide protection against the political risk associated with all of those events.

Another interesting example is the June 2012 Greek election. This election was perceived as crucial for the future of the eurozone, as noted earlier. Our results support that view.

\footnotetext{
${ }^{18}$ Consider a forward ATM put option, whose strike price is equal to the current stock price compounded forward at the risk-free rate. It is easy to show that the elasticity of this option's price $P$ to changes in implied volatility $\sigma$ is approximately equal to one; i.e., $(d P / P) /(d \sigma / \sigma) \approx 1$.
} 
The average value of $I V D$ across all European countries for this election is $6.7 \%$, almost five times the full-sample mean. The countries that were the most affected by this election are Spain $(I V D=10.3 \%)$ and Italy $(7.7 \%)$, which were arguably "next in line" to exit the eurozone after Greece. The effects on Germany and France, the key eurozone players, are also large (7.4\% and 7.2\%, respectively). The least affected European countries are Sweden and Switzerland, neither of which is a eurozone member. Similarly, in the May 2012 Greek election, the largest values of $I V D$ are observed for Italy, France, and Spain, while the smallest values belong to the eurozone non-members U.K. and Switzerland.

Table 3 shows that the average $V R P D$ across all events is $0.0107(t=2.61)$, in annualized variance terms. The averages for the election and summit subsamples are similar in magnitude and also significant. The positive mean of $V R P D$ indicates that the variance risk premia of treatment-group options exceed those of the control-group options, on average. This result shows that options provide valuable protection against the variance risk associated with political events. In addition, it shows that political uncertainty is truly priced in the sense of affecting the state price density and having a risk premium attached to it, rather than just in the sense of being reflected in option prices.

To judge the economic significance of $V R P D$, we convert variance risk premia from units of variance into option price premia. The mean of 0.0107 is equal to the difference between 0.0465, which is the average VRP of treatment-group options, and 0.0358 , the average VRP of control-group options. The VRP of 0.0465 translates into a $48.1 \%$ price premium for a one-month forward ATM put option with realized volatility equal to the average volatility observed in the treatment group. The VRP of 0.0358 translates into a $36.5 \%$ price premium for the same option given the average volatility of the control group. That is, treatmentgroup options are $48.1 \%$ more expensive relative to the Black-Scholes model, on average, whereas control-group options are $36.5 \%$ more expensive. Investors are thus willing to pay a lot for option protection against variance risk in our international sample. Moreover, this protection is proportionally more valuable for treatment-group options.

Table 3 also shows that the average Slope $D$ across all events is $0.0173(t=3.59)$. The average Slope $D$ is also positive and significant in both election and summit subsamples. This result indicates that the relative expensiveness of deep-OTM put options tends to be higher for treatment-group options, suggesting that such options provide valuable protection against the tail risk associated with political events.

To assess the economic value of this protection, we compute the price premium for OTM options in the treatment group relative to the control group. For both groups, we use their 
mean slope estimates to compute the implied volatilities of options that are $5 \%$ and $10 \%$ OTM, and then convert those implied volatilities into option prices for one-month puts. We find that treatment-group options that are 5\% OTM are 9.6\% more expensive than the control-group options with the same moneyness, on average, while treatment-group options that are 10\% OTM are 16.0\% more expensive. (Recall that treatment-group ATM options are $5.1 \%$ more expensive.) The price premium thus increases as the put options become progressively deeper OTM. These results show that investors are willing to pay substantially more for options that provide insurance against the tail risk linked to political events.

\subsection{The Role of Economic Conditions}

Columns 2 through 5 of Table 3 report differences between the average values of $I V D$ in weak versus strong economic conditions, as defined in Section 2.2. Specifically, we report the slope coefficient from the regression of $I V D$ on an indicator variable that takes the value of one if the event occurs during weak conditions and zero otherwise. The estimated value of this coefficient is positive in all 12 specifications (four measures of economic conditions times three sets of events), and it is statistically significant in 11 of them. ${ }^{19}$ IVD is clearly higher when the economy is weaker, on average. In other words, the value of option protection against political risk is larger in a weaker economy, as predicted by the model.

To assess the economic significance of this result, we again calculate the average percentage difference between the prices of treatment- and control-group options, but now we do so separately for weak and strong conditions. We find that the option price mark-up for protection against political risk is large in weak conditions but relatively small in strong conditions. Across the four measures of economic conditions, the price mark-up in weak conditions ranges from $7.1 \%$ for $G D P$ to $9.0 \%$ for $C L I$, whereas in strong conditions, it ranges from $0.1 \%$ for $F S T$ to $1.2 \%$ for $M K T$. Put differently, when the economy is weak, options providing protection against political risk are more expensive by about $8 \%$, but they are only slightly more expensive, by about $1 \%$, when the economy is strong.

Table 3 shows that the averages of $V R P D$ and SlopeD are also higher in weak economic conditions. For both variables, the weak-minus-strong average difference across all events is positive and statistically significant for all four measures of economic conditions. The same difference is also positive in both election and summit subsamples, and it is statistically significant in most of the subsample specifications. The results clearly show that the option protection against both variance and tail risks associated with political events is more

\footnotetext{
${ }^{19}$ To calculate standard errors, both here and in our subsequent regressions, we allow for two-way clustering of the residuals by month and country, following the procedure of Cameron, Gelbach, and Miller (2011).
} 
valuable when the economy is weaker.

Table 3 analyzes the role of economic conditions simply by comparing the average values of IVD, VRPD, and SlopeD in weak versus strong conditions. In Tables 4, 5, and 6, we perform additional analysis by regressing each of the three option-market variables on economic conditions. Let $E C O N$ denote any of the four measures of economic conditions defined in Section 2.2.: MKT, GDP, FST, and CLI. We scale all four ECON variables to unit variance within each regression so that we can interpret the regression slope coefficient as a response of the dependent variable to a one-standard-deviation change in the independent variable. We regress each of the three option variables on $E C O N$. We also run regressions on both ECON and ECON multiplied by an indicator for $E C O N>0$. This piecewise linear regression is motivated by the $\mathrm{PV}$ model, which implies that $I V D, V R P D$, and SlopeD should all be zero, and thus unrelated to $E C O N$, when the economy is strong.

Table 4 shows a strong negative relation between $I V D$ and $E C O N$, for all four $E C O N$ measures. The slope coefficient on $E C O N$ is estimated to be negative in all 24 specifications (four measures of ECON times three sets of events times two regressions), and it is statistically significant in 21 of them. The relation is economically significant as well: for example, a one-standard-deviation increase in $G D P$ decreases $I V D$ by $2.01 \%$ per year across all events. For both $G D P$ and $M K T$, we also find a convex kink that flattens the relation between $I V D$ and $E C O N$ for $E C O N>0$, as predicted by the PV model.

Tables 5 and 6 show that both $V R P D$ and SlopeD are negatively related to ECON. For $V R P D$, the slope coefficient on $E C O N$ is negative in all 24 specifications, and it is statistically significant in 19 of them. For SlopeD, the slope coefficient on ECON is negative in all 24 specifications, and it is statistically significant in 14 of them (at the $95 \%$ confidence level; in five additional specifications, it is significant at the $90 \%$ level). In both tables, the estimated kink in the piecewise linear regression is mostly positive but often insignificant. Tables 4 through 6 thus provide strong support for Hypothesis 2.

Figures 2, 3, and 4 plot the individual data points from the regressions in Tables 4, 5 , and 6, respectively. The figures plot the three option-market variables against ECON, with the four panels corresponding to the four ECON measures. They also plot the lines of best fit from the simple linear and piecewise linear regressions estimated on all events. The figures complement the evidence from the tables with three additional observations. First, the negative relations between the option-market variables and $E C O N$ are not driven by outliers. Second, there is more dispersion in the option-market variables for summit observations (marked as circles) than for election observations (marked as squares), but 
there is a fair amount of dispersion for both. Finally, there is more dispersion in the optionmarket variables in weak conditions than in strong conditions.

\subsection{The Role of Political Uncertainty}

Table 7 relates our three option-market variables to $U N C$, uncertainty about the election outcome, which is defined in Section 2.3. Our sample includes only elections because the poll spread data used in the construction of $U N C$ are obviously unavailable for summits. We scale $U N C$ to unit variance within each regression to facilitate the interpretation of the regression slope coefficients, analogous to the scaling of ECON in Tables 4 through 7.

Column 1 of Table 7 reports the slope coefficients from the simple regressions of $I V D$, $V R P D$, and SlopeD on $U N C$. The point estimates are positive for all three variables, but they are significant only for $I V D$ and $V R P D$. A one-standard-deviation increase in $U N C$ increases $I V D$ by $1.87 \%$ per year $(t=5.39)$, a magnitude that exceeds the unconditional mean of $I V D$ from Table 3. The same increase in $U N C$ increases $V R P D$ by $0.0106(t=$ 3.48), which is also substantial and close to the mean of $V R P D$ from Table 3. In contrast, the effect of $U N C$ on SlopeD is small and indistinguishable from zero.

The rest of Table 7 reports results from multiple regressions that control for economic conditions. The ECON controls enter with negative signs throughout, consistent with our earlier results. The results for $I V D$ and $V R P D$ are essentially unaffected by the $E C O N$ controls: the slopes on $U N C$ remain positive, large, and statistically significant. In contrast, the results for Slope $D$ are weak: the point estimate of the slope on $U N C$ is positive for three of the four ECON measures, but it is never statistically significant. This insignificance might be related to the sample size, which can be as low as 50 . Recall that we have 64 election observations, but we lose some of them due to unavailable macro data and especially due to the tighter option data requirements in the construction of SlopeD.

Figure 5 plots the individual data points underlying the simple regressions in Table 7. The three panels plot $I V D, V R P D$, and SlopeD against $U N C$ across all election events, along with the lines of best fit. All three of these lines are upward-sloping, reflecting the

positive slope estimates in Column 1 of Table 7 . There are no obvious outliers. Finally, the dispersion in the option-market variables is generally higher when $U N C$ is higher.

Overall, we find strong positive relations between $U N C$ and both $I V D$ and $V R P D$, consistent with Hypothesis 3. These results suggest that higher uncertainty about the election outcome increases the value of option protection against both price and variance risks 
associated with elections. The relation between $U N C$ and SlopeD is weak - while the point estimates are mostly positive, they are statistically insignificant.

\subsection{Robustness}

We conduct six sets of tests to assess the robustness of our results. In this subsection, we describe those tests and summarize their results, without tabulating them to save space. All the tables are shown in the robustness section of the Internet Appendix.

First, we repeat our regressions without combining political events that are close in calendar time. Recall from Section 2.3. that we combine into a single observation all country events that share the same expiration date $b$ in Figure 1. When we uncombine these events and include them separately, we find very similar results.

Second, we repeat our tests on all summit observations listed in Table A.2, instead of just the economically relevant subset. The total number of summit observations thus increases from 216 to 310 for $I V D$ and $V R P D$, and from 191 to 273 for SlopeD. As before, we regress $I V D, V R P D$ and SlopeD on ECON. The point estimates of the slope coefficient are negative for all three option variables in all 24 specifications, and they are statistically significant in 22 of them. Therefore, our conclusions about the role of economic conditions hold also for the broader set of summits. The magnitudes of the slope coefficients on ECON are smaller compared to the corresponding regressions based on the subset of economically relevant summits, almost without exception (23 out of 24 times; cf. Table B1 in the Internet Appendix with Panels $\mathrm{C}$ in Tables 4, 5, and 6). This is exactly what we should expect to see a priori: option prices should be less affected by summits that are less economically relevant. Overall, this evidence based on all summits strengthens our conclusions.

Third, we repeat our tests on the subset of events for which there is no doubt about the exogeneity of the event's timing. This is a large subset because elections and summits are usually scheduled many months in advance. We find that all elections in our sample, as well as most summits, had been scheduled more than four weeks in advance. Their timing is therefore known to investors at the time we calculate the prices of treatment-group options, which is at most 20 trading days before the event. Any political uncertainty associated with those events is exogenous from the investors' perspective. For only five events in our sample, we cannot rule out the possibility that they had been scheduled less than four weeks in advance. $^{20}$ When we exclude those five events, we find very similar results.

\footnotetext{
${ }^{20}$ All five events are European summits: 20081107, 20090301, 20100507, 20110721, and 20111026.
} 
Fourth, we repeat our tests after redefining $I V D$ in equation (1) to be a percentage difference rather than an arithmetic difference between the $I V$ s of treatment- and controlgroup options. This test aims to check whether our results could somehow be driven by different levels of volatility across strong and weak economic conditions. They are not.

Fifth, we recompute our standard errors by bootstrapping. To allow for residual correlation across both countries and months, we implement a two-way resampling procedure. We draw political events randomly, with replacement, from our sample of events. For each randomly drawn event, we add to the sample all other events for the same country (regardless of the month) as well as all other events from the same month (regardless of the country). We continue resampling until we reach the same number of observations as in our sample. The standard errors increase somewhat but none of our conclusions change.

Finally, we conduct a placebo test to alleviate the potential concern that our results might be caused by interactions between option prices and economic conditions rather than by political events. For example, market volatility is well known to be higher during economic crises. If elections or summits are more likely to occur during crises, our finding of higher implied volatility before political events could in principle be caused by crises rather than political events. We do not expect this concern to be valid given the differencing applied in the construction of our option-market variables (see equations (1), (4), and (6)). The adjacent option expiration dates are likely to occur during the same crisis if one is taking place. Nonetheless, we conduct a placebo test to provide additional evidence.

The idea behind our placebo test is to construct many random samples of "pseudo-event" dates in which the treatment effect - the political event - is absent. For each placebo sample, we rerun our regressions and retain the estimated coefficients. By comparing the actual coefficient estimates to their distribution in the placebo samples, we infer the likelihood of the hypothesis that our empirical results have nothing to do with political events.

We construct 10,000 placebo samples of 271 pseudo-events each, the same number as in our actual sample. We allocate these pseudo-events to countries based on the frequency of actual events in the data (see Table 2). For each country, we draw its pseudo-event dates randomly from the set of all dates satisfying two conditions: the date must not occur within 30 days of any actual political event for that country, and option data must be available to calculate $I V D$ for that date and country. We calculate $I V D, V R P D$ and Slope $D$ for each pseudo-event, record their means, and regress them on the actual economic conditions at the time of the pseudo-event. Finally, we use the 10,000 samples to calculate one-sided $p$-values as the fractions of placebo estimates that exceed the actual estimate in the direction 
predicted by theory. For example, since the theory predicts a negative relation between $I V D$ and $E C O N$, the $p$-value for the slope from the regression of $I V D$ on $E C O N$ is the fraction of placebo estimates that are more negative than the actual estimate.

Table 8 shows the placebo test results corresponding to Table $3 .^{21}$ Most $p$-values in Table 8 are smaller than 0.001 , and all of them are smaller than 0.02 . The only nontrivial $p$-value, 0.017, obtains for the difference in average $I V D$ in weak versus strong conditions as measured by $M K T$. Even placebo samples can thus generate a positive weak-minus-strong difference in average $I V D$, perhaps due to the volatility feedback effect, but they are very unlikely to generate a difference as large as that observed in the data. Overall, our placebo tests show that it is extremely unlikely that our results could arise spuriously.

Colleagues have suggested drawing the pseudo-event dates from the set of dates on which macroeconomic news is announced. Such a test could allow us to compare the relative importance of macro news and political news for option prices. However, our empirical methodology is not well suited for macro announcements because such announcements typically occur every month (e.g., U.S. payroll data are released on the first Friday of each month). Since the option expiration grid is monthly as well, for every treatment-group option spanning a macro announcement, the control-group options would span the macro announcements one month earlier and one month later, effacing the difference between the treatment and the control. Our empirical results clearly reflect political uncertainty, not macro uncertainty, because we pick $\tau$ as the dates of political events. Moreover, our theory makes predictions that seem unique to political uncertainty, such as the asymmetric impact of economic conditions, which is due to the endogeneity of the government's policy choice. It is not clear why the same asymmetry would apply to macro uncertainty in general. ${ }^{22}$

\section{Theory}

In this section, we discuss theoretical predictions for option prices around political events. Let $S_{t}$ denote a vector of state variables, which follow a generic stochastic process

$$
d S_{t}=\mu_{S}\left(S_{t}\right) d t+\sigma_{S}\left(S_{t}\right) d W_{S, t},
$$

\footnotetext{
${ }^{21}$ In the Internet Appendix, we show placebo test results corresponding to Tables 4, 5, and 6 . Those results lead to the same conclusions as Table 8. There is no placebo test for Table 7 because $U N C$ cannot be calculated for pseudo-event dates due to non-existent poll spread data.

${ }^{22}$ We also run two modified versions of the placebo test. First, we draw the pseudo-event dates from the subset of available dates that exhibit high market volatility; specifically, dates on which volatility exceeds the full-sample median volatility for the given country. Second, we require that the pseudo-event dates must not occur within 60 (instead of 30) days of any actual political event. Both versions of the placebo test produce results very similar to those reported in Table 8. See the Internet Appendix for details.
} 
where $d W_{S, t}$ is a vector of independent Brownian motions. The stock market value, $M_{t}$, and the stochastic discount factor, $\pi_{t}$, follow generic processes with jumps at a given time $\tau$ :

$$
\begin{aligned}
\frac{d M_{t}}{M_{t}} & =\mu_{M}\left(S_{t}\right) d t+\sigma_{M}\left(S_{t}\right) d W_{M, t}+J_{M, \tau} 1_{t=\tau} \\
\frac{d \pi_{t}}{\pi_{t}} & =\sigma_{\pi}\left(S_{t}\right) d W_{\pi, t}+J_{\pi, \tau} 1_{t=\tau}
\end{aligned}
$$

where $d W_{M, t}$ and $d W_{\pi, t}$ are Brownian motions possibly correlated with each other and with $d W_{S, t}, 1_{t=\tau}$ is an indicator function that is equal to one when $t=\tau$ and zero otherwise, $J_{M, \tau}$ and $J_{\pi, \tau}$ are random jumps with generic probability distributions

$$
\begin{aligned}
J_{M, \tau} & \sim F_{M}\left(S_{\tau}\right) \\
J_{\pi, \tau} & \sim F_{\pi}\left(S_{\tau}\right),
\end{aligned}
$$

and $\mathrm{E}_{\tau-}\left(J_{\pi, \tau}\right)=0 .{ }^{23}$ We assume that the risk-free rate is zero, for simplicity, and that all the regularity conditions are met so that the stochastic processes above are well defined. The price of a put option on the stock market index at time $t$ is then given by

$$
\operatorname{Put}\left(S_{t}, m, K\right)=\mathrm{E}\left[\frac{\pi_{m}}{\pi_{t}} \max \left(K-M_{m}, 0\right) \mid S_{t}\right],
$$

where $m$ is the option's maturity and $K$ is its strike price. In the rest of this section, we show that the PV model imposes a rich set of restrictions on the general dynamics of stock and option prices in equations (7) through (12), where $\tau$ is the date of a political event.

\subsection{The PV Model}

We begin by providing a verbal overview of the PV model. In this general equilibrium model, firm profitability follows a process whose mean depends on the current government policy. The policy's impact on the mean is uncertain. Both the government and investors learn about it in a Bayesian fashion by observing realized profitability. There is no asymmetric information (we relax this assumption in Section 5.2.). At a given point in time, denoted by $\tau$, the government decides whether to change its policy and if so, which new policy to adopt.

\footnotetext{
${ }^{23}$ The jump terms in equations (8) and (9) can also be rewritten more formally as $J_{M, \tau} d N_{t}$ and $J_{\pi, \tau} d N_{t}$, respectively, where $N_{t}$ is a right-continuous step function such that $N_{t}=0$ for $t<\tau$ and $N_{t}=1$ for $t \geq \tau$. This assumption of jumps at a single point in time, $t=\tau$, maps directly into the PV model. As an example of an alternative approach, Piazzesi (2005) estimates a reduced-form model with jumps in the target federal funds rate whose intensity during pre-scheduled FOMC meetings is higher than outside those meetings. Piazzesi's framework also differs from ours in that her jumps are of nonrandom magnitude (25 basis points), she does not allow for jumps in $\pi_{t}$, and her focus is on the prices of bonds, not options. Another approach is pursued by Chernov, Gallant, Ghysels, and Tauchen (2003) who consider various models of stock price dynamics with jumps at random times, along with their implications for option pricing.
} 
If a policy change occurs, the agents' beliefs are reset: the posterior beliefs about the old policy's impact are replaced by the prior beliefs about the new policy's impact.

When making its policy decision, the "quasi-benevolent" government has both economic and non-economic motives: it cares about its citizens' economic welfare but also takes into account the political costs associated with adopting any given policy. These costs are uncertain until time $\tau$, so that investors cannot fully anticipate which policy will be chosen by the government. Uncertainty about political costs is a key source of political uncertainty, or uncertainty about the government's future actions. Agents learn about political costs by observing political signals that represent the flow of news about upcoming political events. For technical details of the model, see its formal exposition in the Appendix.

\subsubsection{Election Interpretation}

The PV model of government policy choice can be naturally reinterpreted as a model of democratic elections. Let the original PV model be known as "version A" and its alternative election interpretation as "version B." In both versions, a structural change can potentially take place at time $\tau$. In version $\mathrm{A}, \tau$ is the time of the policy decision; in version $\mathrm{B}$, it is the time of the election. In version $\mathrm{A}$, the government decides whether to change its current policy and if so, which new policy to adopt. In version B, voters decide whether to replace the incumbent government and if so, which new government to elect. In version A, political uncertainty is uncertainty about which policy will be chosen; in version B, it is uncertainty about who will be elected. In version A, the government cares not only about economic wellbeing but also about the political costs of the various policy choices. In version $\mathrm{B}$, voters care not only about economic well-being but also about non-economic aspects of the electoral choices, such as the candidates' charisma and their attitudes toward religion, abortion, etc. In version A, agents learn about the impact of the current policy on profitability; in version $\mathrm{B}$, they learn about the impact of the incumbent government. Both versions share the same analytical framework - all equations are identical, only their interpretations differ.

In our empirical analysis, we analyze two types of political events: national elections and global summits. When we study elections, we rely on the model's election interpretation (version B). For summits, we appeal to the original version of the model (version A).

\subsection{Restrictions on General Dynamics}

In the PV model, before time $\tau$, the state variables from equation (7) are

$$
S_{t}=\left(\widehat{g}_{t}, \widehat{c}_{t}^{1}, \ldots, \widehat{c}_{t}^{N}, t\right)^{\prime}
$$


where $\widehat{g}_{t}$ is the perceived impact of the current government policy and $\widehat{c}_{t}^{n}$ is the logarithm of the perceived political cost of implementing a potential new policy $n$, for $n=1, \ldots, N$. The variable $\widehat{g}_{t}$, which is the only economic state variable in the model, is a natural measure of the state of the economy: a high $\widehat{g}_{t}$ denotes strong economic conditions. In contrast, $\widehat{c}_{t}^{n}$ are driven by political shocks. The state variables are driven by Bayesian learning; they follow independent martingale processes given in equations (A6) and (A13) in the Appendix.

Proposition 1: The PV model implies that $\mu_{S}\left(S_{t}\right), \mu_{M}\left(S_{t}\right), \sigma_{S}\left(S_{t}\right), \sigma_{M}\left(S_{t}\right), \sigma_{\pi}\left(S_{t}\right), J_{M, \tau}$, $J_{\pi, \tau}, d W_{S, t}, d W_{M, t}$, and $d W_{\pi, t}$ in equations (7) through (11) are given in equations (A16) through (A25) in the Appendix.

The PV model imposes tight restrictions on the parameters and Brownian motions from equations (7) through (11). To explore those restrictions, we simplify the above setting to $N=2$. There are two potential new policies, $H$ and $L$. The impact of policy $H$ is more uncertain but also higher in expectation so that both policies provide the same level of utility a priori. This two-policy setting is identical to the one used by PV to analyze different implications of their model. We use the same parameter values as PV (see their Table 1). For the parameters $\left\{\sigma_{g}, \sigma_{c}, \mu, \sigma, \sigma_{1}, T, \tau, \gamma, h, \sigma_{g, L}, \sigma_{g, H}, \mu_{g, L}, \mu_{g, H}\right\}$, which we define in the Appendix, we choose the values $\{2 \%, 10 \%, 10 \%, 5 \%, 10 \%, 20,10,5,5 \%, 1 \%, 3 \%,-0.8 \%, 0.8 \%\}$. There are three stochastic state variables: $\widehat{g}_{t}, \widehat{c}_{t}^{H}$, and $\widehat{c}_{t}^{L}$. We set $\widehat{c}_{t}^{H}$ equal to its prior mean, $-\frac{1}{2} \sigma_{c}^{2}$, and vary $\widehat{g}_{t}$ and $\widehat{c}_{t}^{L}$, thus varying both economic conditions and political uncertainty.

Figure 6 plots the policy adoption probabilities $p_{t}^{0}, p_{t}^{L}$, and $p_{t}^{H}$ against $\widehat{g}_{t}$ and $\widehat{c}_{t}^{L}$ at time $t$ immediately preceding time $\tau$, so $t \approx \tau$. We scale both $\widehat{g}_{\tau}$ and $\widehat{c}_{\tau}^{L}$ by their volatilities to convert them into "z-scores." We see that the policy decision is influenced by political costs: $p_{\tau}^{L}$ is low if policy $L$ imposes a political cost on the government, while it is high if $L$ brings a political benefit. The policy decision also strongly depends on economic conditions. Panel A highlights a key implication of the PV model: the government is more likely to replace its current policy in weaker economic conditions. When $\widehat{g}_{\tau}$ is low, $p_{\tau}^{0} \approx 0$. A low $\widehat{g}_{\tau}$ indicates that the current policy is "not working" so the government is likely to replace it. In contrast, when $\widehat{g}_{\tau}$ is high, the current policy is likely to be retained.

This result can be easily reinterpreted in the election version (version B) of the PV model: the incumbent government is more likely to be reelected when the economy is doing well, and more likely to be removed from power when the economy is doing poorly. Consistent with this theoretical prediction, after surveying the empirical literature, Lewis-Beck and Stegmaier (2000) conclude that economic conditions are an important determinant of election outcomes: "Good times keep parties in office, bad times cast them out." (p. 183). 
Figure 6 also plots the jumps in stock prices resulting from the three possible policy announcements at time $\tau$. These jumps, $J_{M, \tau}$, exhibit strong dependence on the state variables. When $\widehat{g}_{\tau}$ is high, the retention of the current policy elicits no stock price reaction because it is widely expected, whereas the adoption of either $H$ or $L$ is bad news because it is driven by political considerations. When $\widehat{g}_{\tau}$ is low, the retention of the current (poorly-performing) policy is bad news while the adoption of the low-risk policy $L$ is good news. For intermediate values of $\widehat{g}_{\tau}$, the retention of the current policy is good news, especially if $\widehat{c}_{t}^{L}$ is high because investors then expect the high-risk policy $H$ and they are relieved to learn that there is no policy change. Policy $H$ is bad for stockholders because the high uncertainty about its impact increases discount rates. The adoption of $H$ thus results in a negative jump unless $\widehat{c}_{t}^{L}$ is so high that the adoption is already priced in before time $\tau$. We see that the PV model imposes tight restrictions on jumps in stock prices in equation (8).

Panel A of Figure 7 shows the restrictions on the diffusive volatility $\sigma_{M}\left(S_{t}\right)$ from equation (8) as of time $t=\tau-1 / 2$. The volatility is highest when $\widehat{g}_{t} \approx 0$ and $\widehat{c}_{t}^{L}$ is high because investors are then uncertain between the current policy and policy $H$ so that any new signal carries a lot of weight. The volatility is also high when $\widehat{g}_{t}$ is low and $\widehat{c}_{t}^{L} \approx 0$ because of uncertainty between $H$ and $L$. In contrast, $\sigma_{M}\left(S_{t}\right)$ is low when there is no policy uncertainty, such as when $\widehat{g}_{t}$ is high (so that $p_{t}^{0} \approx 1$ ) or when $\widehat{g}_{t}$ is low and $\widehat{c}_{t}^{L}$ is either high or low $\left(p_{t}^{H} \approx 1\right.$ or $\left.p_{t}^{L} \approx 1\right)$. Panel B plots the expected volatility of stock returns between times $\tau-\frac{1}{2}$ and

$\tau+\frac{1}{2}$, as of time $t=\tau-1 / 2$. This volatility differs from $\sigma_{M}\left(S_{t}\right)$ plotted in Panel A because it reflects not only diffusive volatility before $\tau$ but also expectations of the stock price jump at $\tau$ and diffusive volatility after $\tau$. The biggest difference occurs when $\widehat{g}_{t}$ is low and $\widehat{c}_{t}^{L}$ is high; we then expect policy $H$, which raises expected $\sigma_{M}\left(S_{t}\right)$ after $\tau$, thus elevating the expected volatility in Panel B above the diffusive pre- $\tau$ volatility in Panel A.

\subsection{Implications for Option Prices}

The restrictions from Proposition 1 imply restrictions on put option prices in equation (12). Our main interest is in equity index options whose lives span time $\tau$ when the political event occurs. We derive a closed-form expression for the price of such options.

Proposition 2: At time $t<\tau$, the price of a European put option expiring at time $m>\tau$, $\operatorname{Put}\left(S_{t}, m, K\right)$, is given by equation (A26) in the Appendix.

At time $\tau$, the government can either retain its current policy or adopt one of $N$ potential new policies. At any time $t<\tau$, investors assign a probability to each of those $N+1$ policy choices. If one of those probabilities is equal to one, the option price is given by the standard 
Black-Scholes formula, with implied volatility equal to the average stock return volatility during the remaining life of the option (see Corollary A.1). In general, the probabilities of the $N+1$ policies depend on $S_{t}$. The option price in Proposition 2 is essentially a probability-weighted average of $N+1$ quantities, each of which is the expected present value of a Black-Scholes option price conditional on the corresponding policy choice.

In addition to option prices, we solve in closed form for the jump risk premium associated with political events. When the government announces its policy decision at time $\tau$, stock prices jump because this decision is not fully predictable, due to uncertainty about political costs. The expected value of the stock price jump at time $\tau$ represents the risk premium that compensates investors for the risk associated with holding stocks at time $\tau$.

Proposition 3: Immediately before time $\tau$, the jump risk premium associated with the political event at time $\tau$ is given by equation (A28) in the Appendix.

Figure 8 examines the restrictions imposed by the PV model on option prices and the jump risk premium in the context of the $N=2$ setting analyzed earlier. At time $\tau-\frac{1}{2}$, we consider one-period European put options that expire at time $\tau+\frac{1}{2}$. We calculate modelimplied values of three option-market variables that correspond to the variables examined in our empirical work: implied volatility $(I V)$, the variance risk premium $(V R P)$, and the implied volatility slope (Slope). ${ }^{24}$ To calculate $I V$, we first use Proposition 2 to calculate the model-implied price of an at-the-money put option, or option $\mathcal{O}_{\text {Aтм }}$, and then convert this price to a Black-Scholes implied volatility value. To calculate $V R P$, we subtract from the squared value of $I V$ the expected variance of stock returns between times $\tau-\frac{1}{2}$ and $\tau+\frac{1}{2}$. Finally, we calculate Slope as the difference between the implied volatilities of options that are $5 \%$ out-of-the-money $\left(\mathcal{O}_{\text {отм }}\right)$ and $5 \%$ in-the-money $\left(\mathcal{O}_{\text {Iтм }}\right)$.

Panel A of Figure 8 shows that $I V$ is generally higher in weaker economic conditions. A significant part of option $\mathcal{O}_{\text {Aтм }}$ 's value derives from the protection against the drop in stock prices that would result from an unfavorable policy decision at time $\tau$. In good economic conditions, such a drop is unlikely because the current policy is likely to be retained, and that decision is priced in before time $\tau .^{25}$ In bad conditions, though, a policy change is likely, and prices jump when it becomes clear whether $H$ or $L$ is adopted. Option $\mathcal{O}_{\text {атм }}$ provides protection against the price risk associated with this resolution of uncertainty. In bad conditions, we also see that $I V$ is high when $\widehat{c}_{t}^{L}$ is high, which is when $H$ is likely so the

\footnotetext{
${ }^{24}$ In our empirical analysis, we analyze $I V D, V R P D$ and SlopeD. When we construct such differences within the PV model, we find predictions identical to those for $I V, V R P$ and Slope. We therefore do not difference these variables here, for simplicity. The purpose of the differencing in the empirical analysis is to account for realistic departures from our simple theoretical model, as explained earlier.

${ }^{25}$ As $\widehat{g}_{t} \rightarrow \infty, p_{t}^{0} \rightarrow 1, \mathcal{O}_{\mathrm{ATM}}$ is priced by the Black-Scholes formula, and $I V$ equals expected volatility.
} 
expected post- $\tau$ volatility is high. But $I V$ is even higher when $\widehat{c}_{t}^{L} \approx 0$, which is when the uncertainty about $H$ versus $L$ is highest. In short, $I V$ is higher when the economy is weaker and when there is more uncertainty about the government's policy choice.

Panel $\mathrm{B}$ of Figure 8 shows that $V R P$ also tends to be higher when the economy is weaker and when there is more political uncertainty. In general, $V R P$ is high if investors are willing to pay a lot for insurance against variance risk. This risk stems from two sources: stochastic fluctuations in return variance and the jump in stock prices at time $\tau .^{26}$ Variance fluctuates before time $\tau$ as a result of political shocks. The resolution of political uncertainty at time $\tau$ makes both variance and stock prices jump: if $H$ is adopted, variance jumps up and prices down; if $L$ is adopted, variance jumps down and prices up. In good economic conditions, $V R P \approx 0$ because $p_{t}^{0} \approx 1$ so that political shocks do not matter much and there is little risk of a jump at time $\tau$. In bad conditions, though, political shocks do matter and the risk of a jump is higher, and so is $V R P$. This is especially true when $\widehat{c}_{t}^{L} \approx 0$, which is when the uncertainty about $H$ versus $L$ is highest. The importance of political uncertainty is clear from comparing the two components of $V R P: I V$ in Panel A of Figure 8 and expected volatility in Panel B of Figure 7. Whereas the latter quantity varies smoothly with $\widehat{g}_{t}$ and $\widehat{c}_{t}^{L}$, the former quantity - and hence also $V R P$ - is elevated when political uncertainty is high, such as when $\widehat{g}_{t} \approx 0$ and $\widehat{c}_{t}^{L}$ is high or when $\widehat{g}_{t}$ is low and $\widehat{c}_{t}^{L} \approx 0$.

Panel C of Figure 8 shows that Slope exhibits a pattern similar to that of $V R P$. Recall that Slope is high whenever $\mathcal{O}_{\text {отм }}$ is expensive relative to $\mathcal{O}_{\text {Ітм }}$. The key difference between the two options is that $\mathcal{O}_{\text {отм }}$ provides better protection against catastrophic events, namely, the adoption of policy $H$. Since that is more likely when the economy is weaker, Slope is generally higher when $\widehat{g}_{t}$ is low. Also note that Slope $\approx 0$ whenever investors assign a high probability to one of the three policies. If $p_{t}^{n} \approx 1$ for any $n \in\{0, H, L\}$, both $\mathcal{O}_{\text {отм }}$ and $\mathcal{O}_{\text {Iтм }}$ are priced according to the Black-Scholes formula, so their implied volatilities are equal and Slope $\approx 0$. When there is uncertainty about policy choice, though, Slope is typically positive due to negative skewness in stock returns around time $\tau .{ }^{27}$ One reason behind the negative skewness is the interaction between the price jump at time $\tau$ and the post- $\tau$ return volatility. If $H$ is adopted, prices drop and the volatility rises; if $L$ is adopted, prices rise and the volatility declines. Returns thus become more volatile after a drop in prices, resulting in negative skewness over periods extending beyond time $\tau$.

\footnotetext{
${ }^{26}$ Todorov (2010) separates the jump component of $V R P$ from the stochastic variance component in a semiparametric empirical framework. He finds that jumps play an important role in explaining $V R P$.

${ }^{27}$ Across many samples simulated from the model, the correlation between Slope and expected skewness from $\tau-\frac{1}{2}$ to $\tau+\frac{1}{2}$ is -0.95 . Bakshi, Kapadia, and Madan (2003) find empirically that the implied volatility curve is steeper when the risk-neutral distribution of stock returns is more negatively skewed.
} 
Panel D of Figure 8 shows that the jump risk premium from Proposition 3, JRP, is generally larger when the economy is weaker and when political uncertainty is higher. When there is little doubt about what will happen at time $\tau, J R P \approx 0$. But in weak conditions and when uncertainty is high, investors demand compensation for holding stocks at time $\tau$. Since the jump in stock prices at time $\tau$ is a part of the stock return variance between $\tau-\frac{1}{2}$ and $\tau+\frac{1}{2}$, the patterns of $J R P$ and $V R P$ are similar, suggesting that jumps induced by political events account for a substantial part of $V R P .{ }^{28}$ The patterns in all four panels of Figure 8 look similar for a wide range of parameter values (see the Internet Appendix).

Finally, the model implies that all three variables, $I V, V R P$, and Slope, take larger values, on average, than than they would if we were to remove the political event from time $\tau$. The absence of a political event is a special case of our setting in which the probability of a policy change at time $\tau$ is zero (i.e., $p_{t}^{0}=1$ ). In that case, the Black-Scholes formula applies, and the three variables take the same values as in Figure 8 when $\widehat{g}_{t} \rightarrow \infty: I V=0.08$ and $S l o p e=V R P=0$. These values are lower, on average, than the unconditional means of these variables in the presence of political risk.

To provide additional insight, we simulate many paths from the PV model and plot the realized values of the three option-market variables against $\widehat{g}_{t}$ and political uncertainty, measured by the entropy of the policy probabilities. The results provide further support for the conclusions from Figure 8. In addition, they motivate the piecewise linear regression specifications estimated in Section 3. See the Internet Appendix for details.

\subsection{Model-Implied Correlations}

The three option-market variables are negatively correlated with economic conditions and positively correlated with political uncertainty, as discussed earlier. How large are the modelimplied correlations and how do they compare to the correlations observed in the data?

To answer these questions, we simulate many samples from the PV model. For each sample, we calculate the three option-market variables at time $t=\tau-1 / 2$. We compute the correlations of these variables with $\widehat{g}_{t}$ and entropy across the simulated samples. Table 9 shows that the correlations with $\widehat{g}_{t}$ range from -0.32 to -0.46 and those with entropy range from 0.58 to $0.74 .^{29}$ These correlations have the same signs as those observed in the data.

\footnotetext{
${ }^{28}$ Across many samples simulated from the model, the correlation between $J R P$ and $V R P$ is 0.70 .

${ }^{29}$ We obtain similar correlations, ranging from 0.59 to 0.77 , when we replace entropy by a different measure of political uncertainty: the theoretical poll spread, which we compute as the difference between the first and second largest policy probabilities. Also note that we compute model-implied IVD, VRPD and SlopeD for direct comparisons with the data but the correlations for $I V, V R P$ and Slope are very similar.
} 
The empirical correlations are slightly smaller, ranging from -0.10 to -0.46 across the four measures of $E C O N$ and from 0.06 to 0.44 for $U N C$, but the overall fit between the model and the data is very good. Moreover, the model-implied correlations are similar for a wide range of parameter changes, as we show in Table B23 of the Internet Appendix.

We submit the PV model to one more hurdle. We conduct an event study to analyze the correlations between stock returns and changes in the option-market variables around political events. To obtain theoretical predictions, we simulate many samples from the PV model. For each sample, we solve for the optimal policy choice at time $\tau$ and calculate stock returns $($ Ret) as well as changes in the option-market variables $(\Delta I V, \Delta S l o p e$, and $\Delta V R P)$ over the two-week period from time $\tau-1$ week to $\tau+1$ week. We then calculate the correlation matrix of the four variables across the simulated samples. We find three correlations whose magnitudes exceed 0.1: $\operatorname{Corr}(\Delta I V, R e t)=-0.34, \operatorname{Corr}(\Delta I V, \Delta S l o p e)=$ 0.27, and $\operatorname{Corr}(\Delta I V, \Delta V R P)=0.80$. We show the full correlation matrix in the Internet Appendix, along with the discussion of the sources of these correlations.

We conduct analogous calculations in the data. For each election in our sample, we calculate the stock index return as well as changes in the option-market variables over the two-week period around the election date for the country in which the election is held. For summits, we calculate averages across all countries participating in the summit. The results are remarkably similar to those produced by the model. Only three of the six correlations are statistically significant, and they are the same correlations that we highlighted in the previous paragraph: $\operatorname{Corr}(\Delta I V$, Ret $)=-0.16(t=-2.11), \operatorname{Corr}(\Delta I V, \Delta$ Slope $)=0.28(t=3.66)$, and $\operatorname{Corr}(\Delta I V, \Delta V R P)=0.69(t=14.19)$. The remaining correlations are not only insignificant but also much smaller, no larger than 0.08. The similarity between the two correlation matrices is striking, providing additional support for the model.

To conclude, Section 4. shows that the PV model makes various predictions that help explain our empirical findings. Those predictions are not obvious. For example, while it is intuitive for $I V D$ to be positive, it is not clear why $V R P D$ or Slope $D$ should be positive, or why any of these variables should be negatively correlated with economic conditions. To emphasize this point, in the Internet Appendix, we consider a simple reduced-form model in which there are no state variables, all drifts and volatilities in equations (8) and (9) are constant, and the jumps in equations (10) and (11) are log-normally distributed. While this model does generate $I V D>0$ (because $I V D$ in this model is equal to jump variance), that $I V D$ is not state-dependent, and the model also implies $V R P D=S l o p e D=0$ despite the presence of priced jump risk. The restrictions on option prices implied by the PV model are thus nontrivial and economically meaningful. 


\section{Model Extensions}

In this section, we discuss two extensions of the PV model and their empirical implications.

\subsection{Extension: Two Countries}

We extend the single-country PV model to two countries. The extension allows us to analyze spillovers of political uncertainty across countries and its implications for foreign exchange (FX) options. We only summarize the model here; its formal presentation including propositions, proofs, and numerical examples is in the Internet Appendix.

We assume that aggregate profitability in country $i$, for $i=1,2$, follows the process

$$
d \Pi_{t}^{i}=\left(\mu+\beta^{i} g_{t}\right) d t+\sigma d Z_{t}+\sigma_{1} d Z_{t}^{i}
$$

which is identical to the process in the PV model (see equation (A1)) except that policy impact is now measured by $\beta^{i} g_{t}$. We set $\beta^{1}=1$ so that $g_{t}$ is the impact of the current policy on country 1's profitability. We vary $\beta^{2}$; for example, $\beta^{2}=1$ implies that the policy affects both countries equally while $\beta^{2}=0.5$ implies that its impact on country 2 is only half as large as that on country 1. Agents learn about $g_{t}$ by observing realized profits in both countries. At time $\tau$, a policy decision is made to maximize the social welfare function

$$
\max _{n \in[0,1, \ldots, N]} C^{n} E_{\tau}\left[\frac{\left(\left(B_{T}^{1}\right)^{\alpha}\left(B_{T}^{2}\right)^{1-\alpha}\right)^{1-\gamma}}{1-\gamma} \mid \text { policy } n\right],
$$

which is the PV objective function in equation (A9) except for the Cobb-Douglas structure with $\alpha \in[0,1]$. When $\alpha=1$, the policy decision is made by country 1 (e.g., an election in country 1); when $\alpha=0.5$, it can be thought of as a summit that treats the interests of both countries equally. We assume complete markets and full consumption home bias so that consumers in both countries derive utility from their home-country good only. We solve for the posterior distribution of $g_{t}$, optimal policy choice, exchange rates, stock and option prices, and the responses of stocks and FX to the policy announcement at time $\tau$.

Figure 9 plots the key model predictions for the baseline calibration, with $\alpha=1$ and four values of $\beta^{2}\left(0.25,0.5,0.75\right.$, and 1). ${ }^{30}$ It plots the three option-market variables, $I V, V R P$, and Slope, against economic conditions, measured by $\widehat{g}_{t}$. The variables are computed as of time $t=\tau-1 / 2$ for options expiring at time $\tau+1 / 2$. Each panel plots the regression line of best fit estimated across many samples simulated from the two-country model.

\footnotetext{
${ }^{30}$ The results for $\alpha=0.5$ are very similar. See the Internet Appendix.
} 
The top three panels of Figure 9 show spillover effects, which we define as the effects of political uncertainty in country 1 on equity option prices in country 2 . Those effects are strong when $\beta^{2}=1$ but they weaken as $\beta^{2}$ decreases. The spillover effects are stronger in weaker economic conditions, for the same reason as in the PV model.

The bottom panels show the effects of political uncertainty on the prices of FX options, or options on the exchange rate between the two countries. When $\beta^{2}=1$, the policy decision at time $\tau$ affects both countries equally, and there is no FX effect. But when $\beta^{2}$ decreases, FX effects become more important. The relative importance of spillovers and FX effects is thus parameter-dependent in a complementary way: if the parameter values $\left(\beta^{2}\right)$ are such that spillovers are large then FX effects are small, and vice versa.

Finally, for a given set of parameter values, the model predicts a positive relation between spillovers and FX effects across political events. The reason is that both effects tend to be larger for political events that are more important and whose outcomes are harder to predict. Similarly, if the event is unimportant or predictable, both spillovers and FX effects are small. When analyzing a sample of political events for a given pair of countries, we implicitly hold the parameter values fixed since the parameters are country-specific. We should therefore look for a positive relation between spillover effects and FX effects in the data.

In our empirical analysis, we split the world into two "countries," the U.S. and the Eurozone. These are the two largest global economic powers so this choice comes closest to our theoretical framework in which the two countries add up to the whole world. Moreover, the EUR/USD FX options are easily available and fairly liquid. We analyze two types of political events: U.S. elections and European summits. ${ }^{31}$

First, we analyze spillovers from U.S. elections to European equity options and from European summits to U.S. equity options. We regress $I V D$ on indicators of whether the event occurred in the home country $(1$ (OwnEvent $))$ or the other country $(1$ (SpillEvent)), with and without controls for economic conditions $(E C O N)$ and with and without interaction terms. The European $I V D$ is an equal-weighted average of $I V D$ 's across all Eurozone countries. The results are reported in Panel A of Table 10. The slope on 1(OwnEvent) is positive and the slopes on both ECON and 1 (OwnEvent $) \times E C O N$ are negative; these results confirm that our main prior conclusions hold also for this subset of political events. More interesting, the slope on 1 (SpillEvent) is significantly positive, indicating significant spillover effects, whether or not we control for 1 (OwnEvent) and ECON. Moreover, the slope on $1($ SpillEvent $) \times E C O N$ is negative, indicating that spillovers are stronger in weaker economic

\footnotetext{
${ }^{31}$ We treat the Eurozone as a single country because of the common currency. Political events in the Eurozone are thus European summits, not national elections.
} 
conditions. This latter result is significant for only two of the four ECON measures, but the point estimate has a negative sign for all four measures. Both results are consistent with the two-country model. When we replace $I V D$ by $V R P D$ and SlopeD (see Panels B and $\mathrm{C}$ ), all slopes on 1 (SpillEvent) and 1 (SpillEvent) $\times$ ECON have the model-predicted sign (that is 28 out of 28 slopes!) but only one of them is statistically significant. These results are weaker than those in Panel A but they are broadly consistent with the model.

Second, we analyze the effects of political uncertainty on FX option prices. We obtain the EUR/USD FX option data for puts and calls from the Chicago Mercantile Exchange. These data are available from January 1999 (when the euro was created), which reduces our sample to 30 political events. For each event, we calculate the FX implied volatility difference, FXIVD, analogous to $I V D$. The results are underwhelming. The relevant coefficient estimates do have model-predicted signs, suggesting that FX options are more expensive when they span political events, especially in weaker economic conditions. But the magnitudes are small and none of them are statistically significant. The results are tabulated in the Internet Appendix. This combination of weak FX effects but stronger spillovers is consistent with the two-country model in which $\beta^{2}$ is close to one.

Finally, we regress spillover $I V D$, or SpillIVD, on FXIVD across political events. For each event, SpillIVD is the equity option $I V D$ for the country not experiencing the event: for European summits, SpillIVD is the U.S. $I V D$, and for U.S. elections, it is the European $I V D$. Table 11 shows that SpillIVD is positively related to $F X I V D$ whether or not we control for economic conditions in the country experiencing the event, consistent with the two-country model. The results are similar when we replace $I V D$ by $V R P D$ (see Panel B). We do not report results for SlopeD because we have only six observations (calculating Slope D requires FX option deltas which are available only since November 2010).

To summarize, we find weak FX results but stronger spillover results: political uncertainty in one country affects equity option prices in the other country. These spillover effects are larger in weaker economic conditions. They are also positively correlated with FX effects across political events. These findings are consistent with the two-country model.

\subsection{Extension: Asymmetric Information}

We extend the symmetric-information PV model by adding asymmetric information, allowing the government to know more than investors about the true state of the economy. Again, we only summarize the model here; the details are in the Internet Appendix. 
As in the PV model, both investors and the government observe realized profitability, which follows the process in equation (A1). We add the assumption that the government observes one more signal about $g$, the unknown impact of the government's policy on the economy, resulting in information asymmetry. This signal follows the process

$$
d s_{t}^{G}=g d t+\sigma_{G} d Z_{G, t}
$$

where $d Z_{G, t}$ is an independent Brownian motion. The degree of information asymmetry is summarized by $\sigma_{G}$. When $\sigma_{G} \rightarrow 0$, the information asymmetry is at its peak because the government has perfect information about $g$. When $\sigma_{G} \rightarrow \infty$, the additional signal is worthless and we are back in the symmetric-information setting.

After solving the government's and investors' learning problems, we derive the government's optimal policy rule. This rule is the same as in PV, except that it is based on an information set enlarged by the additional signal. But asset prices depend on the investors' information set, not the government's, and the investors' perception of the policy rule is different. Specifically, the cutoff for $\widehat{g}_{\tau}$ includes an additional random term $\eta_{\tau}=\widehat{g}_{\tau}^{G}-\widehat{g}_{\tau}$, where $\widehat{g}_{\tau}^{G}$ and $\widehat{g}_{\tau}$ are the government's and investors' posterior means of $g$, respectively. The variance of $\eta_{\tau}$ is decreasing in $\sigma_{G}$. Therefore, when there is more information asymmetry (i.e., when $\sigma_{G}$ is smaller), $\eta_{\tau}$ is more uncertain from the investors' perspective.

The presence of the additional random term $\eta_{\tau}$ in the perceived policy rule has two asset pricing implications. First, information asymmetry increases the investors' uncertainty about the policy decision. Stock prices thus jump more at time $\tau$ and the implied volatility of options spanning $\tau$ is higher. Second, the presence of $\eta_{\tau}$ adds noise to the relation between $\widehat{g}_{\tau}$ and the policy decision, thereby flattening the dependence of asset prices on $\widehat{g}_{\tau}$. The model thus predicts that for political events marked by information asymmetry, IVD should be higher and the relations between the option-market variables and economic conditions should be weaker. We confirm both of these new predictions by simulating from the model. The simulations also confirm that the nine central predictions of the PV model, listed in Section 2.4., generalize to the asymmetric-information setting.

To test the new predictions, we rely on our existing empirical evidence by comparing the results for elections and summits. Our premise is that asymmetric information might be present for summits but not for elections. Summits are run by policy makers who could potentially know more than investors about the state of the economy. Elections, however, are decided by voters who are very unlikely to have superior information. Given our premise, the model predicts that for summits, we should observe higher average $I V D$ and weaker relations between the option-market variables and economic conditions. 
We do not find such results in the data. The average $I V D$ for summits is slightly lower than for elections (1.42 vs. 1.63 in Table 3), though the difference is well within one standard error. The relations to economic conditions are also similar; if anything, they are stronger for summits. These results suggest that asymmetric information does not play a big role in our sample of political events. In other words, when policy makers meet at global summits, they do not seem to know more than the investors who set prices in financial markets.

\section{Conclusions}

We find that political uncertainty is priced in the option market. Options provide valuable protection against the risk associated with major political events. Option protection against price, variance, and tail risks is more expensive before a political event. This protection is more valuable when the economy is weaker and when political uncertainty is higher.

These empirical findings are consistent with the predictions of the PV model in which political uncertainty carries a risk premium. This premium is larger when the economy is weaker because that is when policy changes and election upsets are more likely to occur. Our results indeed suggest a sizable risk premium for political uncertainty, especially in a weak economy. We establish a close link between the variance and jump risk premia associated with political events. Due to this link, the elevated variance risk premium around political events suggests that the equity risk premium contains a jump component driven by such events. By raising the cost of financing, political uncertainty can thus have real effects. Another implication of our results is that empirical models of option price behavior would benefit from including jumps at deterministic times that correspond to political events.

We extend the PV model to settings with two countries and asymmetric information, generating additional testable predictions. Consistent with those predictions, we find spillovers of political uncertainty across countries, especially in weak economic conditions. We do not find any sign of asymmetric information during global summits.

We analyze two types of political events: elections and summits. Since these events capture only a subset of the political uncertainty faced by investors, our findings represent a lower bound on the importance of political risk for asset prices. Future research can analyze other political events, such as regulatory reforms and government shutdowns, as well as other assets, such as sovereign debt. More work is needed to improve our understanding of the role of political risk, and government more broadly, in the pricing of financial assets. 
Table 1

Option sample

The table gives an overview of our option sample. For each country listed in the first column, the second column reports the index underlying the country's options that are used in our analysis. The third and fourth columns report the beginning and ending dates for the available option data. All data come from OptionMetrics, except for pre-1996 U.S. data, which come from Market Data Express.

\begin{tabular}{llcc}
\hline Country & Index & $\begin{array}{c}\text { Start } \\
\text { Date }\end{array}$ & $\begin{array}{c}\text { End } \\
\text { Date }\end{array}$ \\
\hline Australia & ASX 200 & 20040102 & 20120604 \\
Belgium & BEL20 & 20020102 & 20120831 \\
Brazil & MSCI Brazil & 20060525 & 20120131 \\
Canada & MSCI Canada & 20060302 & 20120131 \\
Finland & OMXH25 & 20020102 & 20120831 \\
France & CAC 40 & 20030414 & 20120831 \\
Germany & DAX & 20020102 & 20120831 \\
Italy & FTSE MIB & 20061011 & 20120831 \\
Japan & NIKKEI 225 & 20040506 & 20120604 \\
Korea & Kospi & 20040503 & 20120131 \\
Mexico & MSCI Mexico & 20071129 & 20120131 \\
Netherlands & AEX & 20020102 & 20120831 \\
Singapore & MSCI Singapore & 20091118 & 20120131 \\
South Africa & MSCI South Africa & 20070524 & 20120131 \\
Spain & IBEX 35 & 20070514 & 20120831 \\
Sweden & OMXS30 & 20070126 & 20120831 \\
Switzerland & SMI & 20020102 & 20120831 \\
Taiwan & TAIEX & 20040102 & 20120131 \\
UK & FTSE 100 & 20020102 & 20120831 \\
USA & S\&P 500 & 19900101 & 20120131 \\
\hline
\end{tabular}


Table 2

Number of political events

The table reports the number of political events in our sample by event type and country. These are events for which option data are available so that it is possible to calculate $I V D$ in equation (1). Totals represent the size of a set union, so they may be smaller than the sum of the subset sizes. For example, parliamentary and presidential elections may take place on the same date, in which case they are counted only once in the total. In addition, we combine into a single observation all country events that are so close together in calendar time that they are followed by the same first option expiration date (i.e., the same date $b$ in Figure 1). Euro summits are included as observations for all European countries; G8 summits for all G8 countries, and G20 summits for all G20 countries. The 2012 Greek elections are included as observations for all European countries.

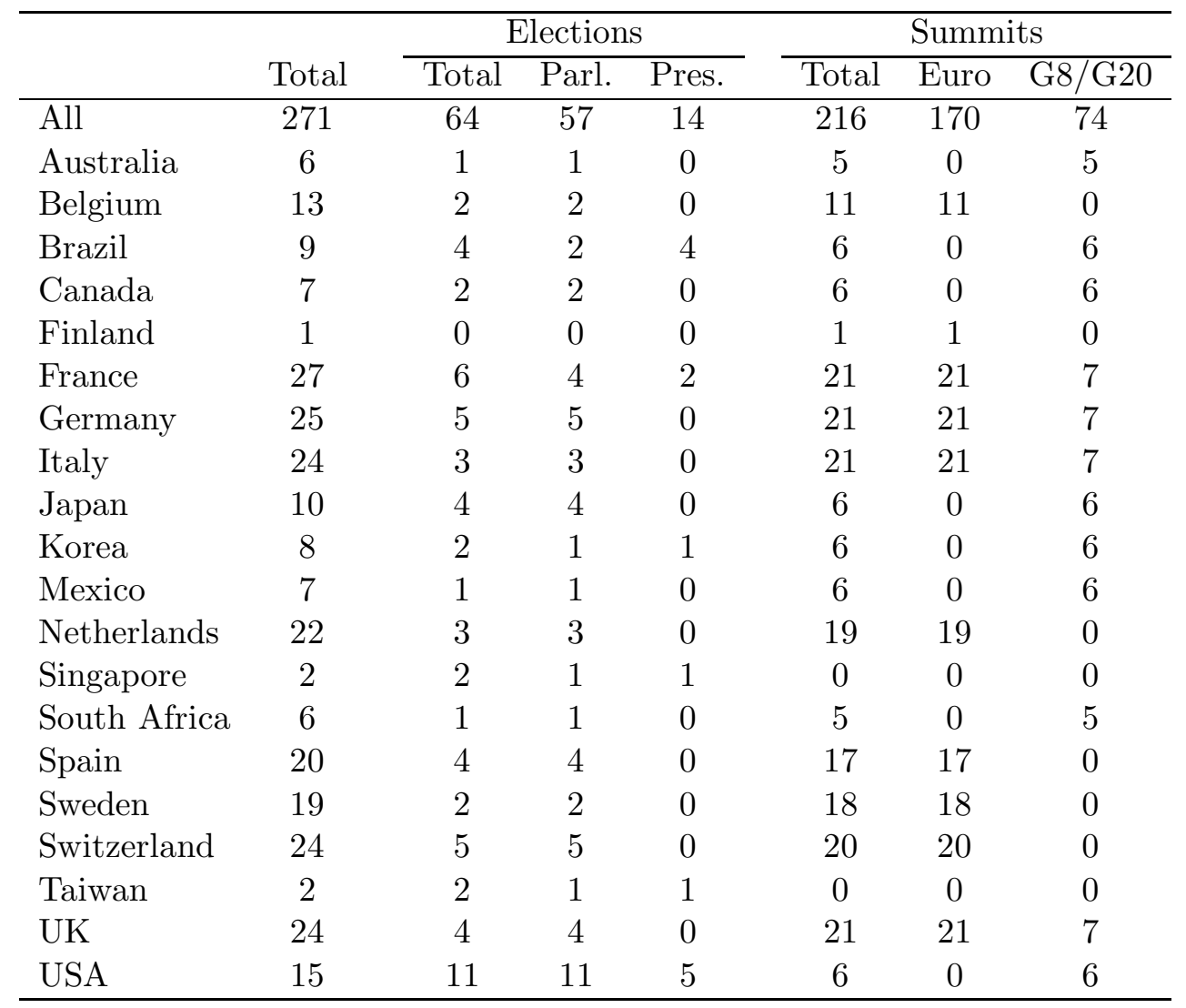


Table 3

Implied volatility, variance risk premium, and slope: Mean differences

Column 1 reports the average value of $I V D$, the implied volatility difference from equation (1), across all political events. Columns 2 through 5 report differences between the average values of $I V D$ in weak economic conditions $(E C O N<0)$ and strong economic conditions $(E C O N \geq 0)$. The remaining columns report analogous results for $V R P D$, the variance risk premium difference from equation (4), and SlopeD, the implied volatility slope difference from equation (6). We use four measures of economic conditions: the country's stock market index return $(M K T)$, real GDP growth (GDP), the IMF's GDP growth forecast $(F S T)$, and the OECD's Composite Leading Indicator $(C L I)$. We standardize GDP, FST, and $C L I$ to zero mean within each country by using data from 1990 through 2012. IVD is in percent per year. VRPD is in decimals per year. Both VRPD and SlopeD are multiplied by 100. The $t$-statistics, reported in parentheses, use standard errors with two-way clustering at the month and country levels. Panel A uses all observations while Panels B and C report results for election and summit events separately.

\begin{tabular}{|c|c|c|c|c|c|c|c|c|c|c|c|c|c|c|c|}
\hline & \multicolumn{5}{|c|}{ Implied volatility $(I V D)$} & \multicolumn{5}{|c|}{ Variance risk premium $(V R P D)$} & \multicolumn{5}{|c|}{ Implied volatility slope $($ Slope $D)$} \\
\hline & All & \multicolumn{4}{|c|}{ Weak minus strong economy } & All & \multicolumn{4}{|c|}{ Weak minus strong economy } & All & \multicolumn{4}{|c|}{ Weak minus strong economy } \\
\hline Mean & $\begin{array}{c}1.43 \\
(4.43)\end{array}$ & $\begin{array}{c}2.57 \\
(3.79)\end{array}$ & $\begin{array}{c}1.94 \\
(3.34)\end{array}$ & $\begin{array}{c}2.22 \\
(3.78)\end{array}$ & $\begin{array}{c}3.00 \\
(4.61)\end{array}$ & $\begin{array}{c}1.07 \\
(2.61)\end{array}$ & $\begin{array}{c}3.02 \\
(3.51)\end{array}$ & $\begin{array}{c}2.07 \\
(2.80)\end{array}$ & $\begin{array}{c}2.55 \\
(3.54)\end{array}$ & $\begin{array}{c}3.05 \\
(3.63)\end{array}$ & $\begin{array}{c}1.73 \\
(3.59)\end{array}$ & $\begin{array}{c}3.26 \\
(3.11)\end{array}$ & $\begin{array}{c}2.11 \\
(2.52)\end{array}$ & $\begin{array}{c}2.66 \\
(3.08)\end{array}$ & $\begin{array}{c}3.02 \\
(2.97)\end{array}$ \\
\hline Obs. & 271 & 271 & 271 & 266 & 267 & 271 & 271 & 271 & 266 & 267 & 238 & 238 & 238 & 233 & 236 \\
\hline Mean & $\begin{array}{c}1.63 \\
(3.13)\end{array}$ & $\begin{array}{c}2.63 \\
(2.73)\end{array}$ & $\begin{array}{c}1.73 \\
(1.78)\end{array}$ & $\begin{array}{c}2.51 \\
(2.34)\end{array}$ & $\begin{array}{c}2.36 \\
(2.39)\end{array}$ & $\begin{array}{c}1.30 \\
(2.59)\end{array}$ & $\begin{array}{c}2.46 \\
(2.62)\end{array}$ & $\begin{array}{c}1.07 \\
(1.11)\end{array}$ & $\begin{array}{c}2.45 \\
(2.20)\end{array}$ & $\begin{array}{c}1.26 \\
(1.25)\end{array}$ & $\begin{array}{c}1.14 \\
(2.08)\end{array}$ & $\begin{array}{c}3.56 \\
(3.69)\end{array}$ & $\begin{array}{c}1.14 \\
(1.08)\end{array}$ & $\begin{array}{c}1.96 \\
(1.71)\end{array}$ & $\begin{array}{c}1.38 \\
(1.28)\end{array}$ \\
\hline Obs. & 64 & 64 & 64 & 59 & 60 & 64 & 64 & 64 & 59 & 60 & 55 & 55 & 55 & 50 & 53 \\
\hline & \multicolumn{15}{|c|}{ Panel C: Summits only } \\
\hline
\end{tabular}


Table 4

Implied volatility difference and economic conditions

The table reports the slope coefficients from the regressions of $I V D$, the implied volatility difference from equation (1), on four different measures of economic conditions $(E C O N)$. For each of the four measures, we estimate a simple regression of $I V D$ on $E C O N$ as well as a piecewise linear regression of $I V D$ on both $E C O N$ and $E C O N$ times an indicator for $E C O N$ being positive. The four measures of economic conditions are the country's stock market index return $(M K T)$, real GDP growth $(G D P)$, the IMF's GDP growth forecast $(F S T)$, and the OECD's Composite Leading Indicator $(C L I)$. We standardize GDP, FST, and $C L I$ to zero mean within each country by using data from 1990 through 2012 . We then scale all four $E C O N$ variables to unit variance within each regression. $I V D$ is in percent per year. The $t$-statistics, reported in parentheses, use standard errors with two-way clustering at the month and country levels. Panel A uses all observations while Panels B and C report results for election and summit events separately.

\begin{tabular}{|c|c|c|c|c|c|c|c|c|}
\hline & \multicolumn{8}{|c|}{ Measure of economic conditions } \\
\hline & \multicolumn{2}{|c|}{$M K T$} & \multicolumn{2}{|c|}{$G D P$} & \multicolumn{2}{|c|}{$F S T$} & \multicolumn{2}{|c|}{$C L I$} \\
\hline & \multicolumn{8}{|c|}{ Panel A: All political events } \\
\hline$E C O N$ & $\begin{array}{c}-2.42 \\
(-5.34)\end{array}$ & $\begin{array}{c}-3.58 \\
(-5.10)\end{array}$ & $\begin{array}{c}-2.01 \\
(-4.82)\end{array}$ & $\begin{array}{c}-2.71 \\
(-5.01)\end{array}$ & $\begin{array}{c}-0.83 \\
(-2.55)\end{array}$ & $\begin{array}{c}-0.63 \\
(-1.37)\end{array}$ & $\begin{array}{c}-1.39 \\
(-3.85)\end{array}$ & $\begin{array}{l}-1.47 \\
(-2.74)\end{array}$ \\
\hline$E C O N \cdot 1_{(E C O N>0)}$ & & $\begin{array}{c}3.77 \\
(3.33)\end{array}$ & & $\begin{array}{c}4.02 \\
(3.85)\end{array}$ & & $\begin{array}{c}-0.96 \\
(-0.87)\end{array}$ & & $\begin{array}{c}0.26 \\
(0.28)\end{array}$ \\
\hline$R^{2}$ & 0.21 & 0.25 & 0.14 & 0.18 & 0.02 & 0.03 & 0.07 & 0.07 \\
\hline \multirow[t]{2}{*}{ Obs. } & 271 & 271 & 271 & 271 & 266 & 266 & 267 & 267 \\
\hline & \multicolumn{8}{|c|}{ Panel B: Elections only } \\
\hline$E C O N$ & $\begin{array}{c}-1.72 \\
(-3.49)\end{array}$ & $\begin{array}{c}-2.60 \\
(-3.51)\end{array}$ & $\begin{array}{l}-1.56 \\
(-3.03)\end{array}$ & $\begin{array}{c}-2.39 \\
(-4.63)\end{array}$ & $\begin{array}{l}-1.69 \\
(-3.00)\end{array}$ & $\begin{array}{c}-2.01 \\
(-2.09)\end{array}$ & $\begin{array}{c}-1.34 \\
(-2.15)\end{array}$ & $\begin{array}{c}-1.10 \\
(-0.86)\end{array}$ \\
\hline$E C O N \cdot 1_{(E C O N>0)}$ & & $\begin{array}{c}2.69 \\
(1.62)\end{array}$ & & $\begin{array}{c}3.26 \\
(2.75)\end{array}$ & & $\begin{array}{c}1.18 \\
(0.61)\end{array}$ & & $\begin{array}{l}-0.57 \\
(-0.34)\end{array}$ \\
\hline$R^{2}$ & 0.17 & 0.20 & 0.14 & 0.18 & 0.15 & 0.16 & 0.12 & 0.13 \\
\hline \multirow[t]{2}{*}{ Obs. } & 64 & 64 & 64 & 64 & 59 & 59 & 60 & 60 \\
\hline & \multicolumn{8}{|c|}{ Panel C: Summits only } \\
\hline$E C O N$ & $\begin{array}{l}-2.68 \\
(-5.04)\end{array}$ & $\begin{array}{c}-3.93 \\
(-4.86)\end{array}$ & $\begin{array}{c}-2.27 \\
(-4.84)\end{array}$ & $\begin{array}{c}-3.02 \\
(-5.08)\end{array}$ & $\begin{array}{c}-0.77 \\
(-2.10)\end{array}$ & $\begin{array}{c}-0.54 \\
(-1.10)\end{array}$ & $\begin{array}{c}-1.53 \\
(-3.91)\end{array}$ & $\begin{array}{c}-1.88 \\
(-3.18)\end{array}$ \\
\hline$E C O N \cdot 1_{(E C O N>0)}$ & & $\begin{array}{c}4.16 \\
(3.24)\end{array}$ & & $\begin{array}{c}4.61 \\
(3.89)\end{array}$ & & $\begin{array}{l}-1.26 \\
(-0.95)\end{array}$ & & $\begin{array}{c}1.23 \\
(1.04)\end{array}$ \\
\hline$R^{2}$ & 0.23 & 0.28 & 0.17 & 0.20 & 0.02 & 0.02 & 0.08 & 0.08 \\
\hline Obs. & 216 & 216 & 216 & 216 & 216 & 216 & 216 & 216 \\
\hline
\end{tabular}




\section{Table 5}

\section{Variance risk premium difference and economic conditions}

The table reports the slope coefficients from the regressions of $V R P D$, the variance risk premium difference from equation (4), on four different measures of economic conditions $(E C O N)$. For each of the four measures, we estimate a simple regression of $V R P D$ on $E C O N$ as well as a piecewise linear regression of $V R P D$ on both $E C O N$ and ECON times an indicator for ECON being positive. The four measures of economic conditions are the country's stock market index return $(M K T)$, real GDP growth $(G D P)$, the IMF's GDP growth forecast $(F S T)$, and the OECD's Composite Leading Indicator $(C L I)$. We standardize GDP, FST, and $C L I$ to zero mean within each country by using data from 1990 through 2012 . We then scale all four $E C O N$ variables to unit variance within each regression. $V R P D$ is annualized and multiplied by 100 . The $t$-statistics, reported in parentheses, use standard errors with two-way clustering at the month and country levels. Panel A uses all observations while Panels B and C report results for election and summit events separately.

\begin{tabular}{|c|c|c|c|c|c|c|c|c|}
\hline & \multicolumn{8}{|c|}{ Measure of economic conditions } \\
\hline & \multicolumn{2}{|c|}{$M K T$} & \multicolumn{2}{|c|}{$G D P$} & \multicolumn{2}{|c|}{$F S T$} & \multicolumn{2}{|c|}{$C L I$} \\
\hline & \multicolumn{8}{|c|}{ Panel A: All political events } \\
\hline$E C O N$ & $\begin{array}{l}-2.98 \\
(-4.56)\end{array}$ & $\begin{array}{l}-4.55 \\
(-4.45)\end{array}$ & $\begin{array}{l}-1.97 \\
(-3.52)\end{array}$ & $\begin{array}{l}-2.43 \\
(-3.40)\end{array}$ & $\begin{array}{l}-1.32 \\
(-3.42)\end{array}$ & $\begin{array}{l}-1.40 \\
(-2.50)\end{array}$ & $\begin{array}{c}-1.72 \\
(-3.38)\end{array}$ & $\begin{array}{l}-2.23 \\
(-2.88)\end{array}$ \\
\hline$E C O N \cdot 1_{(E C O N>0)}$ & & $\begin{array}{c}5.10 \\
(3.41)\end{array}$ & & $\begin{array}{c}2.62 \\
(1.67)\end{array}$ & & $\begin{array}{c}0.35 \\
(0.27)\end{array}$ & & $\begin{array}{c}1.75 \\
(1.44)\end{array}$ \\
\hline$R^{2}$ & 0.19 & 0.24 & 0.08 & 0.09 & 0.04 & 0.04 & 0.06 & 0.07 \\
\hline \multirow[t]{2}{*}{ Obs. } & 271 & 271 & 271 & 271 & 266 & 266 & 267 & 267 \\
\hline & \multicolumn{8}{|c|}{ Panel B: Elections only } \\
\hline$E C O N$ & $\begin{array}{l}-1.62 \\
(-2.34)\end{array}$ & $\begin{array}{l}-2.22 \\
(-1.90)\end{array}$ & $\begin{array}{c}-1.32 \\
(-1.78)\end{array}$ & $\begin{array}{c}-2.79 \\
(-3.80)\end{array}$ & $\begin{array}{l}-1.78 \\
(-2.69)\end{array}$ & $\begin{array}{l}-1.76 \\
(-1.70)\end{array}$ & $\begin{array}{l}-1.18 \\
(-1.51)\end{array}$ & $\begin{array}{l}-1.79 \\
(-1.18)\end{array}$ \\
\hline$E C O N \cdot 1_{(E C O N>0)}$ & & $\begin{array}{c}1.86 \\
(0.92)\end{array}$ & & $\begin{array}{c}5.79 \\
(3.73)\end{array}$ & & $\begin{array}{l}-0.09 \\
(-0.05)\end{array}$ & & $\begin{array}{c}1.40 \\
(0.70)\end{array}$ \\
\hline$R^{2}$ & 0.16 & 0.18 & 0.11 & 0.25 & 0.18 & 0.18 & 0.09 & 0.10 \\
\hline \multirow[t]{2}{*}{ Obs. } & 64 & 64 & 64 & 64 & 59 & 59 & 60 & 60 \\
\hline & \multicolumn{8}{|c|}{ Panel C: Summits only } \\
\hline$E C O N$ & $\begin{array}{l}-3.45 \\
(-4.52)\end{array}$ & $\begin{array}{c}-5.27 \\
(-4.53)\end{array}$ & $\begin{array}{c}-2.32 \\
(-3.67)\end{array}$ & $\begin{array}{c}-2.67 \\
(-3.39)\end{array}$ & $\begin{array}{l}-1.40 \\
(-3.13)\end{array}$ & $\begin{array}{l}-1.53 \\
(-2.48)\end{array}$ & $\begin{array}{l}-2.01 \\
(-3.56)\end{array}$ & $\begin{array}{c}-2.69 \\
(-3.08)\end{array}$ \\
\hline$E C O N \cdot 1_{(E C O N>0)}$ & & $\begin{array}{c}6.07 \\
(3.59)\end{array}$ & & $\begin{array}{c}2.17 \\
(1.18)\end{array}$ & & $\begin{array}{c}0.71 \\
(0.46)\end{array}$ & & $\begin{array}{c}2.37 \\
(1.56)\end{array}$ \\
\hline$R^{2}$ & 0.22 & 0.28 & 0.10 & 0.10 & 0.04 & 0.04 & 0.07 & 0.08 \\
\hline Obs. & 216 & 216 & 216 & 216 & 216 & 216 & 216 & 216 \\
\hline
\end{tabular}




\section{Table 6}

\section{Implied volatility slope difference and economic conditions}

The table reports the slope coefficients from the regressions of SlopeD, the implied volatility slope difference from equation (6), on four different measures of economic conditions $(E C O N)$. For each of the four measures, we estimate a simple regression of SlopeD on ECON as well as a piecewise linear regression of SlopeD on both ECON and ECON times an indicator for ECON being positive. The four measures of economic conditions are the country's stock market index return $(M K T)$, real GDP growth $(G D P)$, the IMF's GDP growth forecast $(F S T)$, and the OECD's Composite Leading Indicator $(C L I)$. We standardize GDP, FST, and $C L I$ to zero mean within each country by using data from 1990 through 2012. We then scale all four $E C O N$ variables to unit variance within each regression. SlopeD is multiplied by 100 . The $t$-statistics, reported in parentheses, use standard errors with two-way clustering at the month and country levels. Panel A uses all observations while Panels B and C report results for election and summit events separately.

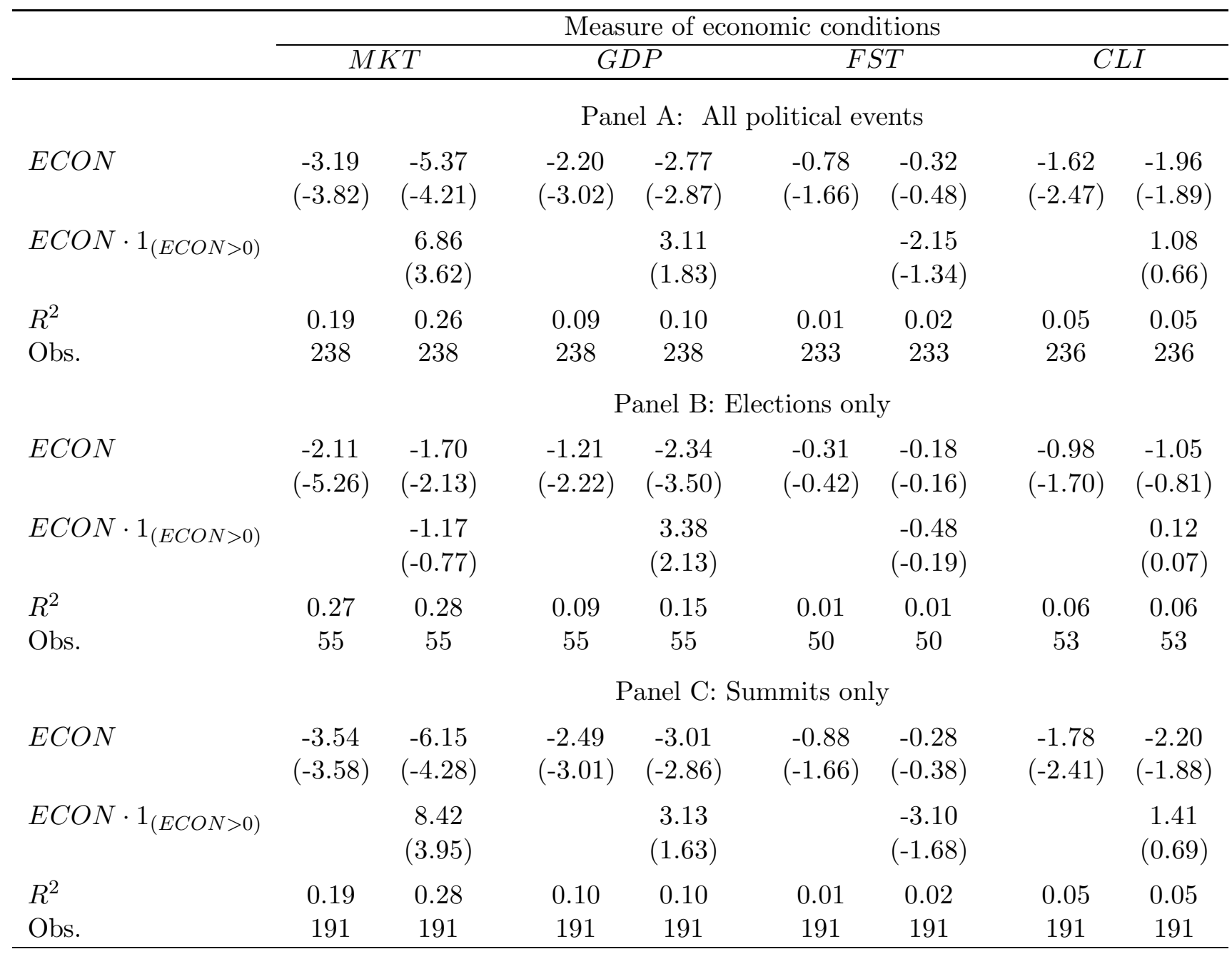




\section{Table 7}

\section{The role of election uncertainty}

Panel A reports the slope coefficients from the regressions of $I V D$, the implied volatility difference from equation (1), on our measure of political uncertainty $(U N C)$. Panel B replaces $I V D$ with $V R P D$, the variance risk premium difference from equation (4), while Panel C replaces it with $S l o p e D$, the slope difference from equation (6). The uncertainty measure $U N C$, which is defined as the negative of the election poll spread, proxies for uncertainty about the election outcome. We estimate a simple regression on $U N C$ as well as multiple regressions that include controls for four different measures of economic conditions $(E C O N)$, in both linear and piecewise linear specifications. The four measures are the country's stock market index return $(M K T)$, real GDP growth $(G D P)$, the IMF's GDP growth forecast $(F S T)$, and the OECD's Composite Leading Indicator $(C L I)$. Both $I V D$ and $V R P D$ are annualized and multiplied by 100. SlopeD is also multiplied by 100 . We scale $U N C$ to unit variance within each regression. The $t$-statistics, reported in parentheses, use standard errors with two-way clustering at the month and country levels.

\begin{tabular}{|c|c|c|c|c|c|c|c|c|c|}
\hline & & \multicolumn{8}{|c|}{ Measure of economic conditions } \\
\hline & & \multicolumn{2}{|c|}{$M K T$} & \multicolumn{2}{|c|}{$G D P$} & \multicolumn{2}{|c|}{$F S T$} & \multicolumn{2}{|c|}{$C L I$} \\
\hline & \multicolumn{9}{|c|}{ Panel A: Implied volatility $(I V D)$} \\
\hline$U N C$ & $\begin{array}{c}1.87 \\
(5.39)\end{array}$ & $\begin{array}{c}1.64 \\
(4.52)\end{array}$ & $\begin{array}{c}1.58 \\
(4.43)\end{array}$ & $\begin{array}{c}1.80 \\
(4.93)\end{array}$ & $\begin{array}{c}1.82 \\
(4.49)\end{array}$ & $\begin{array}{c}1.68 \\
(4.11)\end{array}$ & $\begin{array}{c}1.69 \\
(4.28)\end{array}$ & $\begin{array}{c}1.44 \\
(3.21)\end{array}$ & $\begin{array}{c}1.45 \\
(3.14)\end{array}$ \\
\hline$E C O N$ & & $\begin{array}{l}-1.46 \\
(-2.98)\end{array}$ & $\begin{array}{l}-2.17 \\
(-2.85)\end{array}$ & $\begin{array}{l}-1.47 \\
(-3.27)\end{array}$ & $\begin{array}{l}-2.34 \\
(-5.57)\end{array}$ & $\begin{array}{l}-1.36 \\
(-2.45)\end{array}$ & $\begin{array}{l}-1.72 \\
(-1.89)\end{array}$ & $\begin{array}{l}-1.52 \\
(-3.26)\end{array}$ & $\begin{array}{l}-1.61 \\
(-1.77)\end{array}$ \\
\hline$E C O N \cdot 1_{(E C O N>0)}$ & & & $\begin{array}{c}2.14 \\
(1.39)\end{array}$ & & $\begin{array}{c}3.41 \\
(2.65)\end{array}$ & & $\begin{array}{c}1.34 \\
(0.80)\end{array}$ & & $\begin{array}{c}0.22 \\
(0.17)\end{array}$ \\
\hline $\begin{array}{l}R^{2} \\
\text { Obs. }\end{array}$ & $\begin{array}{c}0.20 \\
64\end{array}$ & $\begin{array}{c}0.31 \\
64\end{array}$ & $\begin{array}{c}0.34 \\
64\end{array}$ & $\begin{array}{c}0.32 \\
64\end{array}$ & $\begin{array}{c}0.37 \\
64\end{array}$ & $\begin{array}{c}0.29 \\
59\end{array}$ & $\begin{array}{c}0.30 \\
59\end{array}$ & $\begin{array}{c}0.26 \\
60\end{array}$ & $\begin{array}{c}0.26 \\
60\end{array}$ \\
\hline & \multicolumn{9}{|c|}{ Panel B: Variance risk premium $(V R P D)$} \\
\hline$U N C$ & $\begin{array}{c}1.06 \\
(3.48)\end{array}$ & $\begin{array}{c}0.82 \\
(2.39)\end{array}$ & $\begin{array}{c}0.78 \\
(2.32)\end{array}$ & $\begin{array}{c}0.99 \\
(2.54)\end{array}$ & $\begin{array}{c}1.03 \\
(2.31)\end{array}$ & $\begin{array}{c}0.74 \\
(1.91)\end{array}$ & $\begin{array}{c}0.74 \\
(1.89)\end{array}$ & $\begin{array}{c}0.89 \\
(1.75)\end{array}$ & $\begin{array}{c}1.00 \\
(1.76)\end{array}$ \\
\hline$E C O N$ & & $\begin{array}{l}-1.49 \\
(-2.10)\end{array}$ & $\begin{array}{l}-2.01 \\
(-1.66)\end{array}$ & $\begin{array}{l}-1.27 \\
(-1.75)\end{array}$ & $\begin{array}{l}-2.76 \\
(-3.90)\end{array}$ & $\begin{array}{l}-1.64 \\
(-2.38)\end{array}$ & $\begin{array}{l}-1.63 \\
(-1.58)\end{array}$ & $\begin{array}{l}-1.29 \\
(-1.80)\end{array}$ & $\begin{array}{l}-2.15 \\
(-1.66)\end{array}$ \\
\hline$E C O N \cdot 1_{(E C O N>0)}$ & & & $\begin{array}{c}1.59 \\
(0.79)\end{array}$ & & $\begin{array}{c}5.87 \\
(3.69)\end{array}$ & & $\begin{array}{c}-0.02 \\
(-0.01)\end{array}$ & & $\begin{array}{c}1.95 \\
(1.09)\end{array}$ \\
\hline $\begin{array}{l}R^{2} \\
\text { Obs. }\end{array}$ & $\begin{array}{c}0.07 \\
64\end{array}$ & $\begin{array}{c}0.20 \\
64\end{array}$ & $\begin{array}{c}0.21 \\
64\end{array}$ & $\begin{array}{c}0.17 \\
64\end{array}$ & $\begin{array}{c}0.32 \\
64\end{array}$ & $\begin{array}{c}0.21 \\
59\end{array}$ & $\begin{array}{c}0.21 \\
59\end{array}$ & $\begin{array}{c}0.14 \\
60\end{array}$ & $\begin{array}{c}0.17 \\
60\end{array}$ \\
\hline & \multicolumn{9}{|c|}{ Panel C: Implied volatility slope (SlopeD) } \\
\hline$U N C$ & $\begin{array}{c}0.25 \\
(0.59)\end{array}$ & $\begin{array}{c}-0.11 \\
(-0.33)\end{array}$ & $\begin{array}{c}-0.14 \\
(-0.39)\end{array}$ & $\begin{array}{c}0.07 \\
(0.17)\end{array}$ & $\begin{array}{c}0.11 \\
(0.27)\end{array}$ & $\begin{array}{c}0.25 \\
(0.50)\end{array}$ & $\begin{array}{c}0.24 \\
(0.47)\end{array}$ & $\begin{array}{c}0.23 \\
(0.56)\end{array}$ & $\begin{array}{c}0.24 \\
(0.57)\end{array}$ \\
\hline$E C O N$ & & $\begin{array}{c}-2.13 \\
(-5.08)\end{array}$ & $\begin{array}{l}-1.71 \\
(-2.12)\end{array}$ & $\begin{array}{l}-1.20 \\
(-2.16)\end{array}$ & $\begin{array}{l}-2.33 \\
(-3.39)\end{array}$ & $\begin{array}{l}-0.28 \\
(-0.36)\end{array}$ & $\begin{array}{c}-0.17 \\
(-0.15)\end{array}$ & $\begin{array}{l}-0.98 \\
(-1.67)\end{array}$ & $\begin{array}{c}-1.07 \\
(-0.82)\end{array}$ \\
\hline$E C O N \cdot 1_{(E C O N>0)}$ & & & $\begin{array}{l}-1.20 \\
(-0.78)\end{array}$ & & $\begin{array}{c}3.40 \\
(2.13)\end{array}$ & & $\begin{array}{l}-0.39 \\
(-0.16)\end{array}$ & & $\begin{array}{c}0.18 \\
(0.10)\end{array}$ \\
\hline$R^{2}$ & 0.00 & 0.27 & 0.28 & 0.09 & 0.15 & 0.01 & 0.01 & 0.06 & 0.06 \\
\hline Obs. & 55 & 55 & 55 & 55 & 55 & 50 & 50 & 53 & 53 \\
\hline
\end{tabular}




\section{Table 8}

\section{Placebo events and mean differences}

The first column in each panel compares the average values of IVD (Panel A), VRPD (Panel B), and SlopeD (Panel C) from two samples: our actual data sample and a sample of placebo events. We generate 10,000 placebo samples, each including 271 placebo event dates that are randomly selected from the option samples listed in Table 1. We impose that the frequency of draws from each country's sample matches the frequency of events in column 1 of Table 2 and that placebo events do not occur within 30 days of an actual political event in our sample. The first column reports averages of $I V D, V R P D$, and SlopeD across all placebo events while the remaining columns report differences between the averages in weak economic conditions $(E C O N<0)$ and strong economic conditions $(E C O N \geq 0)$. We use four measures of economic conditions: the country's stock market index return $(M K T)$, real GDP growth $(G D P)$, the IMF's GDP growth forecast $(F S T)$, and the OECD's Composite Leading Indicator $(C L I)$. We standardize GDP, FST, and $C L I$ to zero mean within each country by using data from 1990 through 2012. IVD is in percent per year, $V R P D$ is in decimals per year, and both $V R P D$ and SlopeD are multiplied by 100 . The reported $p$-values are the fractions of placebo estimates that exceed the actual estimate in the direction predicted by theory.

\begin{tabular}{|c|c|c|c|c|c|}
\hline & \multicolumn{5}{|c|}{ Weak minus strong economy } \\
\hline & All & $M K T$ & $G D P$ & $F S T$ & $C L I$ \\
\hline & \multicolumn{5}{|c|}{ Panel A: $I V D$} \\
\hline Mean (data) & 1.43 & 2.57 & 1.94 & 2.22 & 3.00 \\
\hline Mean (pseudo-events) & -0.32 & 1.35 & -0.63 & -1.63 & -1.03 \\
\hline Difference & 1.75 & 1.22 & 2.57 & 3.85 & 4.03 \\
\hline$p$-value & $<0.001$ & 0.017 & $<0.001$ & $<0.001$ & $<0.001$ \\
\hline \multirow[t]{2}{*}{ Obs. } & 271 & 271 & 271 & 266 & 267 \\
\hline & \multicolumn{5}{|c|}{ Panel B: $V R P D$} \\
\hline Mean (data) & 1.07 & 3.02 & 2.07 & 2.55 & 3.05 \\
\hline Mean (pseudo-events) & -0.26 & 0.21 & -0.11 & -0.44 & -0.61 \\
\hline Difference & 1.33 & 2.81 & 2.18 & 2.99 & 3.66 \\
\hline$p$-value & $<0.001$ & $<0.001$ & $<0.001$ & $<0.001$ & $<0.001$ \\
\hline \multirow[t]{2}{*}{ Obs. } & 271 & 271 & 271 & 266 & 267 \\
\hline & \multicolumn{5}{|c|}{ Panel C: SlopeD } \\
\hline Mean (data) & 1.73 & 3.26 & 2.11 & 2.66 & 3.02 \\
\hline Mean (pseudo-events) & -0.31 & 0.41 & -0.65 & 0.59 & -0.46 \\
\hline Difference & 2.04 & 2.85 & 2.75 & 2.06 & 3.48 \\
\hline$p$-value & $<0.001$ & 0.005 & $<0.001$ & $<0.001$ & $<0.001$ \\
\hline Obs. & 238 & 238 & 238 & 233 & 236 \\
\hline
\end{tabular}


Table 9

Correlations with economic conditions and political uncertainty

This table reports the correlations between the three option-market variables (IVD, VRPD and SlopeD) and measures of economic conditions and political uncertainty. The correlations are computed from the data as well as from the PV model. In the data, we consider the same four measures of economic conditions $(M K T, G D P, F S T$, or $C L I)$ and the same measure of uncertainty $(U N C)$ as in the rest of the paper. In the PV model, we measure economic conditions by the state variable $\widehat{g}_{\tau}$ and uncertainty by the entropy of the three policy probabilities. We consider the two-policy version of the PV model with baseline parameter values. For results corresponding to other parameter values, see Table B23 in the Internet Appendix. In the first row, we report correlations estimated from the data, computed across all political events in our sample. The second row reports the corresponding $t$-statistics. The third row reports the correlations from the PV model, computed across many simulated samples.

\begin{tabular}{|c|c|c|c|c|c|c|c|c|c|c|c|c|c|c|c|}
\hline & \multicolumn{3}{|c|}{ Corr with ECON: $M K T$} & \multicolumn{3}{|c|}{ Corr with $E C O N$ : $G D P$} & \multicolumn{3}{|c|}{ Corr with ECON: FST } & \multicolumn{3}{|c|}{ Corr with ECON: $C L I$} & \multicolumn{3}{|c|}{ Corr with $U N C$} \\
\hline & $I V D$ & $V R P D$ & SlopeD & $I V D$ & $V R P D$ & SlopeD & $I V D$ & $V R P D$ & SlopeD & $I V D$ & $V R P D$ & SlopeD & $I V D$ & $V R P D$ & SlopeD \\
\hline $\begin{array}{l}\text { Data } \\
t \text {-statistic }\end{array}$ & $\begin{array}{l}-0.46 \\
(-5.34)\end{array}$ & $\begin{array}{l}-0.44 \\
(-4.56)\end{array}$ & $\begin{array}{l}-0.43 \\
(-3.82)\end{array}$ & $\begin{array}{l}-0.38 \\
(-4.82)\end{array}$ & $\begin{array}{l}-0.29 \\
(-3.52)\end{array}$ & $\begin{array}{l}-0.30 \\
(-3.02)\end{array}$ & $\begin{array}{l}-0.16 \\
(-2.55)\end{array}$ & $\begin{array}{l}-0.19 \\
(-3.42)\end{array}$ & $\begin{array}{l}-0.10 \\
(-1.66)\end{array}$ & $\begin{array}{l}-0.26 \\
(-3.85)\end{array}$ & $\begin{array}{c}-0.25 \\
(-3.38)\end{array}$ & $\begin{array}{l}-0.22 \\
(-2.47)\end{array}$ & $\begin{array}{c}0.44 \\
(5.39)\end{array}$ & $\begin{array}{c}0.26 \\
(3.48)\end{array}$ & $\begin{array}{c}0.06 \\
(0.59)\end{array}$ \\
\hline PV model & -0.32 & -0.41 & -0.46 & -0.32 & -0.41 & -0.46 & -0.32 & -0.41 & -0.46 & -0.32 & -0.41 & -0.46 & 0.58 & 0.74 & 0.68 \\
\hline
\end{tabular}




\section{Table 10 \\ Spillover effects}

This table quantifies the spillovers of political uncertainty from U.S. elections to European equity options and from European summits to U.S. equity options. Each column of Panel A reports slope coefficient estimates from a regression of the implied volatility difference, $I V D$, on the variables described in the row labels. Those variables are: $1_{\text {OwnEvent }}$, an indicator variable that takes the value of one if the political event happens in the home country (i.e., if a U.S. $I V D$ is paired with a U.S. election or a European $I V D$ is paired with a European summit); $1_{\text {Spillevent }}$, an indicator variable for whether the political event happens in the other country (i.e., if a European $I V D$ is paired with a U.S. election or a U.S. $I V D$ is paired with a European summit); $E C O N$, a demeaned value of one of four measures of economic conditions ( $M K T$, $G D P, F S T$, or $C L I)$, and their interactions. For example, the regression in column 3 is $I V D_{\text {reg, } i}=$ $b_{\text {own }} 1_{\text {OwnEvent }}+b_{\text {spill }} 1_{\text {SpillEvent }}+e_{\text {reg, } i}$, where for each event $i$, we include the $I V D$ of both countries $r e g \in\{$ U.S., Eurozone $\}$ on the left-hand side. The regressions contain no intercept because all observations correspond to either an own event or a spillover event so there is no independent information to estimate the intercept. The European $I V D$ is an equal-weighted average of $I V D$ 's for all Eurozone countries. The $R^{2}$ is the fraction of the total variation in $I V D$ around its baseline value of zero that is explained by the occurrence of a political event. Panels B and $\mathrm{C}$ contain analogous results for VRPD and SlopeD, respectively. $t$-statistics are in parentheses.

\begin{tabular}{|c|c|c|c|c|c|c|c|c|c|c|c|}
\hline & 1 & 2 & 3 & $\begin{array}{c}4 \\
M K T\end{array}$ & $\begin{array}{c}5 \\
G D P\end{array}$ & $\begin{array}{c}6 \\
F S T\end{array}$ & $\begin{array}{c}7 \\
C L I\end{array}$ & $\begin{array}{c}8 \\
M K T\end{array}$ & $\begin{array}{c}9 \\
G D P\end{array}$ & $\begin{array}{c}10 \\
F S T\end{array}$ & $\begin{array}{c}11 \\
C L I\end{array}$ \\
\hline \multicolumn{12}{|c|}{ Panel A: $I V D$} \\
\hline $1_{\text {OwnEvent }}$ & $\begin{array}{l}1.79 \\
(2.33)\end{array}$ & & $\begin{array}{l}1.59 \\
(2.12)\end{array}$ & $\begin{array}{l}1.65 \\
(2.46)\end{array}$ & $\begin{array}{c}1.73 \\
(2.58)\end{array}$ & $\begin{array}{c}1.64 \\
(1.96)\end{array}$ & $\begin{array}{l}1.68 \\
(2.36)\end{array}$ & $\begin{array}{l}1.64 \\
(2.51)\end{array}$ & $\begin{array}{l}1.57 \\
(2.37)\end{array}$ & $\begin{array}{c}1.62 \\
(1.87)\end{array}$ & $\begin{array}{l}1.60 \\
(2.21)\end{array}$ \\
\hline $1_{\text {SpillEvent }}$ & & $\begin{array}{l}1.98 \\
(2.56)\end{array}$ & $\begin{array}{l}1.80 \\
(2.37)\end{array}$ & $\begin{array}{l}1.73 \\
(2.55)\end{array}$ & $\begin{array}{l}1.48 \\
(2.16)\end{array}$ & $\begin{array}{c}1.57 \\
(1.89)\end{array}$ & $\begin{array}{c}1.57 \\
(2.16)\end{array}$ & $\begin{array}{l}1.75 \\
(2.64)\end{array}$ & $\begin{array}{c}1.43 \\
(2.12)\end{array}$ & $\begin{array}{c}1.59 \\
(1.88)\end{array}$ & $\begin{array}{c}1.51 \\
(2.05)\end{array}$ \\
\hline$E C O N$ & & & & $\begin{array}{l}-16.14 \\
(-4.06)\end{array}$ & $\begin{array}{l}-1.20 \\
(-4.03)\end{array}$ & $\begin{array}{l}-1.30 \\
(-1.86)\end{array}$ & $\begin{array}{l}-1.04 \\
(-2.82)\end{array}$ & $\begin{array}{l}10.66 \\
(0.80)\end{array}$ & $\begin{array}{c}0.97 \\
(0.90)\end{array}$ & $\begin{array}{l}-1.11 \\
(-0.46)\end{array}$ & $\begin{array}{c}0.33 \\
(0.22)\end{array}$ \\
\hline $1_{\text {OwnEvent }} \times E C O N$ & & & & & & & & $\begin{array}{l}-17.96 \\
(-1.55)\end{array}$ & $\begin{array}{l}-1.75 \\
(-1.81)\end{array}$ & $\begin{array}{c}0.14 \\
(0.07)\end{array}$ & $\begin{array}{l}-1.29 \\
(-0.93)\end{array}$ \\
\hline $1_{\text {SpillEvent }} \times E C O N$ & & & & & & & & $\begin{array}{l}-27.85 \\
(-2.31)\end{array}$ & $\begin{array}{l}-2.13 \\
(-2.14)\end{array}$ & $\begin{array}{l}-0.40 \\
(-0.18)\end{array}$ & $\begin{array}{l}-1.24 \\
(-0.88)\end{array}$ \\
\hline $\begin{array}{l}R^{2} \\
\text { Obs. }\end{array}$ & $\begin{array}{c}0.078 \\
65\end{array}$ & $\begin{array}{c}0.093 \\
65\end{array}$ & $\begin{array}{c}0.153 \\
65\end{array}$ & $\begin{array}{c}0.331 \\
65\end{array}$ & $\begin{array}{c}0.329 \\
65\end{array}$ & $\begin{array}{c}0.193 \\
57\end{array}$ & $\begin{array}{c}0.250 \\
65\end{array}$ & $\begin{array}{c}0.386 \\
65\end{array}$ & $\begin{array}{c}0.377 \\
65\end{array}$ & $\begin{array}{c}0.194 \\
57\end{array}$ & $\begin{array}{c}0.261 \\
65\end{array}$ \\
\hline \multicolumn{12}{|c|}{ Panel B: $V R P D$} \\
\hline $1_{\text {OwnEvent }}$ & $\begin{array}{c}1.22 \\
(1.12)\end{array}$ & & $\begin{array}{c}1.07 \\
(0.98)\end{array}$ & $\begin{array}{c}1.14 \\
(1.08)\end{array}$ & $\begin{array}{c}1.18 \\
(1.09)\end{array}$ & $\begin{array}{c}1.11 \\
(0.90)\end{array}$ & $\begin{array}{c}1.16 \\
(1.08)\end{array}$ & $\begin{array}{c}1.13 \\
(1.07)\end{array}$ & $\begin{array}{c}0.99 \\
(0.91)\end{array}$ & $\begin{array}{c}1.05 \\
(0.83)\end{array}$ & $\begin{array}{c}1.03 \\
(0.94)\end{array}$ \\
\hline $1_{\text {SpillEvent }}$ & & $\begin{array}{c}1.40 \\
(1.27)\end{array}$ & $\begin{array}{c}1.27 \\
(1.14)\end{array}$ & $\begin{array}{c}1.21 \\
(1.13)\end{array}$ & $\begin{array}{c}1.04 \\
(0.95)\end{array}$ & $\begin{array}{c}0.87 \\
(0.71)\end{array}$ & $\begin{array}{l}1.05 \\
(0.96)\end{array}$ & $\begin{array}{c}1.22 \\
(1.14)\end{array}$ & $\begin{array}{c}0.95 \\
(0.87)\end{array}$ & $\begin{array}{c}0.92 \\
(0.74)\end{array}$ & $\begin{array}{c}0.97 \\
(0.87)\end{array}$ \\
\hline$E C O N$ & & & & $\begin{array}{l}-15.80 \\
(-2.53)\end{array}$ & $\begin{array}{l}-0.86 \\
(-1.80)\end{array}$ & $\begin{array}{l}-2.06 \\
(-2.00)\end{array}$ & $\begin{array}{c}-0.98 \\
(-1.75)\end{array}$ & $\begin{array}{c}5.55 \\
(0.26)\end{array}$ & $\begin{array}{c}1.94 \\
(1.11)\end{array}$ & $\begin{array}{l}-1.66 \\
(-0.47)\end{array}$ & $\begin{array}{l}1.26 \\
(0.55)\end{array}$ \\
\hline $1_{\text {OwnEvent }} \times E C O N$ & & & & & & & & $\begin{array}{l}-14.28 \\
(-0.76)\end{array}$ & $\begin{array}{l}-2.49 \\
(-1.58)\end{array}$ & $\begin{array}{c}0.30 \\
(0.10)\end{array}$ & $\begin{array}{c}-2.05 \\
(-0.98)\end{array}$ \\
\hline $1_{\text {SpillEvent }} \times E C O N$ & & & & & & & & $\begin{array}{l}-22.21 \\
(-1.14)\end{array}$ & $\begin{array}{l}-2.54 \\
(-1.57)\end{array}$ & $\begin{array}{c}-0.84 \\
(-0.26)\end{array}$ & $\begin{array}{c}-2.07 \\
(-0.97)\end{array}$ \\
\hline $\begin{array}{l}R^{2} \\
\text { Obs. }\end{array}$ & $\begin{array}{c}0.019 \\
65\end{array}$ & $\begin{array}{c}0.024 \\
65\end{array}$ & $\begin{array}{c}0.039 \\
65\end{array}$ & $\begin{array}{c}0.129 \\
65\end{array}$ & $\begin{array}{c}0.087 \\
65\end{array}$ & $\begin{array}{c}0.098 \\
57\end{array}$ & $\begin{array}{c}0.085 \\
65\end{array}$ & $\begin{array}{c}0.148 \\
65\end{array}$ & $\begin{array}{c}0.127 \\
65\end{array}$ & $\begin{array}{c}0.102 \\
57\end{array}$ & $\begin{array}{c}0.100 \\
65\end{array}$ \\
\hline \multicolumn{12}{|c|}{ Panel C: SlopeD } \\
\hline $1_{\text {OwnEvent }}$ & $\begin{array}{c}1.44 \\
(1.87)\end{array}$ & & $\begin{array}{c}1.42 \\
(1.81)\end{array}$ & $\begin{array}{c}1.49 \\
(1.93)\end{array}$ & $\begin{array}{c}1.50 \\
(1.94)\end{array}$ & $\begin{array}{c}1.53 \\
(1.67)\end{array}$ & $\begin{array}{c}1.47 \\
(1.87)\end{array}$ & $\begin{array}{c}1.52 \\
(1.97)\end{array}$ & $\begin{array}{c}1.36 \\
(1.87)\end{array}$ & $\begin{array}{c}1.49 \\
(1.59)\end{array}$ & $\begin{array}{c}1.34 \\
(1.73)\end{array}$ \\
\hline $1_{\text {SpillEvent }}$ & & $\begin{array}{c}0.48 \\
(0.56)\end{array}$ & $\begin{array}{c}0.33 \\
(0.40)\end{array}$ & $\begin{array}{c}0.31 \\
(0.37)\end{array}$ & $\begin{array}{c}0.20 \\
(0.24)\end{array}$ & $\begin{array}{c}0.29 \\
(0.30)\end{array}$ & $\begin{array}{c}0.24 \\
(0.28)\end{array}$ & $\begin{array}{c}0.40 \\
(0.48)\end{array}$ & $\begin{array}{c}0.10 \\
(0.13)\end{array}$ & $\begin{array}{c}0.29 \\
(0.29)\end{array}$ & $\begin{array}{c}0.13 \\
(0.15)\end{array}$ \\
\hline$E C O N$ & & & & $\begin{array}{l}-7.78 \\
(-1.64)\end{array}$ & $\begin{array}{c}-0.57 \\
(-1.58)\end{array}$ & $\begin{array}{l}-0.16 \\
(-0.20)\end{array}$ & $\begin{array}{l}-0.40 \\
(-0.94)\end{array}$ & $\begin{array}{l}15.79 \\
(0.87)\end{array}$ & $\begin{array}{c}4.47 \\
(2.62)\end{array}$ & $\begin{array}{c}0.81 \\
(0.25)\end{array}$ & $\begin{array}{c}3.00 \\
(1.54)\end{array}$ \\
\hline $1_{\text {OwnEvent }} \times E C O N$ & & & & & & & & $\begin{array}{l}-23.00 \\
(-1.38)\end{array}$ & $\begin{array}{l}-4.91 \\
(-3.01)\end{array}$ & $\begin{array}{l}-0.65 \\
(-0.22)\end{array}$ & $\begin{array}{l}-3.38 \\
(-1.83)\end{array}$ \\
\hline $1_{\text {SpillEvent }} \times E C O N$ & & & & & & & & $\begin{array}{l}-20.14 \\
(-1.19)\end{array}$ & $\begin{array}{l}-4.71 \\
(-2.87)\end{array}$ & $\begin{array}{l}-1.08 \\
(-0.36)\end{array}$ & $\begin{array}{l}-3.02 \\
(-1.64)\end{array}$ \\
\hline$R^{2}$ & 0.056 & 0.005 & 0.059 & 0.101 & 0.098 & 0.058 & 0.073 & 0.131 & 0.227 & 0.061 & 0.126 \\
\hline Obs. & 60 & 60 & 60 & 60 & 60 & 52 & 60 & 60 & 60 & 52 & 60 \\
\hline
\end{tabular}


Table 11

\section{Relations between spillovers and FX options}

Panel A reports slope coefficients from regressions of spillover $I V D$, denoted by SpillIVD, on FX $I V D$, denoted by $F X I V D$, across political events. For each political event (U.S. election or European summit), SpillIVD is the equity option $I V D$ for the country not experiencing the event. That is, for each European summit, SpillIVD is the U.S. IVD, and for each U.S. election, SpillIVD is the average IVD across all Eurozone countries. FXIVD for each event is $I V D$ for at-the-money EUR/USD FX put and call options. $E C O N$ denotes controls for four measures of economic conditions in the country experiencing the event. The numbers in parentheses are $t$-statistics. The sample begins in January 1999 when FX option data become available. Panels B contains analogous results for VRPD. We do not report results for SlopeD because its construction requires data on FX option deltas. That data become available only in November 2010, as a result of which the regression analysis would be based on only six observations and thus unreliable.

\begin{tabular}{|c|c|c|c|c|c|}
\hline & & $M K T$ & $G D P$ & $F S T$ & $C L I$ \\
\hline \multicolumn{6}{|c|}{ Panel A: $I V D$} \\
\hline$F X I V D$ & $\begin{array}{c}1.05 \\
(2.71)\end{array}$ & $\begin{array}{c}0.97 \\
(2.69)\end{array}$ & $\begin{array}{c}0.99 \\
(2.70)\end{array}$ & $\begin{array}{c}1.09 \\
(2.91)\end{array}$ & $\begin{array}{c}1.07 \\
(2.82)\end{array}$ \\
\hline$E C O N$ & & $\begin{array}{l}-14.97 \\
(-2.32)\end{array}$ & $\begin{array}{l}-1.11 \\
(-2.11)\end{array}$ & $\begin{array}{l}-1.69 \\
(-1.69)\end{array}$ & $\begin{array}{c}-0.89 \\
(-1.47)\end{array}$ \\
\hline$R^{2}$ & 0.227 & 0.369 & 0.348 & 0.309 & 0.291 \\
\hline Obs. & 27 & 27 & 27 & 27 & 27 \\
\hline \multicolumn{6}{|c|}{ Panel B: $V R P D$} \\
\hline$F X V R P D$ & $\begin{array}{c}4.19 \\
(2.69)\end{array}$ & $\begin{array}{c}4.16 \\
(2.74)\end{array}$ & $\begin{array}{c}4.21 \\
(2.70)\end{array}$ & $\begin{array}{c}4.66 \\
(3.14)\end{array}$ & $\begin{array}{c}4.41 \\
(2.84)\end{array}$ \\
\hline$E C O N$ & & $\begin{array}{l}-16.85 \\
(-1.51)\end{array}$ & $\begin{array}{l}-0.86 \\
(-0.94)\end{array}$ & $\begin{array}{l}-3.30 \\
(-2.04)\end{array}$ & $\begin{array}{c}-1.21 \\
(-1.19)\end{array}$ \\
\hline$R^{2}$ & 0.224 & 0.292 & 0.252 & 0.339 & 0.268 \\
\hline Obs. & 27 & 27 & 27 & 27 & 27 \\
\hline
\end{tabular}




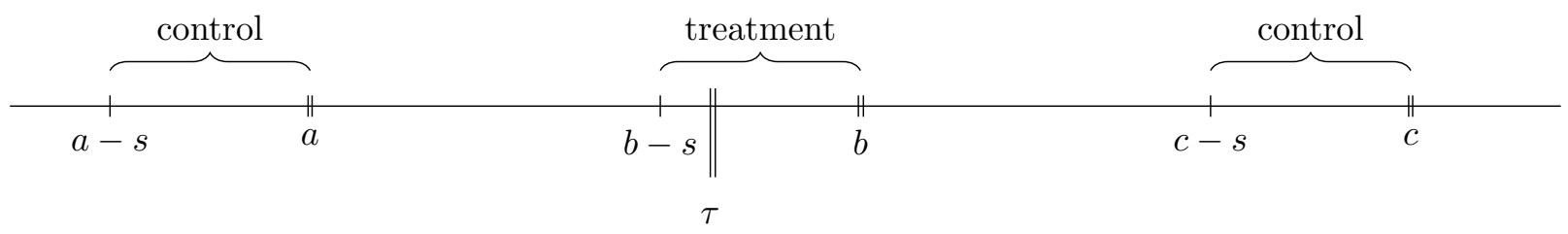

Figure 1. Timeline. Time $\tau$ is the date of the political event. Times $a, b$, and $c$ are option expiration dates. For both treatment and control options, we use prices from multiple dates that are $s$ days prior to expiration. 
Panel A: Stock Market Return

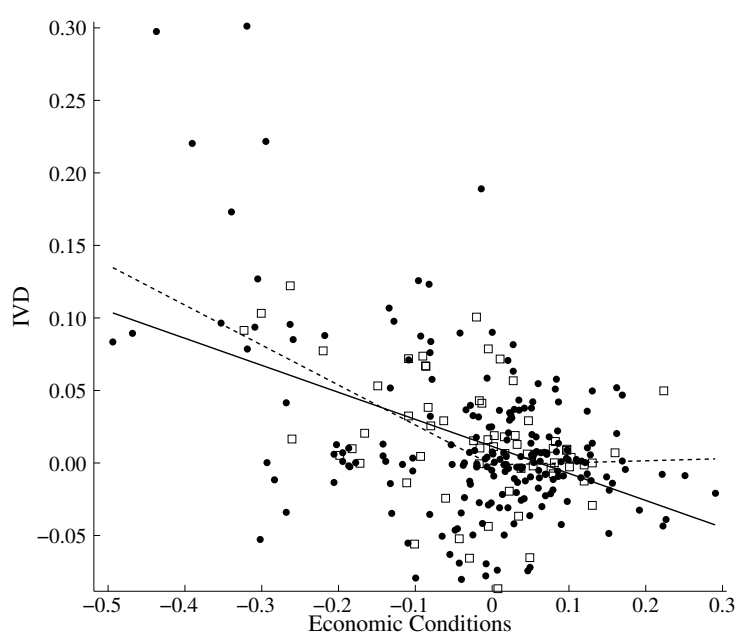

Panel C: GDP Growth Forecast

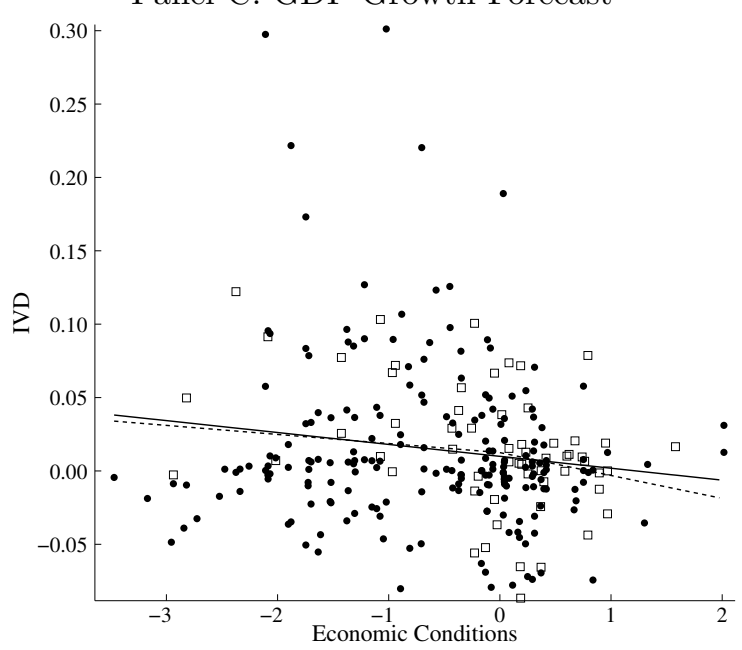

Panel B: GDP Growth

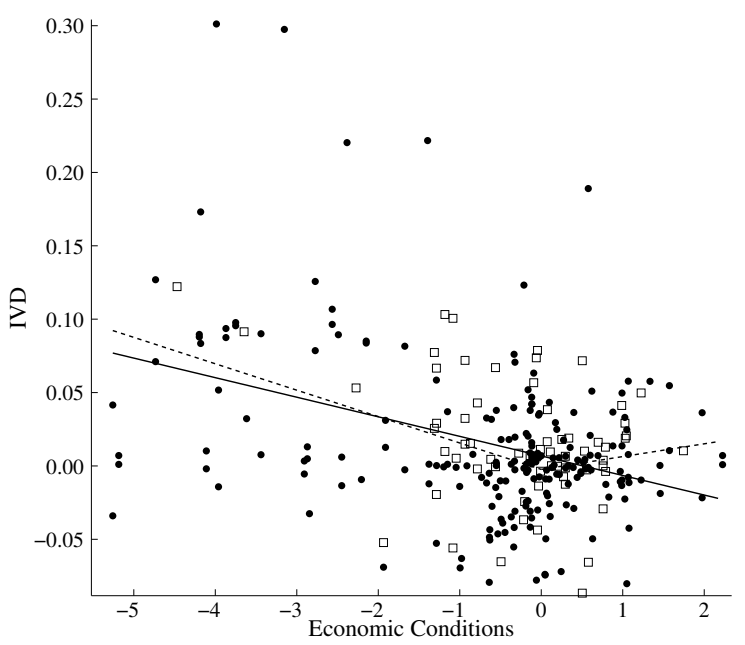

Panel D: Composite Leading Indicator

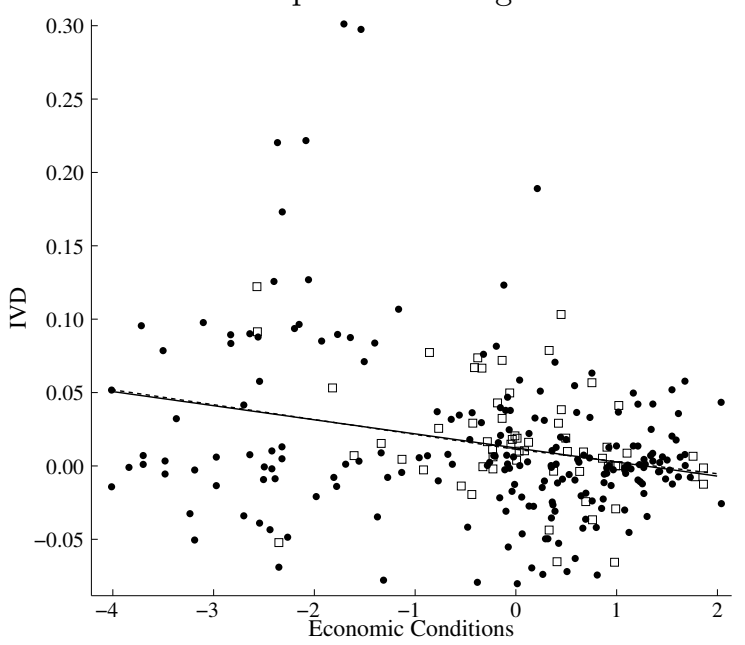

Figure 2. Implied volatility difference vs. economic conditions: Data. The figure plots $I V D$, the annualized implied volatility difference from equation (1), against four measures of economic conditions: the country's stock market index return ( $M K T$; Panel A), real GDP growth (GDP; Panel B), the IMF's GDP growth forecast (FST; Panel C), and the OECD's Composite Leading Indicator (CLI; Panel D). We standardize $G D P, F S T$, and $C L I$ to zero mean and unit variance within each country by using data from 1990 through 2012. Election observations are marked as squares; summit observations as circles. The solid line is the line of best fit from a simple linear regression; the dashed line is from the piecewise linear regression with a kink at zero. 

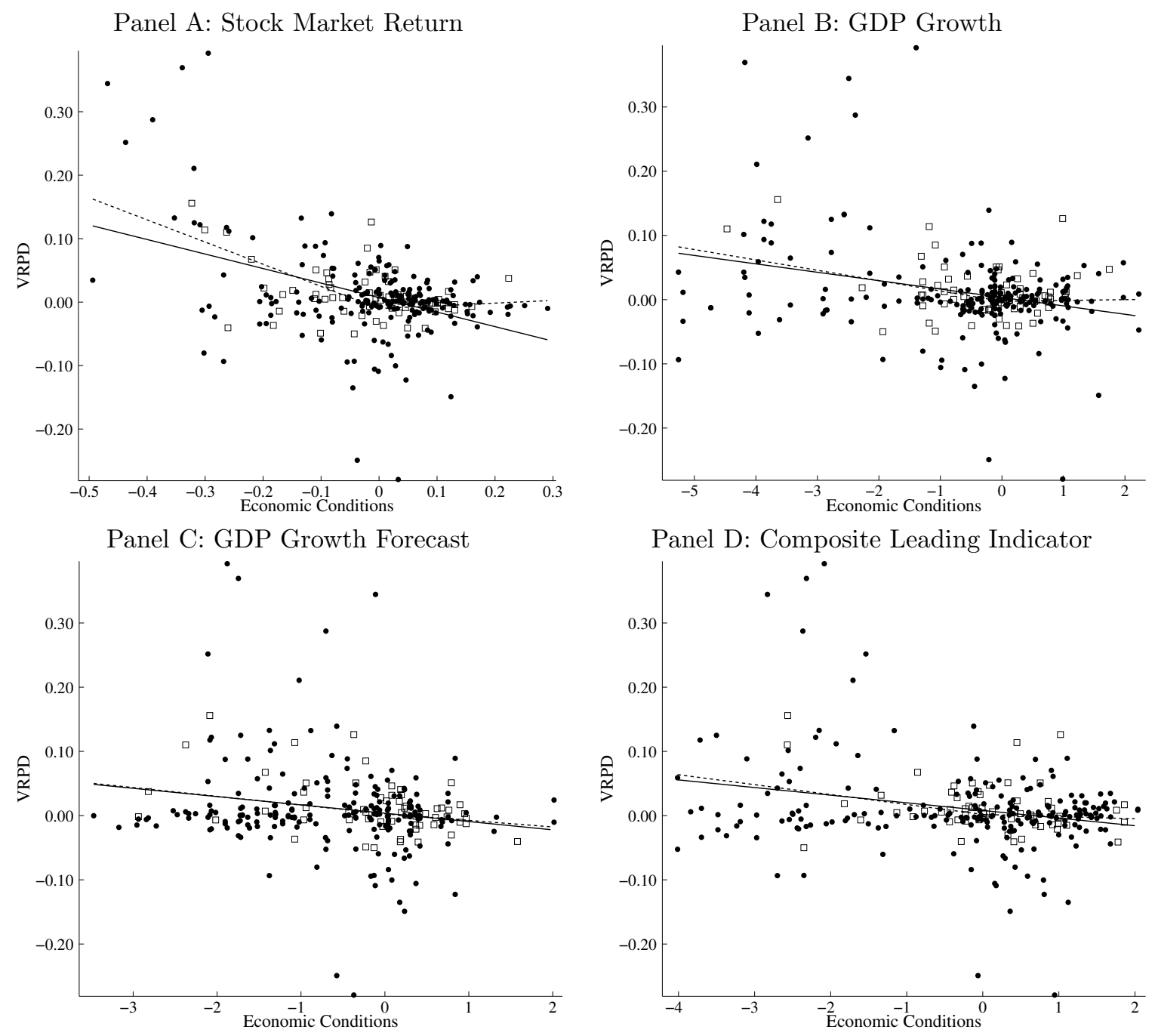

Figure 3. Variance risk premium difference vs. economic conditions: Data. The figure plots $V R P D$, the annualized variance risk premium difference from equation (4), against four measures of economic conditions: the country's stock market index return ( $M K T$; Panel A), real GDP growth (GDP; Panel B), the IMF's GDP growth forecast (FST; Panel C), and the OECD's Composite Leading Indicator (CLI; Panel D). We standardize $G D P, F S T$, and $C L I$ to zero mean and unit variance within each country by using data from 1990 through 2012. Election observations are marked as squares; summit observations as circles. The solid line is the line of best fit from a simple linear regression; the dashed line is from the piecewise linear regression with a kink at zero. 
Panel A: Stock Market Return

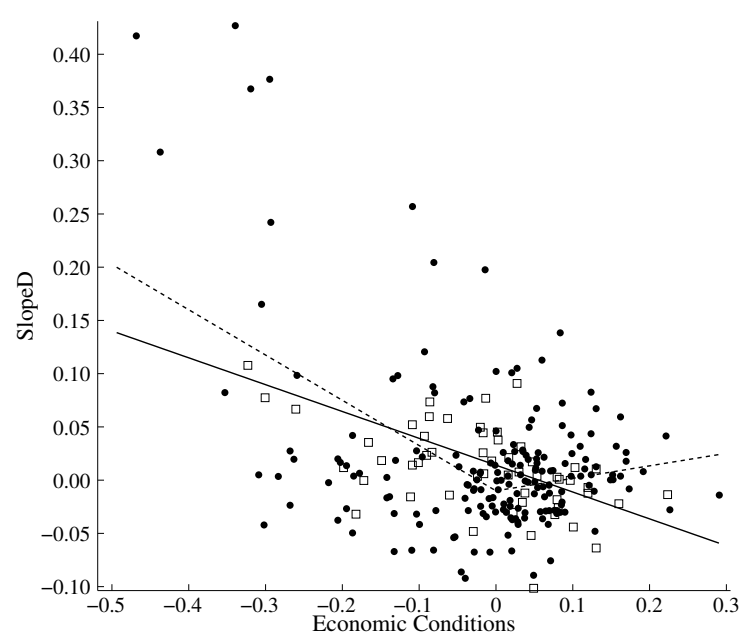

Panel C: GDP Growth Forecast

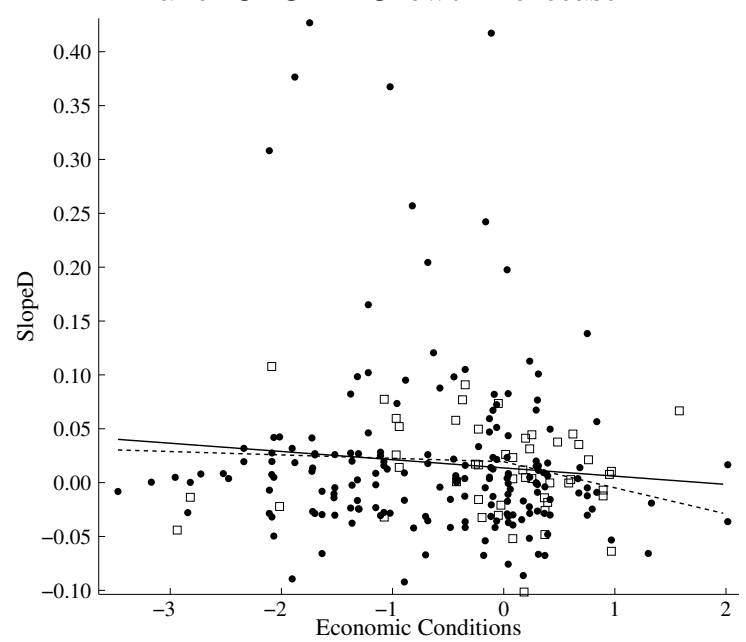

Panel B: GDP Growth

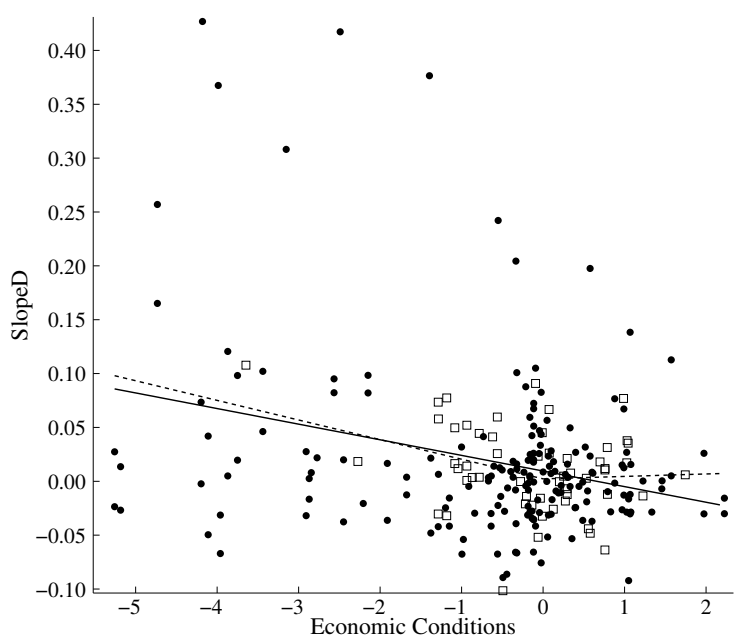

Panel D: Composite Leading Indicator

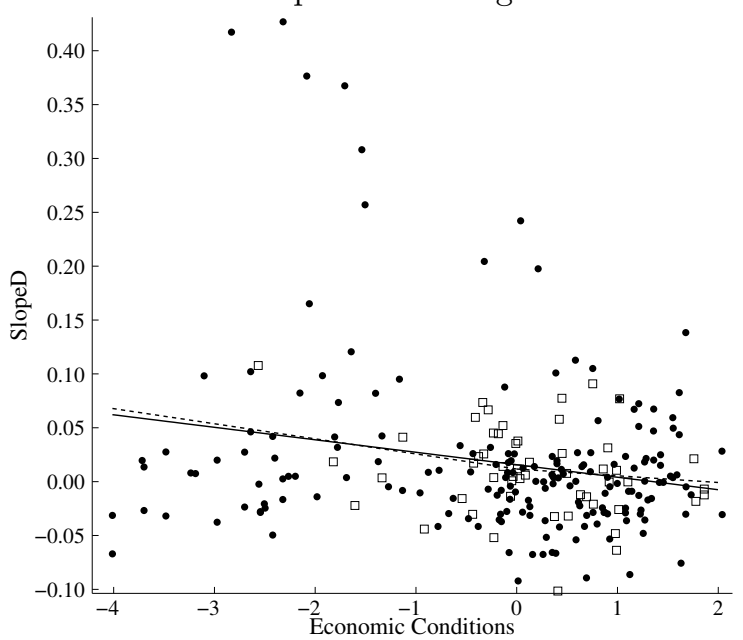

Figure 4. Implied volatility slope difference vs. economic conditions: Data. The figure plots SlopeD, the implied volatility slope difference from equation (6), against four measures of economic conditions: the country's stock market index return ( $M K T$; Panel A), real GDP growth (GDP; Panel B), the IMF's GDP growth forecast (FST; Panel C), and the OECD's Composite Leading Indicator (CLI; Panel D). We standardize $G D P, F S T$, and $C L I$ to zero mean and unit variance within each country by using data from 1990 through 2012. Election observations are marked as squares; summit observations as circles. The solid line is the line of best fit from a simple linear regression; the dashed line is from the piecewise linear regression with a kink at zero. 

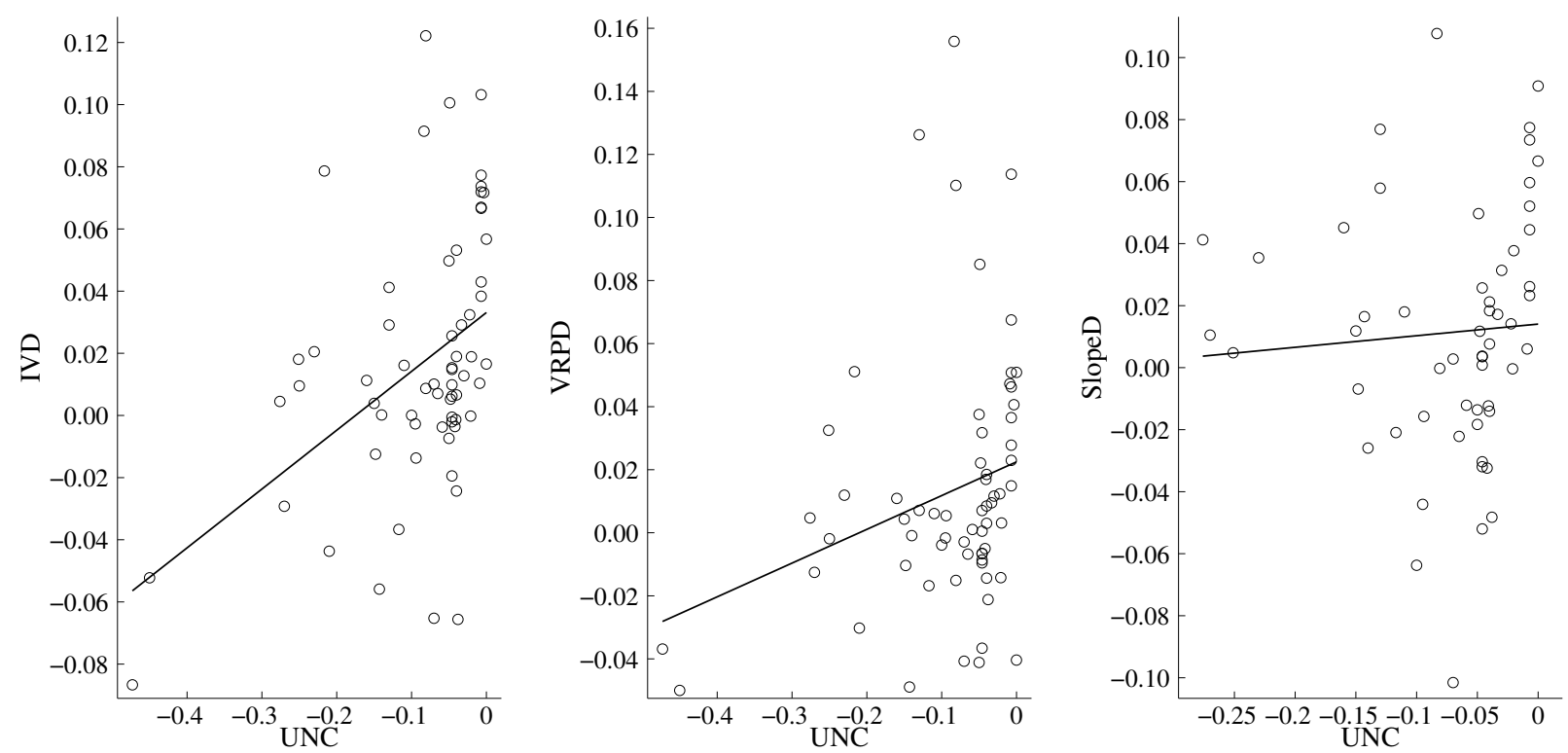

Figure 5. The role of political uncertainty: Data. The figure plots three option-market quantities against uncertainty about election outcome $(U N C)$ for all election observations in our sample. $U N C$ is the negative of the election poll spread. The three quantities are: $I V D$, the annualized implied volatility difference from equation (1), $V R P D$, the annualized variance risk premium difference from equation (4), and SlopeD, the implied volatility slope difference from equation (6). We also show the line of best fit from a simple linear regression. 
A. Probability at $\tau$ of old policy

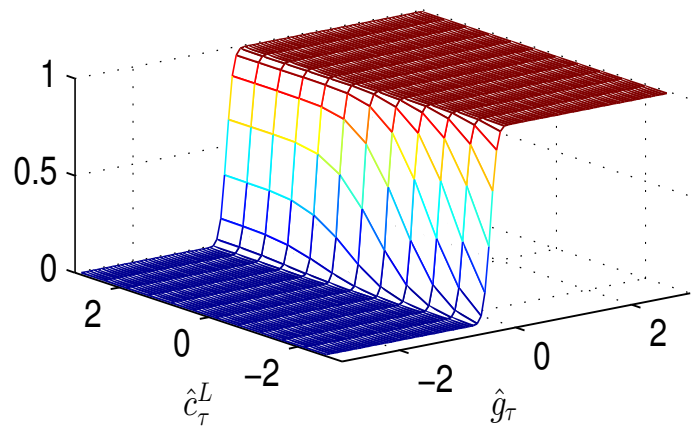

C. Probability at $\tau$ of policy $L$

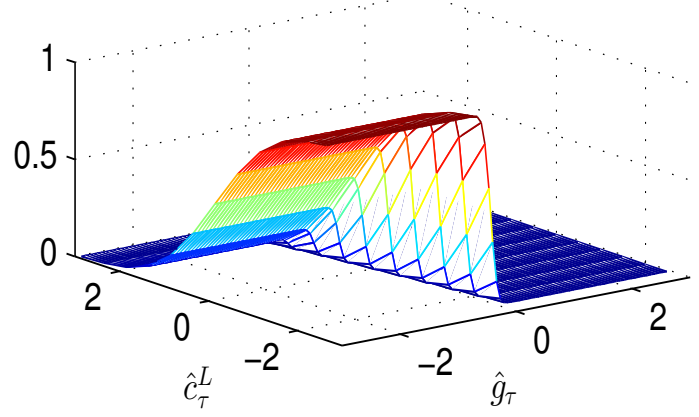

E. Probability at $\tau$ of policy $H$

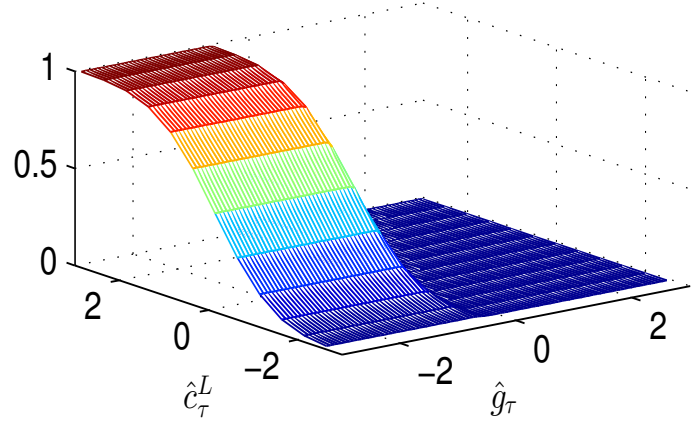

B. Jump at $\tau$ if old policy chosen

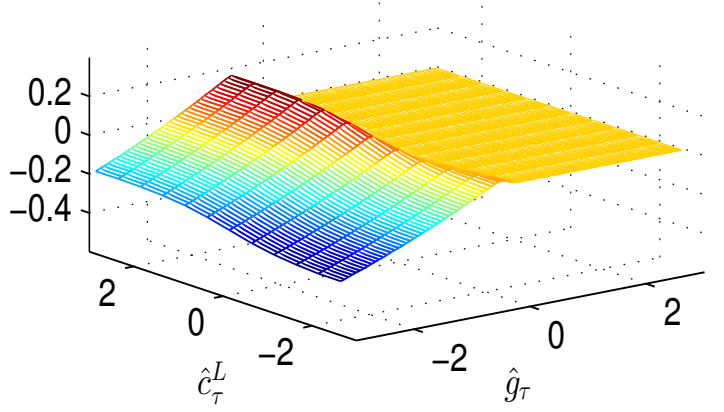

D. Jump at $\tau$ if policy $L$ chosen

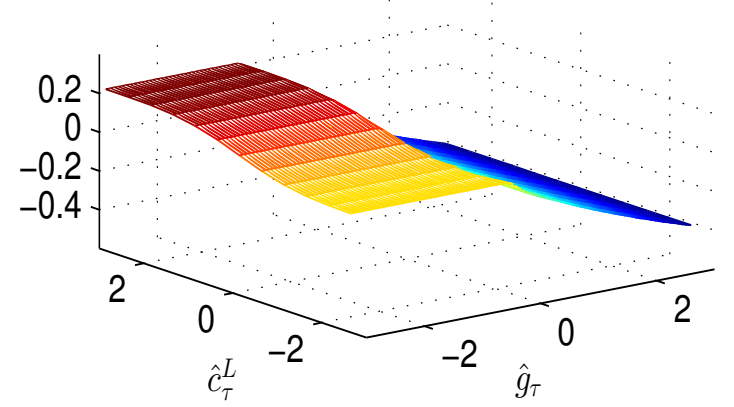

F. Jump at $\tau$ if policy $H$ chosen

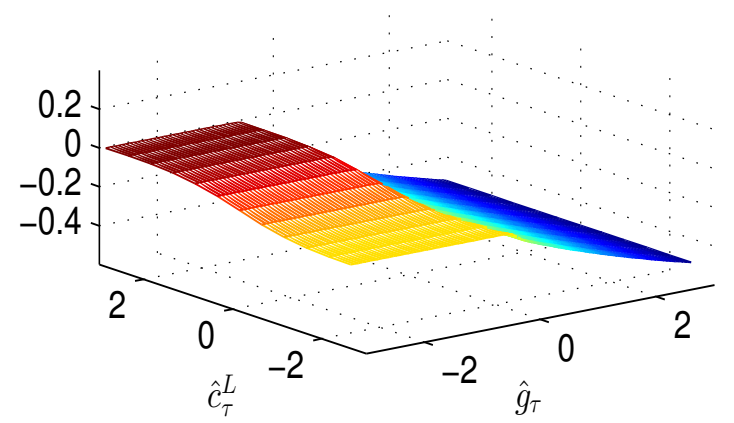

Figure 6. Model-implied policy probabilities and jumps in stock prices. The left-hand-side panels of this figure plot the adoption probabilities of the three government policies (the current or "old" policy and two potential new policies, $L$ and $H$ ) immediately before the policy decision is made at time $\tau$. The right-hand-side panels plot the instantaneous stock market returns conditional on the three potential policy announcements. All quantities are plotted against two state variables, $\hat{g}_{t}$ (the state of the economy) and $\hat{c}_{\tau}^{L}$ (the perceived political cost of policy $L$ ), while holding the third stochastic variable, $\hat{c}_{\tau}^{H}$, equal to its prior mean. The values of $\hat{g}_{t}$ and $\hat{c}_{\tau}^{L}$ are scaled by their posterior standard deviations (and thus converted into "z-scores"). All quantities are computed within the PV model for baseline parameter values. 
A. Diffusive volatility $\sigma_{M}(S)$ at $t$

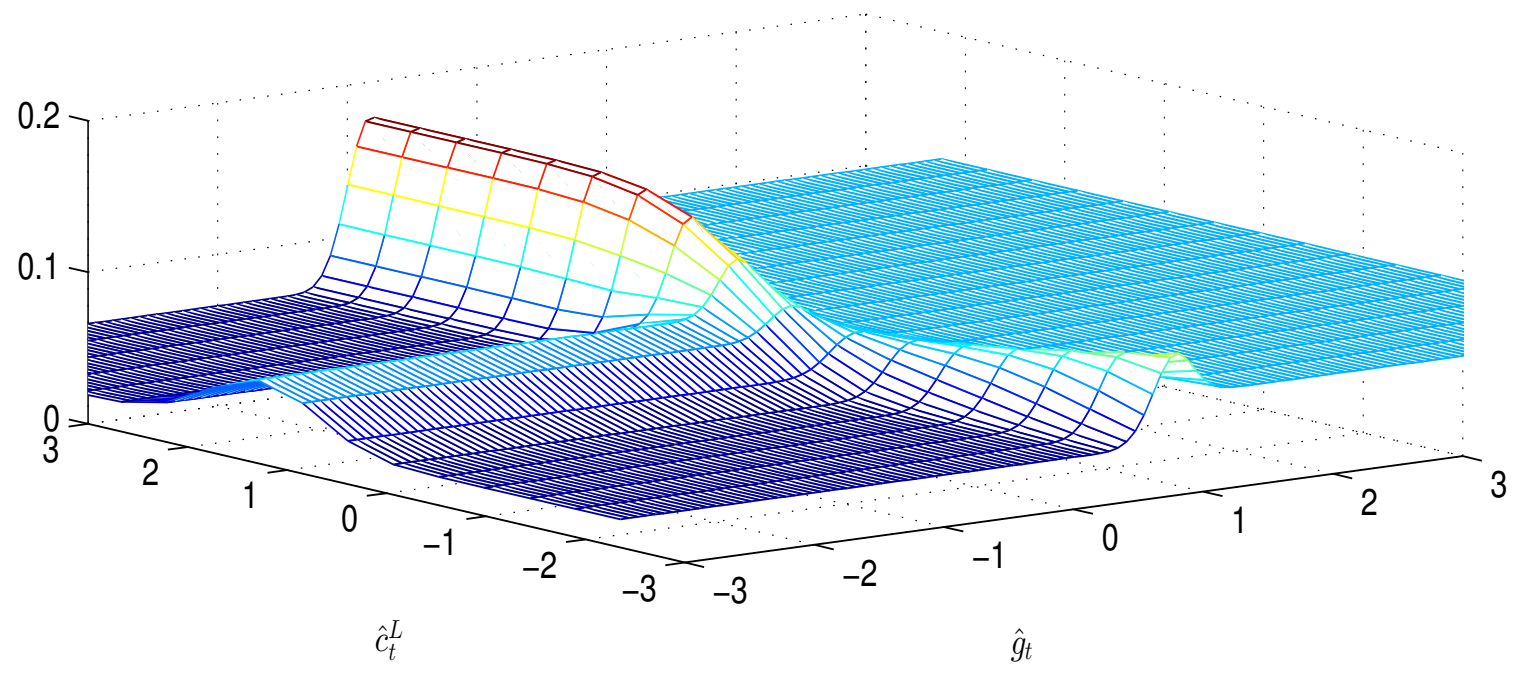

B. Expected volatility at $t$

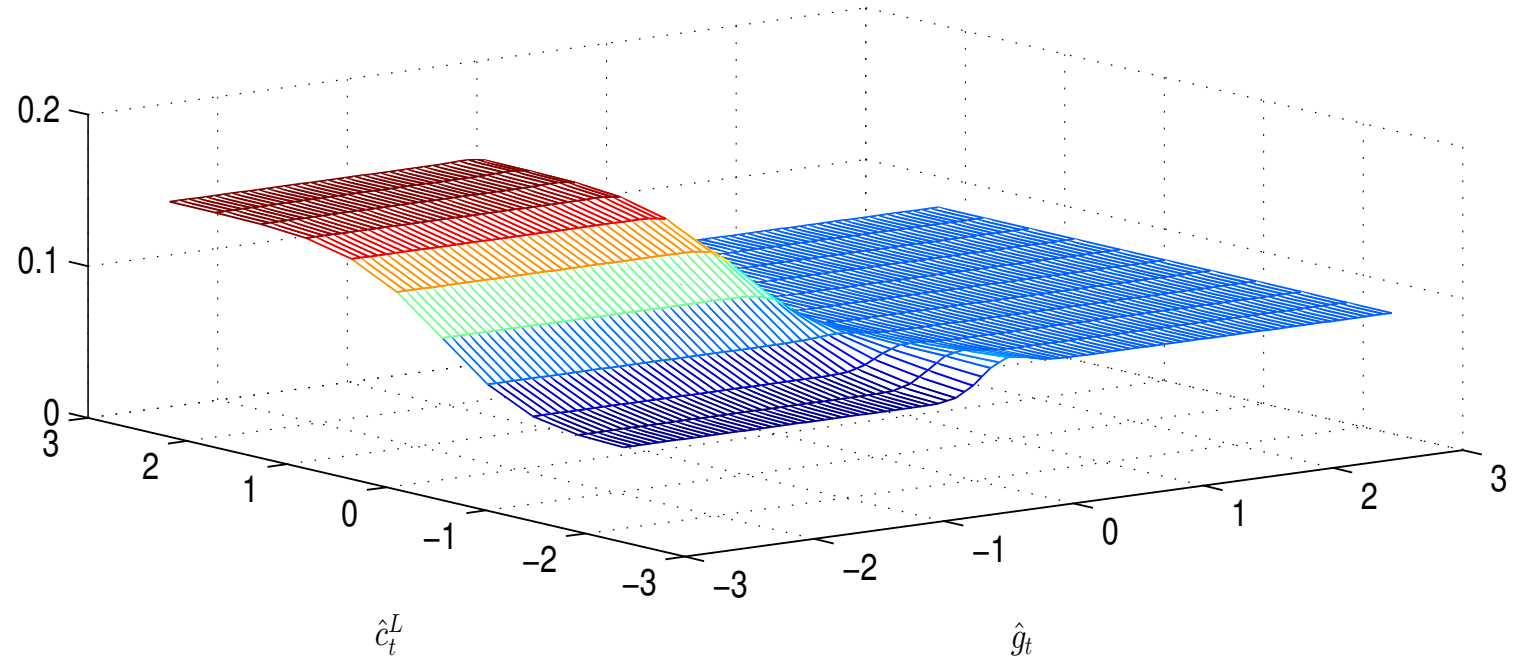

Figure 7. Model-implied stock return volatility. Panel A plots the diffusive volatility of the stock price process, $\sigma_{M}\left(S_{t}\right)$, as a function of the state variables $\widehat{g}_{t}$ (the state of the economy) and $\widehat{c}_{t}^{L}$ (the perceived political cost of policy $L$ ) as of time $t=\tau-1 / 2$. Panel B plots the expected volatility of log stock returns between times $\tau-\frac{1}{2}$ and $\tau+\frac{1}{2}$, evaluated as of time $t=\tau-1 / 2$. The values of $\widehat{g}_{t}$ and $\widehat{c}_{\tau}^{L}$ are scaled by their posterior standard deviations (and thus converted into "z-scores"). The third stochastic variable, $\widehat{c}_{\tau}^{H}$, is set equal to its prior mean. All quantities are computed within the PV model for baseline parameter values. 

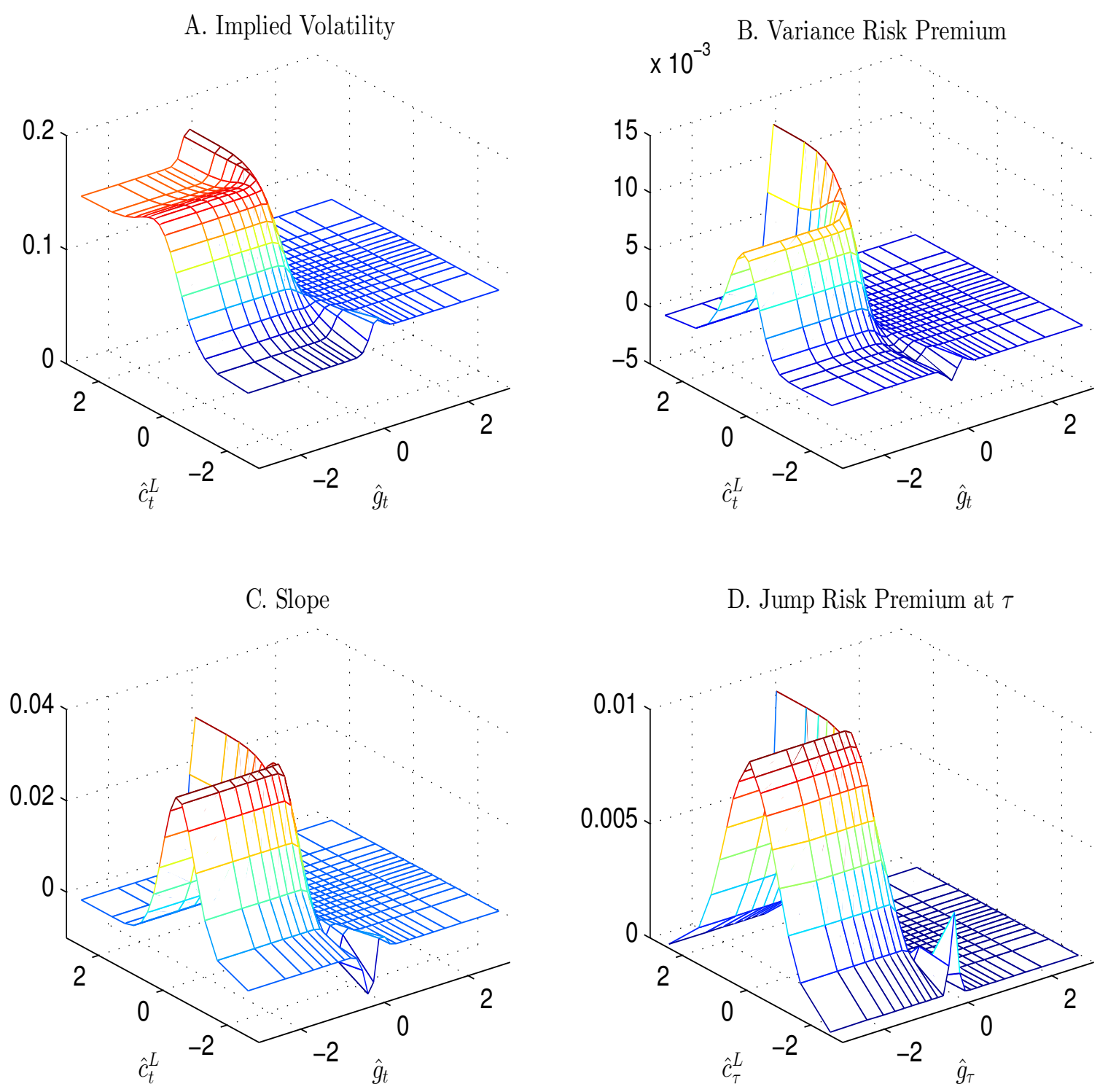

Figure 8. Option pricing implications of the PV model. This figure plots the three option-market variables, implied volatility (Panel A), variance risk premium (Panel B), and slope (Panel C), as a function of the state variables $\widehat{g}_{t}$ (the state of the economy) and $\widehat{c}_{t}^{L}$ (the perceived political cost of policy $L$ ). The variables are computed as of time $t=\tau-1 / 2$ for options expiring at time $\tau+1 / 2$, where $\tau$ is the date of the political event. The values of $\widehat{g}_{t}$ and $\widehat{c}_{\tau}^{L}$ are scaled by their posterior standard deviations (and thus converted into "z-scores"). The third stochastic variable, $\widehat{c}_{\tau}^{H}$, is set equal to its prior mean. Panel D reports the jump risk premium, or the expected instantaneous stock market return, computed immediately before time $\tau$. All quantities are computed within the PV model for baseline parameter values. 


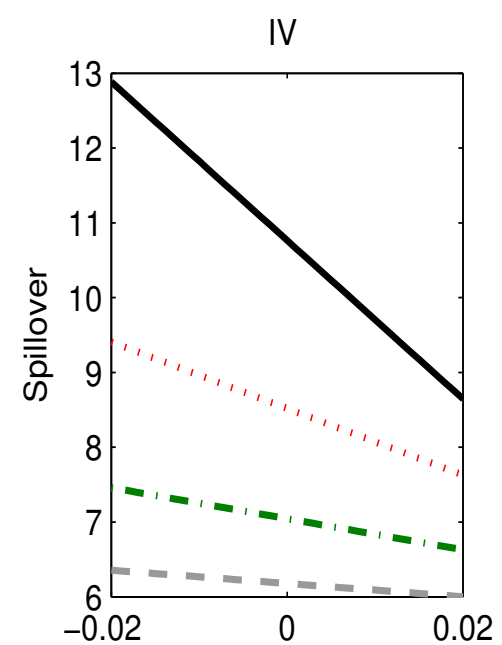

Economic conditions $\left(\hat{g}_{t}\right)$

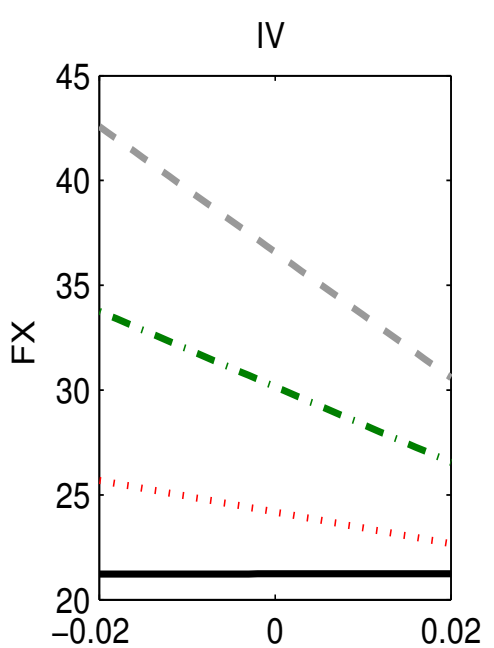

Economic conditions $\left(\hat{g}_{t}\right)$

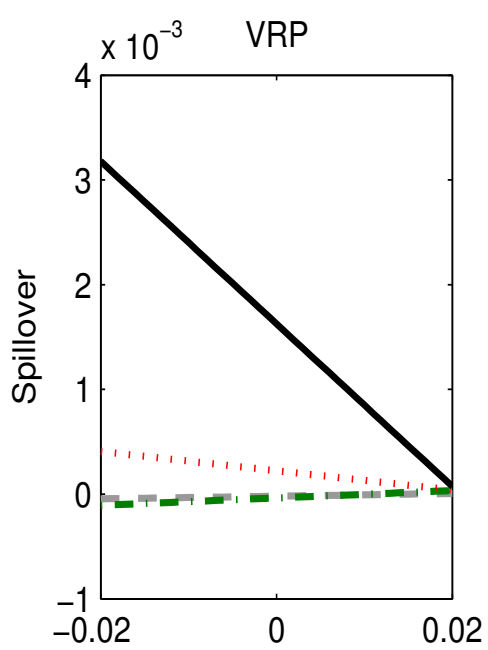

Economic conditions $\left(\hat{g}_{t}\right)$
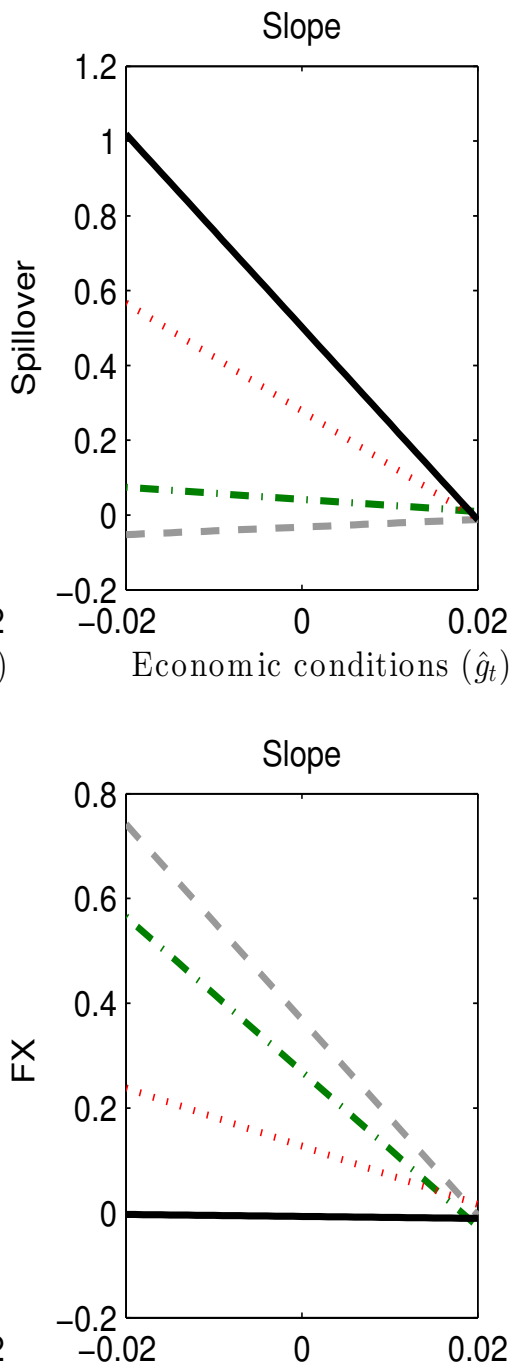

Economic conditions $\left(\hat{g}_{t}\right)$

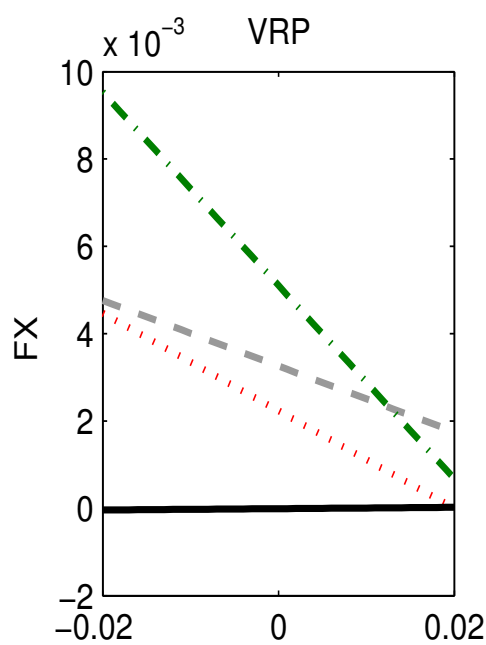

Economic conditions $\left(\hat{g}_{t}\right)$

$$
--\beta^{2}=0.25 \cdots-\beta^{2}=0.5 \cdots \cdots \beta^{2}=0.75-\beta^{2}=1
$$

Figure 9. The effects of political uncertainty in a two-country model. This figure plots the three option-market variables, implied volatility $(I V)$, variance risk premium $(V R P)$, and slope (Slope), against economic conditions, measured by the state variable $\widehat{g}_{t}$. The variables are computed as of time $t=\tau-1 / 2$ for options expiring at time $\tau+1 / 2$, where $\tau$ is the date of the political event. Each panel plots the regression line of best fit estimated across a large number of samples simulated from the two-country extension of the PV model with $\alpha=1$. The top three panels show spillover effects, defined as the effects of political uncertainty in the home country on equity option prices in the foreign country. The bottom three panels show the effects of political uncertainty in the home country on the prices of foreign exchange options. 


\section{Appendix}

In Section A.1, we briefly review the Pástor and Veronesi (2013) model. In Section A.2, we list the model-implied restrictions on the general dynamics in equations (7) through (11). In Section A.3, we show the option pricing formula from Proposition 2. In Section A.4, we give the jump risk premium formula from Proposition 3. In Section A.5, we list all of our political events.

\section{A.1. The Pástor and Veronesi (2013) model (PV)}

Consider an economy with a finite horizon $[0, T]$ and a continuum of all-equity firms $i \in[0,1]$. Let $B_{t}^{i}$ denote firm $i$ 's capital at time $t$. At time 0 , all firms employ an equal amount of capital, $B_{0}^{i}=1$. Firm $i$ 's capital is invested in a linear technology whose rate of return, or profitability, is denoted by $d \Pi_{t}^{i}$. All profits are reinvested, so that firm $i$ 's capital evolves according to $d B_{t}^{i}=B_{t}^{i} d \Pi_{t}^{i}$. For all $t \in[0, T]$, profitability follows the process

$$
d \Pi_{t}^{i}=\left(\mu+g_{t}\right) d t+\sigma d Z_{t}+\sigma_{1} d Z_{t}^{i},
$$

where $\left(\mu, \sigma, \sigma_{1}\right)$ are observable constants, $Z_{t}$ is a Brownian motion, and $Z_{t}^{i}$ is an independent Brownian motion that is specific to firm $i$. The variable $g_{t}$ denotes the impact of the prevailing government policy on the mean of the profitability process of each firm.

The government policy's impact, $g_{t}$, is constant while the same policy is in effect. The value of $g_{t}$ can change only at a given time $\tau, 0<\tau<T$, when the government makes an irreversible policy decision: whether to replace the current policy and, if so, which of $N$ potential new policies to adopt. That is, the government chooses one of $N+1$ policies, where policies $n=\{1, \ldots, N\}$ are the potential new policies and policy 0 is the "old" policy prevailing since time 0 . Let $g^{0}$ denote the impact of the old policy and $g^{n}$ denote the impact of the $n$-th new policy, for $n=\{1, \ldots, N\}$. The value of $g_{t}$ is a simple step function of time:

$$
g_{t}= \begin{cases}g^{0} & \text { for } t \leq \tau \\ g^{0} & \text { for } t>\tau \text { if the old policy is retained (i.e., no policy change) } \\ g^{n} & \text { for } t>\tau \text { if the new policy } n \text { is chosen, } n \in\{1, \ldots, N\}\end{cases}
$$

A policy change replaces $g^{0}$ by $g^{n}$, thereby inducing a permanent shift in average profitability.

The value of $g_{t}$ is unknown to all agents for all $t \in[0, T]$. As of time 0 , the prior distributions of all policy impacts are normal:

$$
\begin{aligned}
& g^{0} \sim N\left(0, \sigma_{g}^{2}\right) \\
& g^{n} \sim N\left(\mu_{g}^{n}, \sigma_{g, n}^{2}\right) \quad \text { for } n=\{1, \ldots, N\} .
\end{aligned}
$$

Between times 0 and $\tau$, agents learn about $g^{0}$ in a Bayesian fashion by observing realized firm profitabilities. The posterior distribution of $g^{0}$ at any time $t \leq \tau$ is given by

$$
g_{t} \sim N\left(\widehat{g}_{t}, \widehat{\sigma}_{t}^{2}\right)
$$

where the posterior mean and variance evolve as

$$
\begin{aligned}
d \widehat{g}_{t} & =\widehat{\sigma}_{t}^{2} \sigma^{-1} d \widehat{Z}_{t} \\
\widehat{\sigma}_{t}^{2} & =\frac{1}{\frac{1}{\sigma_{g}^{2}}+\frac{1}{\sigma^{2}} t},
\end{aligned}
$$

Before time $\tau$, there is no learning about $\left\{g^{n}\right\}_{n=1}^{N}$, so agents' beliefs about those values at any time $t \leq \tau$ are given by the prior distributions in equation (A4). If there is no policy change at time $\tau$, then agents continue to learn about $g^{0}$ after time $\tau$, and the processes (A6) and (A7) continue to hold also for $t>\tau$. If a new policy $n$ is adopted at time $\tau$, agents stop learning about $g^{0}$ and begin learning about $g^{n}$. As a result, a policy change resets agents' beliefs about $g_{t}$ from the posterior $N\left(\widehat{g}_{\tau}, \widehat{\sigma}_{\tau}^{2}\right)$ to the prior $N\left(\mu_{g}^{n}, \sigma_{g, n}^{2}\right)$. 
Firms are owned by a continuum of identical investors who maximize expected utility derived from terminal wealth. For all $j \in[0,1]$, investor $j$ 's utility function is given by

$$
u\left(W_{T}^{j}\right)=\frac{\left(W_{T}^{j}\right)^{1-\gamma}}{1-\gamma},
$$

where $W_{T}^{j}$ is investor $j$ 's wealth at time $T$ and $\gamma>1$ is relative risk aversion. At time 0 , all investors are equally endowed with firm stock. Stocks pay liquidating dividends at time $T$.

The government's preferences over policies $n=0, \ldots, N$ are represented by a utility function that is identical to that of investors, except that the government also faces a nonpecuniary cost (or benefit) associated with any policy change. Specifically, at time $\tau$, the government chooses the policy that maximizes

$$
\max _{n \in\{0, \ldots, N\}}\left\{\mathrm{E}_{\tau}\left[\frac{C^{n} W_{T}^{1-\gamma}}{1-\gamma} \mid \text { policy } n\right]\right\},
$$

where $W_{T}=B_{T}=\int_{0}^{1} B_{T}^{i} d i$ is the final value of aggregate capital and $C^{n}$ is the "political cost" incurred by the government if policy $n$ is adopted. Values of $C^{n}>1$ represent a cost whereas $C^{n}<1$ represents a benefit. We normalize $C^{0}=1$, so that retaining the old policy is known with certainty to present no political costs or benefits to the government. The political costs of the new policies, $\left\{C^{n}\right\}_{n=1}^{N}$, are revealed to all agents at time $\tau$. Immediately after the $C^{n}$ values are revealed, the government makes its policy decision. As of time 0 , the prior distribution of each $C^{n}$ is lognormal and centered at $C^{n}=1$ :

$$
c^{n} \equiv \log \left(C^{n}\right) \sim N\left(-\frac{1}{2} \sigma_{c}^{2}, \sigma_{c}^{2}\right) \quad \text { for } n=\{1, \ldots, N\},
$$

where the $c^{n}$ values are uncorrelated across policies and independent of the Brownian motions in equation (A1). Uncertainty about $\left\{C^{n}\right\}_{n=1}^{N}$, which is given by $\sigma_{c}$ as of time 0 , is the source of political uncertainty, or uncertainty about the government's policy choice. Any $\sigma_{c}>0$ introduces an element of surprise into the policy decision. Given its objective function, the government is "quasi-benevolent": it maximizes the investors' welfare on average (because $\mathrm{E}_{0}\left[C^{n}\right]=1$ for all $n$ ), but it also deviates from this objective randomly.

The political costs $\left\{C^{n}\right\}_{n=1}^{N}$ are unknown to all agents until time $\tau$. At time $t_{0}<\tau$, agents begin learning about each $c^{n}$ by observing unbiased signals:

$$
d s_{t}^{n}=c^{n} d t+h d Z_{c, t}^{n}, \quad n=1, \ldots, N .
$$

The signals $d s_{t}^{n}$ are uncorrelated across $n$ and independent of all other shocks. We refer to $d s_{t}^{n}$ as "political signals," and interpret them as capturing the steady flow of political news relevant to policy $n$. These signals help agents revise their beliefs about the government's future actions. Combining these signals with the prior distribution in equation (A10), we obtain the posterior distribution of $c^{n}$, for $n=1, \ldots, N$, at any time $t \leq \tau$ :

$$
c^{n} \sim N\left(\widehat{c}_{t}^{n}, \widehat{\sigma}_{c, t}^{2}\right),
$$

where the posterior mean and variance evolve as

$$
\begin{aligned}
d \widehat{c}_{t}^{n} & =\widehat{\sigma}_{c, t}^{2} h^{-1} d \widehat{Z}_{c, t}^{n} \\
\widehat{\sigma}_{c, t}^{2} & =\frac{1}{\frac{1}{\sigma_{c}^{2}}+\frac{1}{h^{2}}\left(t-t_{0}\right)} .
\end{aligned}
$$

Assuming complete markets, the state price density in this economy is uniquely given by

$$
\pi_{t}=\frac{1}{\lambda} \mathrm{E}_{t}\left[B_{T}^{-\gamma}\right],
$$

where $\lambda$ is the Lagrange multiplier from the utility maximization problem of the representative investor. 


\section{A.2. Restrictions on general dynamics}

The state variables in the PV model follow the martingale processes given in equations (A6) and (A13). As a result, the model imposes the following restrictions on the state variable process in equation (7):

$$
\begin{aligned}
\mu_{S}\left(S_{t}\right) & =0 \\
\sigma_{S}\left(S_{t}\right) & =\left(\begin{array}{ccccc}
\frac{\sigma^{-1}}{\sigma_{g}^{-2}+\sigma^{-2} t} & 0 & 0 & \ldots & 0 \\
0 & \frac{h^{-1}}{\sigma_{c}^{-2}+h^{-2}\left(t-t_{0}\right)} & 0 & \cdots & 0 \\
\vdots & & & \ddots & \vdots \\
0 & 0 & 0 & \cdots & \frac{h^{-1}}{\sigma_{c}^{-2}+h^{-2}\left(t-t_{0}\right)}
\end{array}\right) \\
d W_{S, t} & =\text { vector of expectation errors denoted byd } d \widehat{Z}_{t} \text { and } d \widehat{Z}_{c, t}^{n} \text { in PV }
\end{aligned}
$$

These restrictions hold until time $\tau$; after that time, the political shocks $\widehat{c}_{t}^{n}$ disappear and $\widehat{g}_{t}$ follows the same process as in equation (A6) except that the prior distribution is reset at time $\tau$.

The restrictions on the dynamics of stock prices in equation (8) are as follows:

$$
\sigma_{M}\left(S_{t}\right)=\left\{\begin{array}{clc}
\sqrt{\left(\sigma+\sigma_{M, 0}\left(S_{t}\right)\right)^{2}+\sum_{n=1}^{N} \sigma_{M, n}\left(S_{t}\right)^{2}} & \text { for } & t<\tau \\
\sigma+(T-t) \widehat{\sigma}_{n, t}^{2} \sigma^{-1} & \text { for } & t \geq \tau, n \text { drawn at } \tau
\end{array}\right.
$$

where $\sigma_{M, n}\left(S_{t}\right)$ for $n=0,1, \ldots, N$ are given in equations (37) and (38) in PV,

$$
\mu_{M}\left(S_{t}\right)=\left\{\begin{array}{ccc}
-\left(\sigma+\sigma_{M, 0}\left(S_{t}\right)\right)\left(-\gamma \sigma+\sigma_{\pi, 0}\left(S_{t}\right)\right) & \text { for } & t<\tau \\
-\sum_{n=1}^{N} \sigma_{M, n}\left(S_{t}\right) \sigma_{\pi, n}\left(S_{t}\right) & & \\
\gamma\left(\sigma+(T-t) \widehat{\sigma}_{n, t}^{2} \sigma^{-1}\right)^{2} & \text { for } & t \geq \tau, n \text { drawn at } \tau
\end{array}\right.
$$

where $\sigma_{\pi, n}\left(S_{t}\right)$, for $n=0,1, \ldots, N$ are given in equations (30) and (31) in PV,

$$
d W_{M, t}=\sigma_{M}(S)^{-1}\left(\left(\sigma+\sigma_{M, 0}\left(S_{t}\right)\right) d \widehat{Z}_{t}+\sum_{n=1}^{N} \sigma_{M, n}\left(S_{t}\right) d \widehat{Z}_{c, t}^{n}\right)
$$

and the jump term $J_{M, \tau}$ is a random variable distributed as follows:

$$
J_{M, \tau}=\left\{\begin{array}{ccc}
R^{0}\left(S_{\tau}\right) & \text { with probability } & p_{\tau}^{0}\left(S_{\tau}\right) \\
R^{1}\left(S_{\tau}\right) & \text { with probability } & p_{\tau}^{1}\left(S_{\tau}\right) \\
\vdots & \vdots & \vdots \\
R^{N}\left(S_{\tau}\right) & \text { with probability } & p_{\tau}^{N}\left(S_{\tau}\right)
\end{array}\right.
$$

where the announcement returns $R^{n}\left(S_{\tau}\right), n=0, \ldots, N$ are given in equations (48) and (49) in PV, and the policy probabilities $p_{\tau}^{n}\left(S_{\tau}\right) n=0, \ldots, N$ are provided in Corollary 2 of PV.

The restrictions on the dynamics of the stochastic discount factor in equation (9) are as follows:

$$
\begin{gathered}
\sigma_{\pi}\left(S_{t}\right)=\left\{\begin{array}{ccc}
\sqrt{\left(-\gamma \sigma+\sigma_{\pi, 0}\left(S_{t}\right)\right)^{2}+\sum_{n=1}^{N} \sigma_{\pi, n}\left(S_{t}\right)^{2}} & \text { for } & t<\tau \\
-\gamma \sigma-\gamma(T-t) \widehat{\sigma}_{n, t}^{2} \sigma^{-1} & \text { for } t \geq \tau, n \text { drawn at } \tau
\end{array}\right. \\
d W_{\pi, t}=\sigma_{\pi}\left(S_{t}\right)^{-1}\left(\left(\sigma+\sigma_{\pi, 0}\left(S_{t}\right)\right) d \widehat{Z}_{t}+\sum_{n=1}^{N} \sigma_{\pi, n}\left(S_{t}\right) d \widehat{Z}_{c, t}^{n}\right),
\end{gathered}
$$


and the jump term $J_{\pi, \tau}$ can take on $n+1$ values $J_{\pi}^{n}, n=0,1, \ldots, N$, given by

$$
J_{\pi}^{n}=\frac{\pi_{\tau+}^{n}}{\pi_{\tau}}-1=\frac{e^{-\gamma \mu_{g}^{n}(T-\tau)+\frac{\gamma^{2}}{2}(T-\tau)^{2} \sigma_{g, n}^{2}}}{\sum_{m=0}^{N} p_{\tau}^{m} e^{-\gamma \mu_{g}^{m}(T-\tau)+\frac{\gamma^{2}}{2}(T-\tau)^{2} \sigma_{g, m}^{2}}}-1,
$$

where $p_{\tau}^{n}$ are the policy probabilities defined earlier and $\mu_{g}^{0}=\widehat{g}_{\tau}$ and $\sigma_{g, 0}^{2}=\widehat{\sigma}_{\tau}^{2}$. It is easy to verify that the expected value of $J_{\pi, \tau}$ right before $\tau$ is zero. Note that, ceteris paribus, selecting a policy with a lower mean $\mu_{g}^{n}$ or higher uncertainty $\sigma_{g, n}^{2}$ results in a higher jump in the state price density.

\section{A.3. The option pricing formula}

We now present the option pricing formula from Proposition 2. This formula can be written in two similar ways, as a function of either book value $B_{t}$ or market value $M_{t}$. First, as a function of book value, at time $t<\tau$, the price of a European put option expiring at time $m>\tau$ is given by

$$
\operatorname{Put}\left(S_{t}, m, K\right)=B_{t} \frac{O\left(S_{t}, \kappa\right)}{\Omega\left(S_{t}\right)},
$$

where $\kappa=K / B_{t}, \Omega\left(S_{t}\right)$ is in Equation (A.1) in PV, and

$$
O\left(S_{t}, \kappa\right)=\sum_{n=0}^{N} e^{-\gamma \mu_{n, g}(T-\tau)+\frac{\gamma^{2}}{2}(T-\tau)^{2} \sigma_{g, n}^{2}} p_{t}^{n} V^{n}\left(S_{t}, \kappa\right),
$$

where $p_{t}^{n}$ is the probability of policy $n$ as of time $t$, given in PV's Corollary 2, and

$$
\begin{aligned}
V^{n}\left(S_{t}, \kappa\right) & =\int e^{-\gamma \Delta b_{\tau}} B S P_{n}\left(\Delta b_{\tau}, \kappa\right) f\left(\Delta b_{\tau} \mid n \text { at } \tau\right) d \Delta b_{\tau} \quad \text { for } n \geq 1 \\
V^{0}\left(S_{t}, \kappa\right) & =\int e^{-\gamma\left(E_{t}\left[\Delta b_{\tau}\right]+\left(\widehat{g}_{\tau}-\widehat{g}_{t}\right)\left[\frac{\sigma^{2}}{\widehat{\sigma}_{t}^{2}}+(\tau-t)\right]\right)-\gamma\left(\widehat{g}_{\tau}-\widehat{g}_{t}\right)(T-\tau)} B S P_{0}\left(\widehat{g}_{\tau}, \kappa ; \widehat{g}_{t}\right) f\left(\widehat{g}_{\tau} \mid 0 \text { at } \tau\right) d \widehat{g}_{\tau} .
\end{aligned}
$$

In the above expression, $b_{\tau}=\log \left(B_{\tau}\right)$, the probability densities $f\left(\Delta b_{\tau} \mid n\right.$ at $\left.\tau\right)$ and $f\left(\widehat{g}_{\tau} \mid 0\right.$ at $\left.\tau\right)$ are given in the Appendix of PV, and $B S P_{n}\left(\Delta b_{\tau}, \kappa\right)$ and $B S P_{0}\left(\widehat{g}_{\tau}, \kappa ; \widehat{g}_{t}\right)$ are standard Black-Scholes formulas for put options with different inputs. Namely, denote

$$
\begin{aligned}
\ell_{n}\left(\Delta b_{\tau}\right)= & \Delta b_{\tau}+\left(\mu-\gamma \sigma^{2}+\mu_{g, n}\right)(T-\tau)+\frac{1-2 \gamma}{2}(T-\tau)^{2} \sigma_{g, n}^{2} \\
\ell_{0}\left(\widehat{g}_{\tau} ; \widehat{g}_{t}\right)= & \left(\mu+\widehat{g}_{t}-\frac{1}{2} \sigma^{2}\right)(\tau-t)+\left(\widehat{g}_{\tau}-\widehat{g}_{t}\right)\left[\frac{\sigma^{2}}{\widehat{\sigma}_{t}^{2}}+(\tau-t)\right] \\
& +\left(\mu-\gamma \sigma^{2}+\widehat{g}_{\tau}\right)(T-\tau)+\frac{1-2 \gamma}{2}(T-\tau)^{2} \widehat{\sigma}_{\tau}^{2} .
\end{aligned}
$$

Then, for $n \geq 1$

$$
\begin{aligned}
B S P_{n}\left(\Delta b_{\tau}, \kappa\right) & =\kappa N\left[-d_{2, n}\left(\Delta b_{\tau}, \kappa\right)\right]-e^{\ell_{n}\left(\Delta b_{\tau}\right)} N\left[-d_{1, n}\left(\Delta b_{\tau}, \kappa\right)\right] \\
d_{1, n}\left(\Delta b_{\tau}, \kappa\right) & =\frac{\ell_{n}\left(\Delta b_{\tau}\right)-\log (\kappa)}{\sigma_{I V, n}}+\frac{1}{2} \sigma_{I V, n} \\
d_{2, n}\left(\Delta b_{\tau}, \kappa\right) & =d_{1}\left(\Delta b_{\tau}, \kappa\right)-\sigma_{I V, n}
\end{aligned}
$$

and for $n=0$

$$
\begin{aligned}
B S P_{0}\left(\widehat{g}_{\tau}, \kappa ; \widehat{g}_{t}\right) & =\kappa N\left[-d_{2}\left(\widehat{g}_{\tau}, \kappa ; \widehat{g}_{t}\right)\right]-e^{\ell_{0}\left(\widehat{g}_{\tau} ; \widehat{g}_{t}\right)} N\left[-d_{1}\left(\widehat{g}_{\tau}, \kappa ; \widehat{g}_{t}\right)\right] \\
d_{1,0}\left(\widehat{g}_{\tau}, \kappa ; \widehat{g}_{t}\right) & =\frac{\ell_{0}\left(\widehat{g}_{\tau} ; \widehat{g}_{t}\right)-\log (\kappa)}{\sigma_{I V, 0}}+\frac{1}{2} \sigma_{I V, 0} \\
d_{2,0}\left(\widehat{g}_{\tau}, \kappa ; \widehat{g}_{t}\right) & =d_{1,0}\left(\widehat{g}_{\tau}, \kappa ; \widehat{g}_{t}\right)-\sigma_{I V, 0}
\end{aligned}
$$


Finally, in these expressions, we have for every $n \geq 0$ :

$$
\sigma_{I V, n}^{2}=\int_{\tau}^{m} \sigma_{M, t}^{2} d t
$$

or expected average variance of stock returns. The square root of that variance after $\tau$ is $\sigma_{M, t}=\sigma+$ $(T-t) \widehat{\sigma}_{t}^{2} \sigma^{-1}$, where $\widehat{\sigma}_{t}^{-2}=\sigma_{g, n}^{-2}+\sigma^{-2}(t-\tau)$.

The option pricing formula from equation (A26) can also be rewritten as a function of market value $M_{t}$ :

$$
\operatorname{Put}\left(S_{t}, m, K\right)=M_{t} \frac{\widetilde{O}\left(S_{t}, K\right)}{H\left(S_{t}\right)},
$$

where $\widetilde{O}\left(S_{t}, K\right)$ and $H\left(S_{t}\right)$ are given in the Internet Appendix.

Corollary A.1: Let $S_{t}$ in equation (13) be such that the probability $p_{t}^{n} \rightarrow 1$ for some $n \geq 0$. Option prices are then given by the Black-Scholes formula with implied variance of

$$
\sigma_{I V, n}^{2}=\int_{t}^{m} \sigma_{M, 0, s}^{2} d s
$$

where for $n \geq 1$ the stock return volatility $\sigma_{M, 0, t}$ is given by

$$
\begin{aligned}
\sigma_{M, 0, t} & =\sigma+(\tau-t) \widehat{\sigma}_{t}^{2} \sigma^{-1} \quad \text { for } t \leq \tau \\
& =\sigma+(T-t) \widehat{\sigma}_{t}^{2} \sigma^{-1} \quad \text { for } t>\tau
\end{aligned}
$$

with

$$
\begin{aligned}
& \widehat{\sigma}_{t}^{-2}=\widehat{\sigma}_{g, 0}^{-2}+\sigma^{-2} t \quad \text { for } t \leq \tau \\
& \widehat{\sigma}_{t}^{-2}=\sigma_{g, n}^{-2}+\sigma^{-2}(t-\tau) \quad \text { for } t>\tau
\end{aligned}
$$

while for $n=0$, stock return volatility is

$$
\sigma_{M, 0, t}=\sigma+(T-t) \widehat{\sigma}_{t}^{2} \sigma^{-1} \quad \text { for all } t
$$

with

$$
\widehat{\sigma}_{t}^{-2}=\widehat{\sigma}_{g, 0}^{-2}+\sigma^{-2} t \text { for all } t
$$

\section{A.4. The jump risk premium formula}

We now present the jump risk premium formula from Proposition 3. Immediately before time $\tau$, the jump risk premium associated with the political event at time $\tau$ is given by

$$
J\left(S_{\tau}\right)=\frac{\sum_{n=0}^{N} p_{\tau}^{n} e^{-\gamma(T-\tau)\left(\widetilde{\mu}^{n}-\widetilde{\mu}^{0}\right)+\frac{\gamma}{2}(T-\tau)^{2}\left(\sigma_{g, n}^{2}-\widehat{\sigma}_{\tau}^{2}\right)} \sum_{n=0}^{N} p_{\tau}^{n} e^{\left(\widetilde{\mu}^{n}-\widetilde{\mu}^{0}\right)(T-\tau)-\frac{\gamma}{2}(T-\tau)^{2}\left(\sigma_{g, n}^{2}-\widehat{\sigma}_{\tau}^{2}\right)}}{\sum_{n=0}^{N} p_{\tau}^{n} e^{(1-\gamma)(T-\tau)\left(\widetilde{\mu}^{n}-\widetilde{\mu}^{0}\right)}}-1,
$$

where

$$
\begin{array}{ll}
\widetilde{\mu}^{n}=\mu_{g}^{n}-\frac{\sigma_{g, n}^{2}}{2}(T-\tau)(\gamma-1) \quad n=1, \ldots, N \\
\widetilde{\mu}^{0}=\widehat{g}_{\tau}-\frac{\widehat{\sigma}_{\tau}^{2}}{2}(T-\tau)(\gamma-1)
\end{array}
$$

and the probabilities $p_{\tau}^{n} \equiv p^{n}\left(S_{\tau}\right)$ are obtained in closed form in Corollary 2 of PV. The jump risk premium can also be computed as $J\left(S_{\tau}\right)=\sum_{n=0}^{N} p_{\tau}^{n} R^{n}\left(S_{\tau}\right)$, where $R^{n}\left(S_{\tau}\right)$ is the instantaneous stock return at time $\tau$ conditional on the announcement of policy $n$. These returns for all $n$ are derived in PV's Proposition 6.

\section{A.5. The full list of political events}

Tables A.1 and A.2 provide the full lists of elections and summits, respectively, that took place during our sample period, along with brief descriptions of these events. 


\section{Table A.1 \\ Elections}

The table lists all national elections that took place in the period for which option data for the given country are available in OptionMetrics (see Table 1). There are three types of elections: parliamentary ('parl.'), presidential ('pres.'), and both parliamentary and presidential occurring at the same time ('both'). The 'options' variable is equal to one if enough option data are available for the corresponding election so that it is possible to calculate $I V D$ in equation (1); if the option data are unavailable then the options variable equals zero. Option data are missing especially in the early years in our sample. All elections for which option data are available are included in our sample.

\begin{tabular}{|c|c|c|c|c|c|c|c|}
\hline Country & Date & Type & Options & Country & Date & Type & Options \\
\hline Australia & 20041009 & Parl. & 0 & Japan & 20090830 & Parl. & 1 \\
\hline Australia & 20071124 & Parl. & 0 & Japan & 20100711 & Parl. & 1 \\
\hline Australia & 20100821 & Parl. & 1 & Korea & 20071219 & Pres. & 1 \\
\hline Belgium & 20030518 & Parl. & 0 & Korea & 20080409 & Parl. & 1 \\
\hline Belgium & 20070610 & Parl. & 1 & Mexico & 20090705 & Parl. & 1 \\
\hline Belgium & 20100613 & Parl. & 1 & Netherlands & 20020515 & Parl. & 0 \\
\hline Brazil & 20061001 & Both & 1 & Netherlands & 20030122 & Parl. & 0 \\
\hline Brazil & 20061029 & Pres. & 1 & Netherlands & 20061122 & Parl. & 0 \\
\hline Brazil & 20101003 & Both & 1 & Netherlands & 20100609 & Parl. & 1 \\
\hline Brazil & 20101031 & Pres. & 1 & Singapore & 20110507 & Parl. & 1 \\
\hline Canada & 20081014 & Parl. & 1 & Singapore & 20110827 & Pres. & 1 \\
\hline Canada & 20110502 & Parl. & 1 & South Africa & 20090422 & Parl. & 1 \\
\hline Finland & 20030316 & Parl. & 0 & Spain & 20080309 & Parl. & 1 \\
\hline Finland & 20060115 & Pres. & 0 & Spain & 20111120 & Parl. & 1 \\
\hline Finland & 20060129 & Pres. & 0 & Sweden & 20100919 & Parl. & 1 \\
\hline Finland & 20070318 & Parl. & 0 & Switzerland & 20031019 & Parl. & 1 \\
\hline Finland & 20110417 & Parl. & 0 & Switzerland & 20071021 & Parl. & 1 \\
\hline Finland & 20120122 & Pres. & 0 & Switzerland & 20111023 & Parl. & 1 \\
\hline Finland & 20120205 & Pres. & 0 & Taiwan & 20040320 & Pres. & 0 \\
\hline France & 20070422 & Pres. & 1 & Taiwan & 20080112 & Parl. & 1 \\
\hline France & 20070506 & Pres. & 1 & Taiwan & 20080322 & Pres. & 1 \\
\hline France & 20070610 & Parl. & 1 & Taiwan & 20120114 & Both & 0 \\
\hline France & 20070617 & Parl. & 1 & UK & 20050505 & Parl. & 1 \\
\hline France & 20120422 & Pres. & 1 & UK & 20100506 & Parl. & 1 \\
\hline France & 20120506 & Pres. & 1 & USA & 19901106 & Parl. & 1 \\
\hline France & 20120610 & Parl. & 1 & USA & 19921103 & Both & 1 \\
\hline France & 20120617 & Parl. & 1 & USA & 19941108 & Parl. & 1 \\
\hline Germany & 20020922 & Parl. & 1 & USA & 19961105 & Both & 1 \\
\hline Germany & 20050918 & Parl. & 1 & USA & 19981103 & Parl. & 1 \\
\hline Germany & 20090927 & Parl. & 1 & USA & 20001107 & Both & 1 \\
\hline Greece & 20120506 & Parl. & 1 & USA & 20021105 & Parl. & 1 \\
\hline Greece & 20120617 & Parl. & 1 & USA & 20041102 & Both & 1 \\
\hline Italy & 20080413 & Parl. & 1 & USA & 20061107 & Parl. & 1 \\
\hline Japan & 20040711 & Parl. & 0 & USA & 20081104 & Both & 1 \\
\hline Japan & 20050911 & Parl. & 1 & USA & 20101102 & Parl. & 1 \\
\hline Japan & 20070729 & Parl. & 1 & & & & \\
\hline
\end{tabular}




\section{Table A.2 \\ Summits}

The table lists all G8, G20, and European summits that took place between January 2007 and December 2011. We assign an economic relevance score to each summit, with "Yes" denoting the relevant ones and "No" denoting the rest. All summits rated "Yes" are included in our main sample. The robustness analysis in Table B1 in the Internet Appendix includes all summits regardless of relevance. The topic list in the last column is constructed based on summit agendas, summit summaries, and press releases.

\begin{tabular}{|c|c|c|c|}
\hline Type & Date & $\begin{array}{l}\text { Economic } \\
\text { Relevance }\end{array}$ & Topics \\
\hline G8 & 20070606 & No & Global warming; US missile defense system; Consortium for Africa \\
\hline G8 & 20080707 & No & $\begin{array}{l}\text { Africa; Climate change; Intellectual property rights; Political is- } \\
\text { sues; World Economy; Food crisis }\end{array}$ \\
\hline G8 & 20090708 & No & $\begin{array}{l}\text { Climate change; Energy; Africa; Intellectual property; Afghan con- } \\
\text { flict; Nuclear security }\end{array}$ \\
\hline G8 & 20100625 & Yes & $\begin{array}{l}\text { Recovery from global recession and European debt crisis; Nuclear } \\
\text { programs of Iran and North Korea; Israel blockade }\end{array}$ \\
\hline G8 & 20110526 & No & $\begin{array}{l}\text { Internet, innovation, green growth and sustainable economy; Nu- } \\
\text { clear safety; Arab spring; Africa }\end{array}$ \\
\hline G20 & 20081114 & Yes & Global financial crisis \\
\hline G20 & 20090402 & Yes & Stimulus; Regulation \\
\hline G20 & 20090924 & Yes & $\begin{array}{l}\text { G20 to become premier forum for international economic coopera- } \\
\text { tion; World economic recovery }\end{array}$ \\
\hline G20 & 20100626 & Yes & Recovery from global recession and European debt crisis \\
\hline G20 & 20101111 & Yes & $\begin{array}{l}\text { Ensuring global economic recovery; Framework for growth; Finan- } \\
\text { cial regulation, institutions and safety nets; Risk of currency war; } \\
\text { Development issues }\end{array}$ \\
\hline G20 & 20111103 & Yes & Recovery from global recession and European debt crisis \\
\hline Euro & 20070308 & No & $\begin{array}{l}\text { Lisbon strategy for growth; Regulation; Climate and energy policy; } \\
\text { International relations }\end{array}$ \\
\hline Euro & 20070621 & No & $\begin{array}{l}\text { Treaty reform; Home affairs; Economic, social and environmental } \\
\text { issues; External relations; Northern Ireland }\end{array}$ \\
\hline Euro & 20071018 & No & Treaty reform; Climate change; US economic crisis \\
\hline Euro & 20071213 & No & $\begin{array}{l}\text { Treaty reform; Security; Economic, social and environmental is- } \\
\text { sues; External relations }\end{array}$ \\
\hline Euro & 20080313 & No & Lisbon strategy; Climate change and energy; Financial stability \\
\hline Euro & 20080619 & No & $\begin{array}{l}\text { Lisbon treaty; Security; Food and oil prices; Economic, social and } \\
\text { environmental issues; Western Balkans; External relations }\end{array}$ \\
\hline Euro & 20080713 & No & Strategy for the Mediterranean ("Barcelona Process") \\
\hline Euro & 20080901 & No & Extraordinary summit on EU-Russia relations (Georgia crisis) \\
\hline Euro & 20081015 & Yes & $\begin{array}{l}\text { Economic and financial situations; Lisbon treaty; energy and cli- } \\
\text { mate change; Immigration }\end{array}$ \\
\hline Euro & 20081107 & Yes & Global financial crisis \\
\hline Euro & 20081211 & Yes & $\begin{array}{l}\text { Lisbon treaty; Economic and financial questions; Energy and cli- } \\
\text { mate change; Agricultural policy; External relations; European se- } \\
\text { curity and defence }\end{array}$ \\
\hline Euro & 20090301 & Yes & Global financial crisis \\
\hline Euro & 20090319 & Yes & $\begin{array}{l}\text { Economic, financial and social situation; Energy and climate } \\
\text { change }\end{array}$ \\
\hline Euro & 20090405 & Yes & $\begin{array}{l}\text { US-EU summit; Economic, financial and social situation; Energy } \\
\text { and climate change; Regional issues; Guantanamo }\end{array}$ \\
\hline Euro & 20090618 & Yes & $\begin{array}{l}\text { Institutional issues; Economic, financial and social situation; Cli- } \\
\text { mate change and sustainable development; Illegal immigration; ex- } \\
\text { ternal relations }\end{array}$ \\
\hline
\end{tabular}




\begin{tabular}{|c|c|c|c|}
\hline Euro & 20090917 & No & Preparation for 2009 G20 Pittsburgh summit \\
\hline Euro & 20091029 & No & $\begin{array}{l}\text { Institutional issues; Climate change; Economic, financial and em- } \\
\text { ployment situation; Strategy for Baltic Region; External relations }\end{array}$ \\
\hline Euro & 20091119 & No & $\begin{array}{l}\text { Chose first President of the European Council and first High Rep- } \\
\text { resentative of the Union for Foreign Affairs and Security Policy }\end{array}$ \\
\hline Euro & 20091210 & Yes & $\begin{array}{l}\text { Institutional issues; Economic, financial and employment situation; } \\
\text { "Stockholm Program"; Climate change; Enlargement; External re- } \\
\text { lations }\end{array}$ \\
\hline Euro & 20100211 & Yes & Greek crisis \\
\hline Euro & 20100325 & Yes & Greek crisis \\
\hline Euro & 20100507 & Yes & Greek crisis \\
\hline Euro & 20100617 & Yes & $\begin{array}{l}\text { Strategy for jobs and growth; Millennium development goals, Cli- } \\
\text { mate change }\end{array}$ \\
\hline Euro & 20100916 & Yes & $\begin{array}{l}\text { Relations with strategic partners; Task force on economic gover- } \\
\text { nance; External policy }\end{array}$ \\
\hline Euro & 20101028 & Yes & Task force on economic governance; Climate change \\
\hline Euro & 20101216 & Yes & Economic policy \\
\hline Euro & 20110204 & Yes & Energy; Innovation; Economic situation; External relations \\
\hline Euro & 20110311 & Yes & Economic policy; Crisis response \\
\hline Euro & 20110324 & Yes & Economic policy; Libya; Japan tsunami \\
\hline Euro & 20110623 & Yes & Economic policy; Immigration; Croatia \\
\hline Euro & 20110721 & Yes & Greek crisis \\
\hline Euro & 20111023 & Yes & $\begin{array}{l}\text { Economy policy; Organization of G20; Climate change; External } \\
\text { relations }\end{array}$ \\
\hline Euro & 20111026 & Yes & Crisis response \\
\hline Euro & 20111208 & Yes & Economic policy; Energy; Enlargement \\
\hline
\end{tabular}




\section{REFERENCES}

Andersen, Torben G., Tim Bollerslev, Peter F. Christoffersen, and Francis X. Diebold, 2006, Volatility and Correlation Forecasting, in Handbook of Economic Forecasting, G. Elliot, C.W.J. Granger, and Allan Timmermann (eds.), Amsterdam: North-Holland, 778-878.

Backus, David, Mikhail Chernov, and Ian Martin, 2011, Disasters implied by equity index options, Journal of Finance 66, 1969-2012.

Baker, Scott R., Nicholas Bloom, and Steven J. Davis, 2013, Measuring economic policy uncertainty, Working paper, Stanford University.

Bakshi, Gurdip, Charles Cao, and Zhiwu Chen, 1997, Empirical performance of alternative option pricing models, Journal of Finance 52, 2003-2049.

Bakshi, Gurdip, Nikunj Kapadia, and Dilip Madan, 2003, Stock return characteristics, skew laws, and the differential pricing of individual equity options, Review of Financial Studies $16,101-143$.

Bates, David S., 1991, The crash of '87: Was it expected? The evidence from options markets, Journal of Finance 46, 1009-1044.

Bates, David S., 2000, Post-'87 crash fears in the S\&P 500 futures option market, Journal of Econometrics 94, 181-238.

Beber, Alessandro, and Michael W. Brandt, 2006, The effect of macroeconomic news on beliefs and preferences: Evidence from the options market, Journal of Monetary Economics 53, 1997-2039.

Belo, Frederico, Vito D. Gala, and Jun Li, 2013, Government spending, political cycles, and the cross-section of stock returns, Journal of Financial Economics 107, 305-324.

Benzoni, Luca, Pierre Collin-Dufresne, and Robert S. Goldstein, 2011, Explaining asset pricing puzzles associated with the 1987 market crash, Journal of Financial Economics $101,552-573$.

Bialkowski, Jedrzej, Katrin Gottschalk, and Tomasz P. Wisniewski, 2008, Stock market volatility around national elections, Journal of Banking and Finance 32, 1941-1953.

Bittlingmayer, George, 1998, Output, stock volatility, and political uncertainty in a natural experiment: Germany, 1880-1940, Journal of Finance 53, 2243-2257.

Bollerslev, Tim, George Tauchen, and Hao Zhou, 2009, Expected stock returns and variance risk premia, Review of Financial Studies 22, 4463-4492.

Bollerslev, Tim, and Viktor Todorov, 2011, Tails, fears, and risk premia, Journal of Finance 66, 2165-2211.

Boutchkova, Maria, Hitesh Doshi, Art Durnev, and Alexander Molchanov, 2012, Precarious politics and return volatility, Review of Financial Studies 25, 1111-1154.

Broadie, Mark, Mikhail Chernov, and Michael Johannes, 2007, Model specification and risk premia: Evidence from futures options, Journal of Finance 62, 1453-1490.

Broadie, Mark, Mikhail Chernov, and Michael Johannes, 2009, Understanding index option returns, Review of Financial Studies 22, 4493-4529. 
Brogaard, Jonathan, and Andrew Detzel, 2013, The asset pricing implications of government economic policy uncertainty, Working paper, University of Washington.

Cameron, A. Colin, Jonah B. Gelbach, and Douglas L. Miller, 2011, Robust inference with multiway clustering, Journal of Business and Economic Statistics 29, 238-249.

Chernov, Mikhail, A. Ronald Gallant, Eric Ghysels, and George Tauchen, 2003, Alternative models for stock price dynamics, Journal of Econometrics 116, 225-257.

Croce, Maximiliano M., Howard Kung, Thien T. Nguyen, and Lukas Schmid, 2012, Fiscal policies and asset prices, Review of Financial Studies 25, 2635-2672.

Croce, Maximiliano M., Thien T. Nguyen, and Lukas Schmid, 2012, The market price of fiscal uncertainty, Journal of Monetary Economics 59, 401-416.

Drechsler, Itamar, and Amir Yaron, 2011, What's vol got to do with it, Review of Financial Studies 24, 1-45.

Du, Du, 2011, General Equilibrium Pricing of options with habit formation and event risks, Journal of Financial Economics 99, 400-426.

Dubinsky, Andrew, and Michael Johannes, 2006, Fundamental uncertainty, earning announcements and equity options, Working paper, Columbia University.

Duffie, Darrell, Jun Pan, and Kenneth Singleton, 2000, Transform analysis and asset pricing for affine jump-diffusions, Econometrica 68, 1343-1376.

Durnev, Art, 2012, The real effects of political uncertainty, Working paper, University of Iowa.

Ederington, Louis H., and Jae Ha Lee, 1996, The creation and resolution of market uncertainty: the impact of information releases on implied volatility, Journal of Financial and Quantitative Analysis 31, 513-539.

Eraker, Bjorn, 2004, Do stock prices and volatility jump? Reconciling evidence from spot and option prices, Journal of Finance 59, 1367-1404.

Eraker, Bjorn, Michael Johannes, and Nicholas Polson, 2003, The impact of jumps in volatility and returns, Journal of Finance 58, 1269-1300.

Erb, Claude B., Campbell R. Harvey, and Tadas E. Viskanta, 1996, Political risk, economic risk, and financial risk, Financial Analysts Journal, December, 29-46.

Fernández-Villaverde, Jesús, Pablo Guerrón-Quintana, Keith Kuester, and Juan RubioRamírez, 2012, Fiscal volatility shocks and economic activity, Working paper, University of Pennsylvania.

Gao, Pengjie, and Yaxuan Qi, 2013, Political uncertainty and public financing costs: Evidence from U.S. gubernatorial elections and municipal bond markets, Working paper, University of Notre Dame.

Gemmill, Gordon, 1992, Political risk and market efficiency: Tests based in British stock and options markets in the 1987 election, Journal of Banking and Finance 16, 211-231.

Goodell, John W., and Sami Vahamaa, 2013, US presidential elections and implied volatility: The role of political uncertainty, Journal of Banking and Finance 37, 1108-1117. 
Gulen, Huseyin, and Mihai Ion, 2013, Policy uncertainty and corporate investment, Working paper, Purdue University.

Hentschel, Ludger, 2003, Errors in implied volatility estimation, Journal of Financial and Quantitative Analysis 38: 779-810.

Jens, Candace E., 2013, Political uncertainty and investment: Causal evidence from U.S. gubernatorial elections, Working paper, Tulane University.

Julio, Brandon, and Youngsuk Yook, 2012, Corporate financial policy under political uncertainty: International evidence from national elections, Journal of Finance 67, 45-83.

Julio, Brandon, and Youngsuk Yook, 2013, Policy uncertainty, irreversibility, and crossborder flows of capital, Working paper, London Business School.

Lewis-Beck, Michael S., and Mary Stegmaier, 2000, Economic determinants of electoral outcomes, Annual Review of Political Science 3, 183-219.

Li, Jinliang, and Jeffery A. Born, 2006, Presidential election uncertainty and common stock returns in the United States, Journal of Financial Research 29, 609-622.

Pan, Jun, 2002, The jump-risk premia implicit in options: Evidence from an integrated time-series study, Journal of Financial Economics 63, 3-50.

Pantzalis, Christos, David A. Stangeland, and Harry J. Turtle, 2000, Political elections and the resolution of uncertainty: The international evidence, Journal of Banking and Finance 24, 1575-1604.

Pástor, Ľuboš, and Pietro Veronesi, 2012, Uncertainty about government policy and stock prices, Journal of Finance 67, 1219-1264.

Pástor, Ľuboš, and Pietro Veronesi, 2013, Political uncertainty and risk premia, Journal of Financial Economics 110, 520-545.

Patell, James M., and Mark A. Wolfson, 1979, Anticipated information releases reflected in call option prices, Journal of Accounting and Economics 1, 117-140.

Piazzesi, Monika, 2005, Bond yields and the Federal Reserve, Journal of Political Economy $113,311-344$.

Seo, Sang Byung, and Jessica A. Wachter, 2013, Option prices in a model with stochastic disaster risk, Working paper, University of Pennsylvania.

Sialm, Clemens, 2006, Stochastic taxation and asset pricing in dynamic general equilibrium, Journal of Economic Dynamics and Control 30, 511-540.

Snowberg, Erik, Justin Wolfers, and Eric Zitzewitz, 2007, Partisan impacts on the economy: Evidence from prediction markets and close elections, Quarterly Journal of Economics $122,807-829$.

Todorov, Viktor, 2010, Variance risk-premium dynamics: The role of jumps, Review of Financial Studies 23, 345-383.

Ulrich, Maxim, 2013, How does the bond market perceive government interventions?, Working paper, Columbia University.

Voth, Hans-Joachim, 2002, Stock price volatility and political uncertainty: Evidence from the interwar period, Working paper, UPF. 